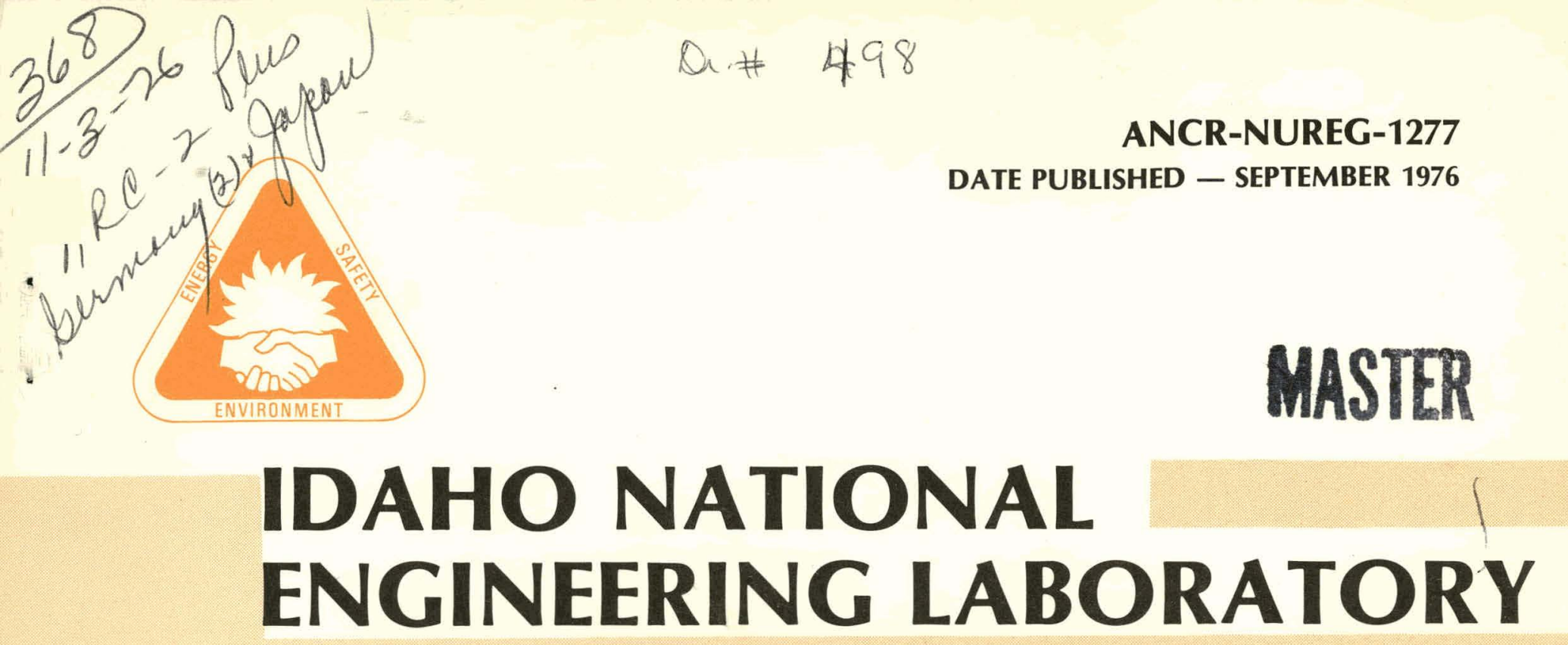

\title{
TECHNICAL SUPPORT TO THE NUCLEAR REGULATORY COMMISSION FOR THE BOILING WATER REACTOR BLOWDOWN HEAT TRANSFER PROGRAM
}

\author{
RICHARD E. RICE
}




\section{DISCLAIMER}

This report was prepared as an account of work sponsored by an agency of the United States Government. Neither the United States Government nor any agency Thereof, nor any of their employees, makes any warranty, express or implied, or assumes any legal liability or responsibility for the accuracy, completeness, or usefulness of any information, apparatus, product, or process disclosed, or represents that its use would not infringe privately owned rights. Reference herein to any specific commercial product, process, or service by trade name, trademark, manufacturer, or otherwise does not necessarily constitute or imply its endorsement, recommendation, or favoring by the United States Government or any agency thereof. The views and opinions of authors expressed herein do not necessarily state or reflect those of the United States Government or any agency thereof. 


\section{DISCLAIMER}

Portions of this document may be illegible in electronic image products. Images are produced from the best available original document. 
Printed in the United States of America Available from

National Technical Information Service

U. S. Department of Commerce 5285 Port Royal Road

Springfield, Virginia 22161

Price: Printed Copy $\$ 5.50$; Microfiche $\$ 2.25$

"The NRC will make available data tapes and operational computer codes on research programs dealing with postulated loss-of-coolant accidents in light water reactors. Persons requesting this information must reimburse the NRC contractors for their expenses in preparing copies of the data tapes and the operational computer codes. Requests should be submitted to the Research Applications Branch, Office of Nuclear Regulatory Research, Nuclear Regulatory Commission, Washington, D.C. 20555."

\section{NOTICE}

This report was prepared as an account of work sponsored by the United States Government. Neither the United States nor the Energy Research and Development Administration, nor the Nuclear Regulatory Commission, nor any of their employees, nor any of their contractors, subcontractors, or their employees, makes any warranty, express or implied, or assumes any legal liability or responsibility for the accuracy, completeness or usefulness of any information, apparatus, product or process disclosed, or represents that its use would not infringe privately owned rights. 
ANCR-NUREG-1277 - TECHNICAL SUPPORT TO NUCLEAR REGULÁTORY COMMISSION FOR THE BOILING

WATER REACTOR BLOWDOWN HEÄT

TRANSFER PROGRAM

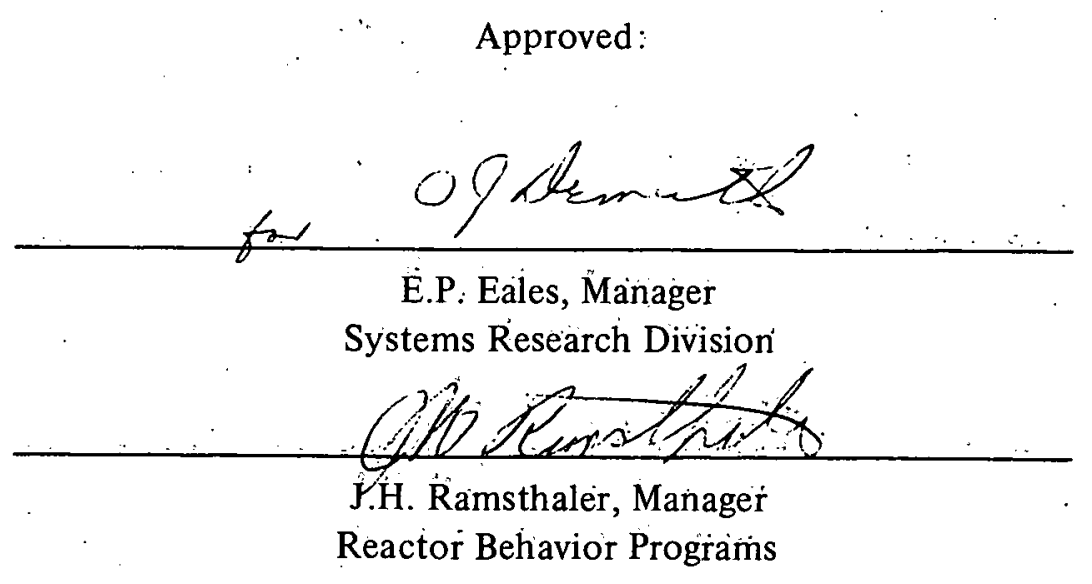


Richard E. Rice

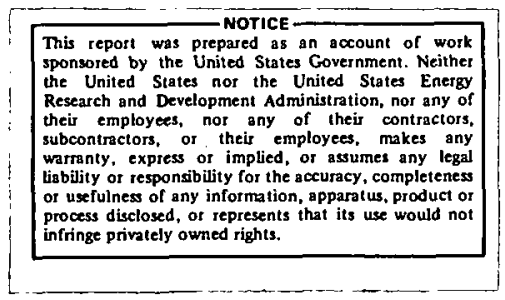

\section{AEROJET NUCLEAR COMPANY}

Date Publisher - September 1976 


\section{ACKNOWLEDGMENTS}

The contributions of several individuals to this document are acknowledged. These include the analysis of two loop test apparatus (TLTA) measurement accuracies by J. B. Colson and the RELAP4 analytical efforts and data comparisons of T. R. Charlton, G. R. Sawtelle, and R. P. Rinrdan. The assistance of R. J. Decker in evaluating the TLTA data is also recognized. 


\begin{abstract}
This report presents the results of studies conducted by Aerojet Nuclear Company (ANC) in FY 1975 to support the Nuclear Regulatory Commission (NRC) on the boiling water reactor blowdown heat transfer (BWR-BDHT) program. This program is jointly sponsored by the NRC and General Electric Company (GE) and mutually funded by the NRC, GE, and the Electric Power Research Institute (EPRI).
\end{abstract}

The support provided by ANC is that of an independent assessor of the program to ensure that the data obtained are adequate for verification of analytical models used for predicting reactor response to a postulated loss-of-coolant accident. The support included reviews of program plans, objectives, measurements, and actual data. Additional activity included analysis of experimental system performance and evaluation of the RELAP4 computer code as applied to the experiments. 


\section{SUMMARY}

The Aerojet Nuclear Company (ANC) support to the Nuclear Regulatory Commission (NRC) on the boiling water reactor blowdown heat transfer (BWR-BDHT) program, conducted by General Electric Company (GE), is provided in the following five catagories:

(1) Review of program plan

(2) Review of operations and measurements

(3) Analytical support

(4) Review of two loop test apparatus (TLTA) data

(5) RELAP4 code evaluation.

Significant results and findings in these categories are as follows.

\section{PROGRAM PLAN REVIEW}

The code verification needs for the boiling water reactor (BWR) loss-of-coolant accident were examined as part of the program plan review. This review indicated that additional experiments are necessary for verification of thermal-hydraulic codes used for analysis of the emergency core cooling period. These experiments should be conducted in a facility which allows interaction between core spray water, bottom reflood water, and the core as affected by flow paths and elevations of the complete system.

GE has proposed that the TLTA be modified to allow conduct of these experiments. ANC supports this proposal.

\section{OPERATIONS AND MEASUREMENTS}

An analysis of the accuracies of selected TLTA measurements has been completcr. Findings of this study were that most of the measurements were adequate for purposes of model verification. Exceptions are the accuracy of all flow rates at low values. This problem, which arises after lower plenum flashing, limits the diagnosis of code problem arcas. Greater flow measurement resolution in TLTA measurements would be beneficial in providing a code-verification data base and is recommended as one of the areas in which improvement should be sought. 


\section{ANALYTICAL SUPPORT}

Pertinent TLTA areas of interest have been investigated using the RELAP4 computer code. Significant results of these studies included the following:

(1) Wall heat transfer will be of significance in the TLTA and must be factored into evaluation of the test results.

(2) The alternate lower plenum geometry proposed for Test 18 is not expected to have significant effect on TLTA performance.

(3) Elevation and momentum differences between the TLTA and BWR will result in a nontypical TLTA core flow coastdown. This nontypical coastdown, which will affect core temperature response, must be accounted for in relating TLTA performance. to that of a BWR.

\section{REVIEW OF TLTA DATA}

Data from all Bundle 1 tests have been reviewed. Emphasis was placed on evaluating the impact of the various Bundle 1 test parameters and on identifying new or unexpected phenomena. Significant results are as follows:

(1) Variations in bundle power have little effect on overall system performance but substantially affect rod temperatures. A thresh old for an early (less than one second) critical heat flux (CHF) exists at power levels between 4.55 and $6.05 \mathrm{MW}$.

(2) Initial downcomer fluid mass, which was not repeatable from test to test, has a significant effect on system performance.

(3) Test-to-test repeatability appears to be good for tests run close together in time.

(4) The test of an alternate power decay curve was inconclusive.

(5) Changes in break area affect system response and event tịming.

(6) Minor changes in bundle performance follow the system changes as expected.

(7) Liquid fallback from the upper plenum may play an important role in holding rod temperatures down in the postflashing period. 
On the basis of these observations, several recommendations have been made. A better control of initial downcomer mass should be established. The CHF threshold should be pinpointed by additional testing. Another test with an alternate power decay profile should be scheduled. An additional long-term repeatability test should be scheduled. The need for additional model development and evaluation work is indicated to account for observed experimental trends in bundle performance.

\section{RELAP4 CODE EVALUATION}

RELAP4 calculations for thrss sxperiments (Tests 1, 3, and 6) have been comparod with the experimental rcsults in order to assess adequacy of the code for application to BWR systems and to suggest areas of code improvement. Improvement areas indicated relate to critical flow calculations, jet pump modeling, bundle heat transfer, horizontal slip, and vertical phase separation. 
ACKNOWLEDGMENTS $\ldots \ldots \ldots \ldots \ldots \ldots \ldots \ldots$ ii ABSTRACT $\ldots \ldots \ldots \ldots \ldots \ldots \ldots \ldots \ldots \ldots \ldots \ldots \ldots \ldots \ldots$ iii

SUMMARY $\ldots \ldots \ldots \ldots \ldots \ldots \ldots \ldots \ldots \ldots \ldots \ldots \ldots \ldots$ iv

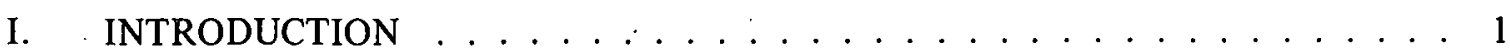

II. PROGRAM PLAN REVIEW $\ldots \ldots \ldots \ldots \ldots \ldots \ldots \ldots$

1. MODEL VERIFICATION BACKGROUND ............ 3

2. TLTA DESIGN CONSIDERATIONS $\ldots \ldots \ldots \ldots \ldots \ldots$

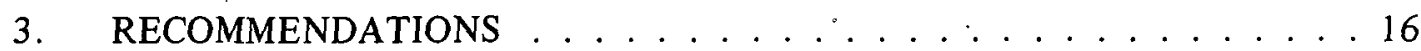

III. OPERATIONS AND MEASUREMENTS $\ldots \ldots \ldots \ldots \ldots \ldots$

1. MEASUREMENT ACCURACY EVALUATION $\ldots \ldots \ldots \ldots$

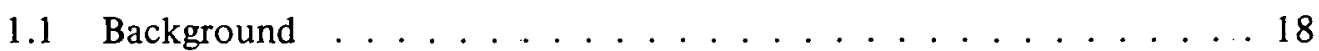

1.2 Analysis Description . . . . . . . . . . . . . . . . . . 18

1.3 Accuracy of Basic Measurements . . . . . . . . . . . 23

1.4 Accuracy of Derived Quantities . . . . . . . . . . . 26

2. OBSERVATION OF TESTS . . . . . . . . . . . . . . 29

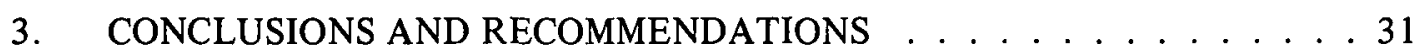

IV. ANALYTICAL SUPPORT $\ldots \ldots \ldots \ldots \ldots \ldots \ldots \ldots \ldots$

1. WALL HEAT TRANSFER EFFECTS $\ldots \ldots \ldots \ldots \ldots \ldots$

2. TLTA ELEVATION EFFECTS $\ldots \ldots \ldots \ldots \ldots \ldots$

3. TLTA FLUID INERTIA EFFECTS $\ldots \ldots \ldots \ldots \ldots$

4. ALTERNATE LOWER PLENUM GEOMETRY . . . . . . . . . . . . . 39

5. CONCLUSIONS AND RECOMMENDATIONS $\ldots \ldots \ldots \ldots \ldots$ 
V. REVIEW OF TLTA DATA $\ldots \ldots \ldots \ldots \ldots \ldots$

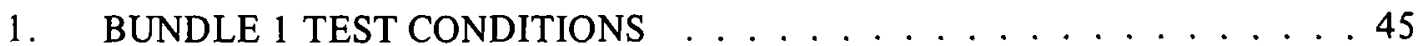

2. EFFECT OF BUNDLE POWER ............. 45

3. EFFECTS OF BREAK AREA ............... . 48

4. EFFECT OF POWER DECAY RATE $\ldots \ldots \ldots \ldots \ldots \ldots$

5. EFFECT OF THERMOCOUPLE LOCATION . . . . . . . . . . 52

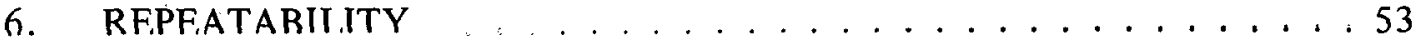

7. CONCLUSIONS AND RECOMMENDATIONS $\ldots \ldots \ldots \ldots \ldots$

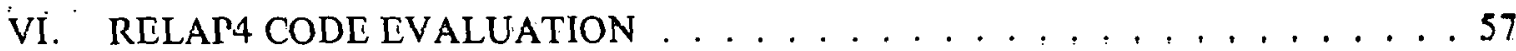

1. RELAP4 MODEL DESCRIPTION . . . . . . . . . . . . . . . 57

1.1 System Model $\ldots \ldots \ldots \ldots \ldots$. . . . . . . . . . . . . . . . .

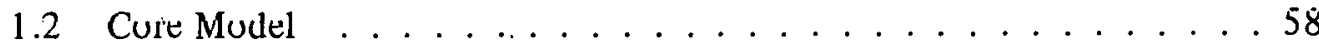

1.3 Model Evolution . . . . . . . . . . . . . . . . . . . 60

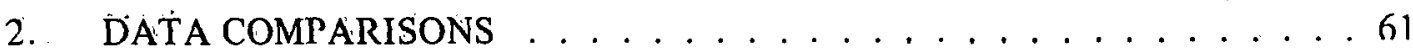

2.1 Break ..................... 61

2.2 Downcomer . . . . . . . . . . . . . . . . 65

2.3 Recirculation Pump . . . . . . . . . . . . . . . . . . . 67

2.4 Jet Pumps . . . . . . . . . . . . . . . . . . . 68

2.5 Lower Plenum . . . . . . . . . . . . . . . . . . . . . 74

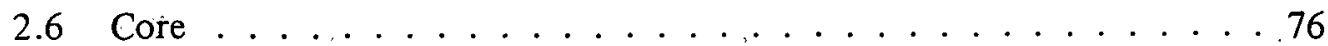

3. CONCLUSIONS AND RECOMMENDATIONS $\ldots \ldots \ldots \ldots \ldots$

VII. REFERENCE3 . . . . . . . . . . . . . . . . . . . 87

\section{TIGURES}

1. Calculation of TLTA derived data . . . . : . . . . . . . . . . . 19

2. TLTA measurement locations . . . . . . . . . . . . . . . . . . 19 


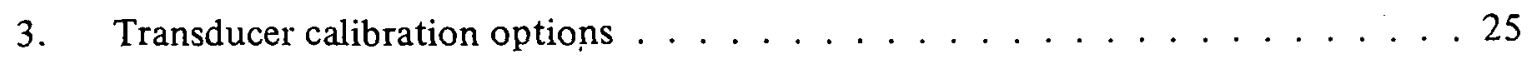

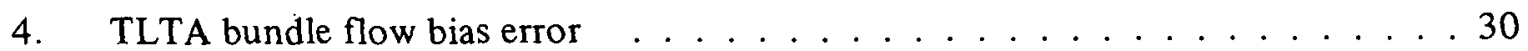

5. GE-BDHT-TLTA base case analy tical model . . . . . . . . . . . . 34

6. Heat transfer - lower plenum vessel wall $\ldots \ldots \ldots$. . . . . . . . 35

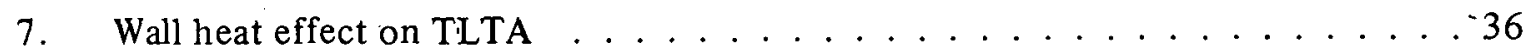

8. TLTA-BWR elevation comparison - core flow . . . . . . . . . . 37

9. TLTA-BWR elevation comparison - rod temperature . . . . . . . 38

10. TLTA-BWR loop momentum comparison - core flow . . . . . . . . . 39

11. Lower plenum and guide tube configurations . . . . . . . . . 40

12. Lower plenum study - average lower plenum quality. . . . . . . . 41

13. Lower plenum study - core inlet flow . . . . . . . . . . . . . 42

14. Lower plenum study - broken loop jet pump flow . . . . . . . . . . . 42

15. Lower plenum study - lower plenum pressure . . . . . . . . . 43

16. Effect of bundle power on bundle inlet flow . . . . . . . . . 47

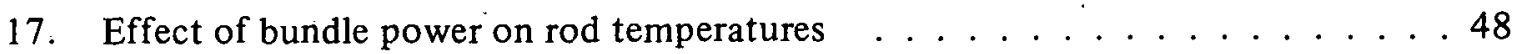

18. Effect of break area on depressurization rate ............... 49

19. Effect of break area on bundle inlet flow . . . . . . . . . . . . 49

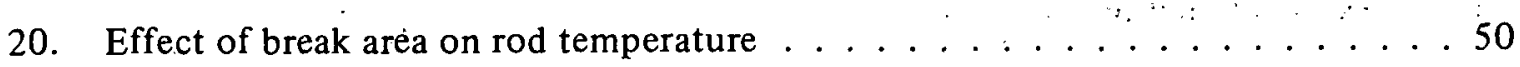

21. Power decay rate - Tests 4 and $7 \ldots \ldots \ldots \ldots \ldots$

22. Effect of power decay rate on rod temperature .......... 51

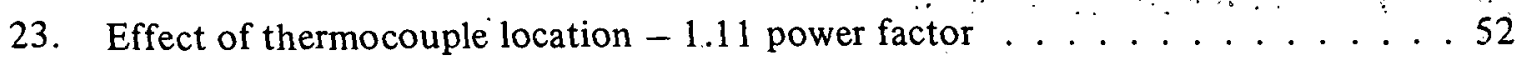

24. Effect of thermocouple location -1.25 power factor $\ldots \ldots \ldots 3$

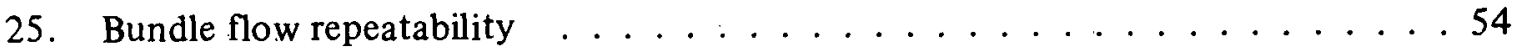


26. Bundle temperature repeatability -71 -inch elevation . . . . . . . . . 54

27. Bundle temperature repeatability -118 -inch elevation . . . . . . . . 55

28. GE-BDHT-TLTA heater rod model . . . . . . . . . . . . . . . . 59

29. Tests 3 and 6 break flow . . . . . . . . . . . . . . . 62

30. Test 3 downcomer mass ........................ 63

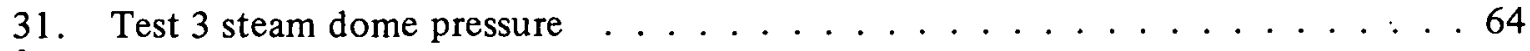

32. Test 3 downcomer mixture level ..................... 66

33. Test 3 downcomer average fluid density . . . . . . . . . . . 66

34. Test 6 intact loop pump flow . . . . . . . . . . . . . 69

35. Tcst 3 intact loop pump spced . . . . . . . . . . . . . . 70

36. Test 3 intact loop pump head . . . . . . . . . . . . . 70

37. Test 1 intact loop jet pump flow rate .................... 71

38. Test 6 intact loop jet pump flow rate $\ldots \ldots \ldots \ldots$

39. Test 3 broken loop jet pump flow rate ................. 73

40. Test 3 bundle inlet density . . . . . . . . . . . . . . . . . 74

41. Test 3 lower plenum density . . . . . . . . . . . . . 75

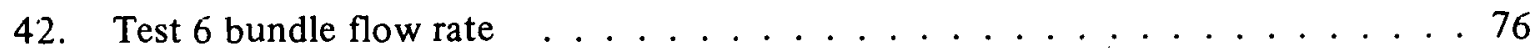

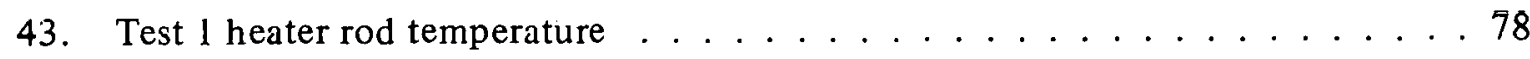

44. Test 3 heater rod temperature -71 -inch elevation . . . . . . . . 78

45. Test 3 heater rod temperature -98 -inch elevation . . . . . . . . . . 79

46. Test 3 heater rod temperature -118 -inch elevation $\ldots \ldots \ldots 1$ 


\section{TABLES}

I. BWR Model Verification for ECC Time Period . . . . . . . . . . . 4

II. Uncertainty and Bias Error Sources . . . . . . . . . . . . . . 21

III. Static Transducer Uncertainties . . . . . . . . . . . . . . . . . 24

IV. Lower Plenum Node 2 Measurement Accuracies . . . . . . . . . . . 26

V. Downcomer Node 6 Measurement Accuracies . . . . . . . . . . . . 27

VI. Flow Rate Measurement Accuracies . . . . . . . . . . . . . 28

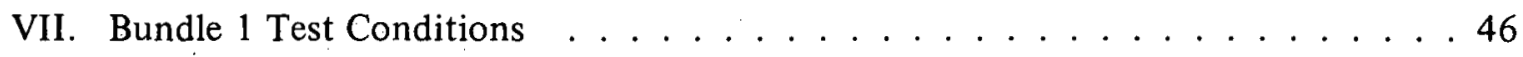

VIIII. Major Differences Between Test Calculations f . . . . . . . . . . . 61

IX. TLTA and Typical BWR Rated Pump Performance . . . . . . . . . 67

X. Overview of RELAP4 Comparisons with TLTA Data . . . . . . . . . . . . 84 


\section{TECHNICAL SUPPORT TO THE NUCLEAR REGULATORY COMMISSION FOR THE \\ BOILING WATER REACTOR BLOWDOWN HEAT TRANSFER PROGRAM}

\section{INTRODUCTION}

In the interest of improving the understanding of the phenomena occurring in a light-water reactor during a postulated loss-of-coolant accident (LOCA), the water reactor safety research program has been established. This program is administered by the Office of Nuclear Regulatory Research of the Nuclear Regulatory Commission (NRC). The overall effort consists of a series of programs to develop computer codes to predict the thermal-hydraulic phenomena during a LOCA and to provide representative experimental data to assess these codes. These programs are being conducted by several of the Energy Research and Development Administration (ERDA) laboratories, nuclear reactor vendors, universities, and independent contractors.

The anticipated end result of this undertaking is verified computer codes with established confidence levels which can be used to predict nuclear plant performance for a wide variety of postulated LOCAs. These codes will be used in the NRC licensing activities.

Industry cooperative test programs are an integral part of this overall effort. These programs are jointly sponsored by the NRC and reactor vendors. Toensure that the needs of code verification are met by the industry cooperative programs, Aerojet Nuclear Company (ANC) has been placed in an independent technical advisory role. Specific ANC duties as NRC's advisor include:

(1) Review of overall experimental program direction and results

(2) Review of specific facilities including measurements, test plans, test conduction, test results, etc.

(3) Analytical support for experimental programs, including investigations of scaling effects, test parameters, and modeling sensitivities

(4) Comparison of computer code results with experimental data to assess code capability.

This topical report summarizes ANC activities in FY 1975 as advisor on the boiling water reactor (BWR) blowdown heat transfer (BDHT) program [1] being conducted by General Electric Company (GE) in San Jose. This program is jointly sponsored by the NRC and GE and mutually. funded by the NRC, GE, and EPRI ${ }^{[a]}$. The experiments are being conducted in the two loop test apparatus (TLTA) which is a scaled simulator of a boiling

[a] Electric Power Research Institute. 
water reactor. The system has been designed to provide BWR blowdown conditions in the test bundle, so that investigations can be made of time to critical heat flux (CHF), post-CHF heat transfer, and the effect of lower plenum swell on bundle thermal preformance. The TLTA utilizes a full-length bundle of 49 electrically heated rods representing the BWR core region. This scaled facility features all major BWR components including two external recirculation loops with a single jet pump in each loop.

Sevêral loss-of-coolant experiments (LOCE) with variation of key parameters have been conducted in the TLTA to determine the influence of the individual parameters on system blowdown response ${ }^{[a]}$. In each test, numerous measurements reflecting system performance were taken. These measurements included mainr flow rates, local fluid state, and rod bundle temperatures.

[a] As of the end of FY 1975, eight tests were completed on the first bundle, and testing of the second bundle was in progress. 


\section{PROGRAM PLAN REVIEW}

Emergency core cooling (ECC) tests have been identified as an extension to the blowdown heat transfer experiments conducted in the GE two loop test apparatus. The purpose of these ECC tests will be to explore the effect of interactions between core spray and reflood water with the total system during a simulated LOCA. In formulating a policy with respect to these proposed tests, the NRC requested Aerojet Nuclear Company to establish a position on these proposed experiments and provide recommendations regarding the future of such a program. This section describes the results of the requested evaluation.

\section{MODEL VERIFICATION BACKGROUND}

ANC's interest in the ECC time regime for BWRs arises from the present efforts to develop and verify best-estimate codes for prediction of peak cladding temperature. The presently planned experimental programs must be carefully evaluated to ensure that sufficient information is obtained for complete verification of the best-estimate codes.

Table I presents the results of a systematic review of the major ECC phenomena occurring in BWRs during a LOCA and summarizes the current best-estimate ECC analysis and experimental verification situation. The table is divided into two regimes during ECC, namely the core spray-refill regime and the reflood regime. The core spray-refill period begins during system blowdown as the high-pressure core spray starts and ends when water first enters the core and reflood starts.

Individual components, or groups of related components, are discussed in the table. This form of presentation was selected to correspond to the method of model verification in which models are evaluated separately for components or groups of components which exhibit similar influences or phenomena. A special category of "systems interactions" is also included, which denotes the interactive influence of the components upon each other. These interactions often require unique modeling techniques to provide the proper analytical interface between components.

The discussion in the table indicates that many aspects of the BWR LOCA analysis for the ECC period will be verified adequately through ongoing or completed experimental programs. However, several critical areas exist in which additional experimental investigation appears to be needed. The primary concern is the lack of confirming data to provide quantitative limits on the systems interactions capability of the codes. The interactions of importance include those among the core spray, core, and upper plenum and between the low-pressure coolant injection (LPCI) and the core bypass region and lower plenum. 


Component
Core $\frac{\text { Regine }}{\text { Core Spray-Refill }} \cdot \frac{\text { Topic }}{\begin{array}{l}\text { Phenomena } \\ \text { Occurring }\end{array}}$

Predictive Moćel

\section{Discuseion}

The core spray period is characteriaet by unequal velocity, unequal temperature (UVUT) separated flow patterns within the core superimposed on a three-dimens-onal rod bundle temperature distribution. Core spray, intrcduced at the top of the core, will collect and penatrate intc the cure and quench the channel walls and fuel rods. The quenching process results. in violent local boiling which separates the core spray liquid into steam and subcooled liquid droplets which continue to interact with the rods, channel wall, and updraft flow through the core. Updraft flow comes Irom toiloff in the lower plenum and spray evaporation. Updraft flow may frovide better cooling the channel walls will quench well te Ecre the. fuel rods at a given axial location and eventua:ly a liquid film will form. This will provide a radiant heat sink for the outermost rods. The radiation cooling will eventuaily reverse the rod temperature rise, but complete quenching of the rods for their full length does not generally occur until after reflood is initiated.

Current ECC core models have be za derived from the BWR-FLECHT experimental program. The core is not analytically linked with a system calculaticn becausa presently no system model exists which can properly accourt for interaction between core spray, reflood water, and zie core. Core flow, oressure, and enthalpy calculations are this presently not made. Work is progressing on a RELAP4 [4] motel for BWR analysis which will allow system calculations bit will be limfted by assumptions of equilibrium between phases. Additional analytical capability will be provided with nev versions of the SCORE[5] code which will eventually allow simultaneous solution of the two-phase UVUT core hydraulics and bundle and channel 


\section{TABLE I (contd.)}

BWR MODEL VERIFICATION FOR ECC TIME PERIOD

\begin{tabular}{|c|c|c|c|}
\hline Component & Regime & Topic & Discussion \\
\hline $\begin{array}{l}\text { Core } \\
\text { (contd })\end{array}$ & $\begin{array}{l}\text { Core Spray-Refill } \\
\text { (contd.; }\end{array}$ & $\begin{array}{l}\text { Predictive } \\
\text { Model (contd.) }\end{array}$ & $\begin{array}{l}\text { wall heat transfer in three dimensions. Currently, } \\
\text { SCORE is available in an equal velocity, equal temperature } \\
\text { (EVET) version but has not been linked with empirical } \\
\text { ECC film coefficients nor a radiation model. }\end{array}$ \\
\hline
\end{tabular}

Supporting Data BWR-FLECHT is the only publicly available source of ECC core for Model heat transfer data for BWRs. In this program, simulated BWR Verffication rod bundles were tested over a wide range of core spray and reflood, flow, temperature, and power conditions. Combined core spray/reflood conditions were examined, and pressure effects were investigated. Most of the tests were conducted with stainless steel rods, but core spray tests were also conducted on a limited basis with zircaloy bundles. Inasmuch as the present analytical models are based completely on the BWRFLECHT data, these models cannot really be verified with the currently available data. The models are shown to be consistent with the FLECHT data, as they should be, but complete verification will require confirming test data from a separate facility. Limited verification of the SCORE code could be made with data from the BWR-FLECHT program.

Effect of Model Inadequacies have a direct effect on calculated core fluid Inadequacies conditions and heat transfer coefficients. These boundary conditions directiy affect calculated rod temperature. Peak temperature of many rods in a BWR core will occur during this time period.

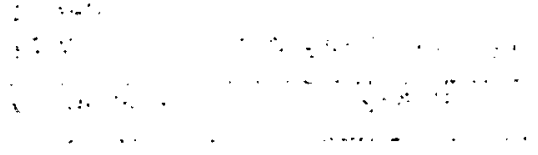

Conclusions

Assessment of a present code and planned codes used for core analysis requires confirming core spray data from a separate facility. 
TABLE I (contd.)

BWR MODEL VERIFICATION FOR ECC TIME PERIOD

\begin{tabular}{|c|c|c|c|c|}
\hline Component & & Regine & Topic & Discussion \\
\hline \multirow[t]{5}{*}{$\begin{array}{l}\text { Lower } \\
\text { Plenum }\end{array}$} & Core & Spray-Refill & $\begin{array}{l}\text { Ehenomena } \\
\text { Gccurring }\end{array}$ & $\begin{array}{l}\text { During core spray-refill, the lower plenum will experience a } \\
\text { varying mixture level due to the combined effects of boiloff } \\
\text { losses and liquid.addition from core spady running down the by- } \\
\text { pass channel walls and from the LPIS. Quench of the lower plenum } \\
\text { will occur when sufficient ECC water accumulates, resulting in } \\
\text { a cessation of steam updraft. }\end{array}$ \\
\hline & & & $\begin{array}{l}\text { Precict:ive } \\
\text { Model }\end{array}$ & $\begin{array}{l}\text { The lower plenum can be represented as a distributed volume } \\
\text { in RELAP4. Empirically determined coefficients used with a } \\
\text { bubble rise and slip model allow calculations of local fluid } \\
\text { conditions, mixture level, and phase slif. }\end{array}$ \\
\hline & & . & $\begin{array}{l}\text { Supporting Data } \\
\text { Eor Model } \\
\text { "erificetion }\end{array}$ & $\begin{array}{l}\text { No lower plenum data exist for the coze spray-refill time regime. } \\
\text { The lower plenum can be verified, however, with data from TLTA } \\
\text { blowdown experiments, as the lower plenum phenomena are similar } \\
\text { ln both reg-mes. Otherjsupporting data Dil- be available from } \\
\text { LOFT[6] and Semiscale[7]. }\end{array}$ \\
\hline & & . & $\begin{array}{l}\text { Iffest of Model } \\
\text { Lnaciequacies }\end{array}$ & $\begin{array}{l}\text { Model is believed to be adequate. Ef Eect of inadequacies would } \\
\text { tie improper timing of start of refioct. }\end{array}$ \\
\hline & $\therefore$ & & Conclusions & $\begin{array}{l}\text { Model verification can be completed timongh presently planned } \\
\text { programs. }\end{array}$ \\
\hline \multirow[t]{2}{*}{ Jet Pumps } & Core & Spray-Refill & $\begin{array}{l}\text { Phenomena } \\
\text { Occurrizg }\end{array}$ & $\begin{array}{l}\text { Reverse flow through the jet pumps carries fluid from the lower } \\
\text { flenum into the lower downcomer region and to the break. }\end{array}$ \\
\hline & & & $\begin{array}{l}\text { Predictive } \\
\text { Model }\end{array}$ & $\begin{array}{l}\text { The jet pumps are represented by the RELAP } 4 \text { two-stream mixing } \\
\text { mode1, which allows momentum exchange between mixing streams of } \\
\text { fluid. }\end{array}$ \\
\hline
\end{tabular}


TABLE I (contd.)

BWR MODEL VERIFICATION FOR ECC TIME PERIOD

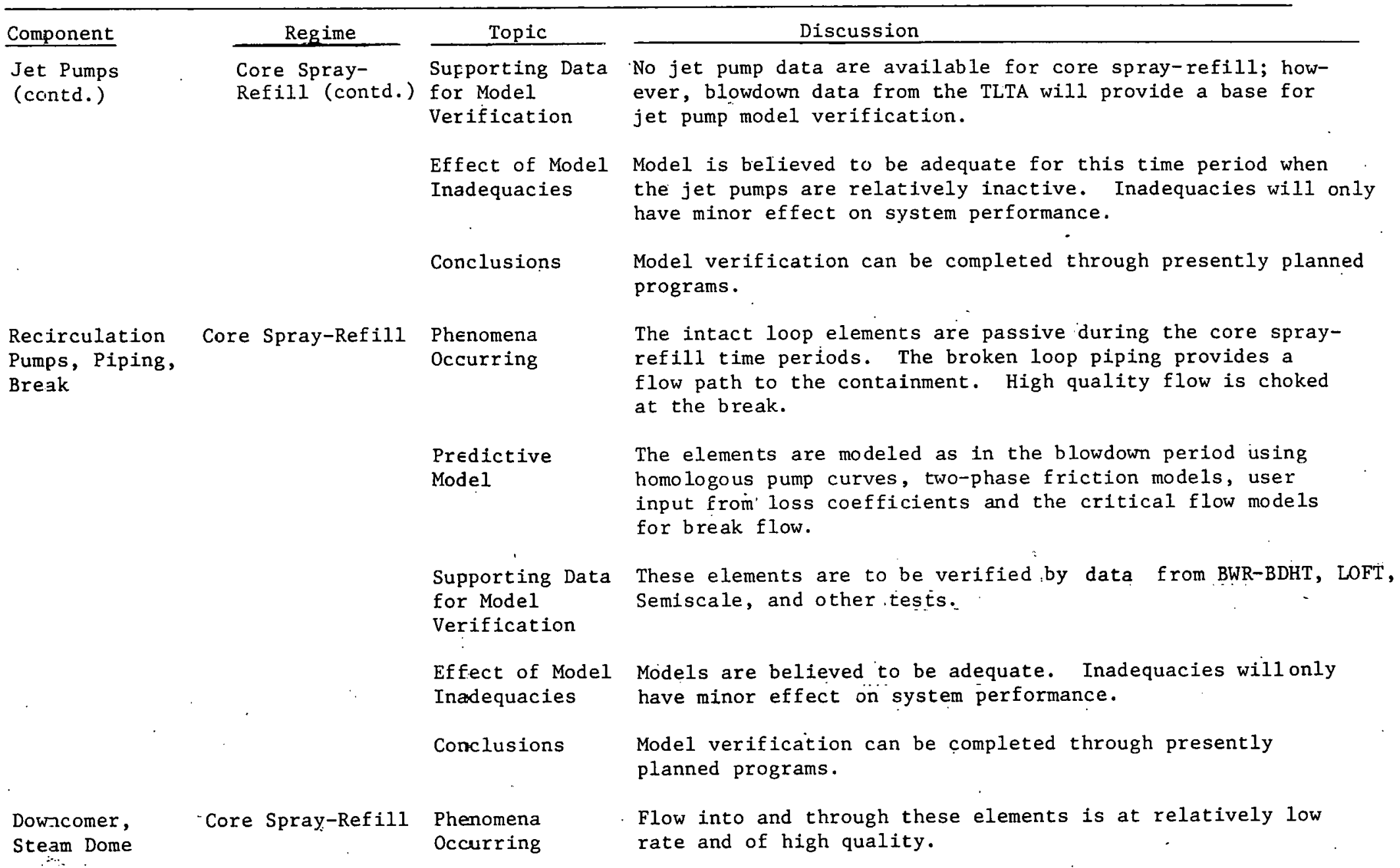


TABLE I (contd.)

BWR MODEL VERIFICATION FOR ECC TIME PERIOD

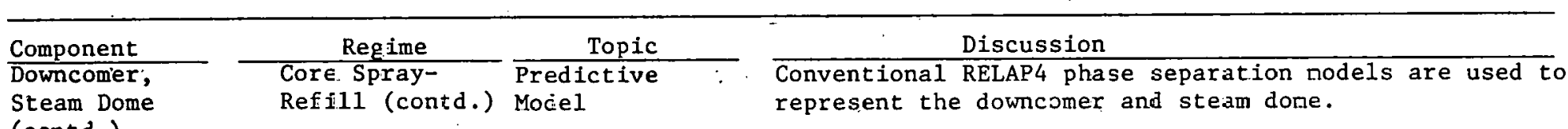

(contd.)

\begin{abstract}
Supporting Deta Many programs are to be used to verify these elements for Model, of the code, including BWR-BDHT, LOFT, and Semiscale.
\end{abstract}

Verification

Effect of Model Models are believed to be adequate. Inadequacies will only Inadequacies have minor effect on system performance.

Conclusions Model verification can be completed through presently planned programs.

\title{
ECC Injec- \\ Core Spray-Refill Phenomena
}

tion Systems

Occurring

Both core spray and LPCI systems pump cold water from reservoirs into the reactcr vessel. Flows are relatively steady and single phase.

Fredictive These elements can be represented comventionally in

RELAP4 using the homologous curves (single phase) for the pump and yolume/junction representations of the piping with single-phase form loss and friction loss models.

Supporting Data for Model

Verification of elements of RElAP4 models (piping, pumps) for ECC injection systens will be made through numerous experimental programs (LOFT, Semiscale, pump tests, etc.).

Effect of ModeI Inadequacies Models are believed to be adequate. Effect of inadequacies will have minor influence on system performance.

Conclusions Model verification can be compieted through presently planned programs. 
TABLE I (contd.)

BWR MODEL VERIFICATION FOR ECC TIME PERIOD

\begin{tabular}{|c|c|c|c|}
\hline Component & Regime & Topic & Discussion \\
\hline Upper,P1enum & Core Spray-Refill & $\begin{array}{l}\text { Phenomena } \\
\text { Jccurring }\end{array}$ & $\begin{array}{l}\text { Flow patterns in the upper plenum are characterized by } \\
\text { nonhomogeneous, nonequilibrium separated phases. } \\
\text { Subcooled droplets of core spray may be entrained } \\
\text { through this volume by steam exiting from the core. } \\
\text { Entrainment would delay spray cooling and reflooding. } \\
\text { The degree of mixing and heat exchange between the } \\
\text { phases affects the quantity of steam condensed. The } \\
\text { spray droplet size and path length will affect the } \\
\text { rate of condensation. Condensation of steam will } \\
\text { locally reduce pressure in the upper plenum which may } \\
\text { alter basic flow patterns throughout the BWR. Core } \\
\text { spray may accumulate and form a mixture level at the } \\
\text { bottom of the upper plenum, prevented from penetrating } \\
\text { the core by the steam updraft. }\end{array}$ \\
\hline
\end{tabular}

Predictive

Mode1

Supporting Data

for Mọde1

Perification
The homogeneous assumptions of RELAP4 do not permit an accurate definition of the UVUT flow patterns and mixing within the upper plenum. Analysis could be performed with RELAP4, but complete mixing and thermal equilibrium would be assumed. The validity of this assumption is not currently known. Present core spray-refill analyses do not consider core spray interactions in the upper plenum. Improvement in modeling capability will be provided upon completion of advanced codes which will allow UVUT solutions in volumes of this type.

No upper plenum data exist specifically for the BWR upper plenum during core spray-refill. Spray tests [8] performed on the Semiscale suppression tank have provided data for nonflowing conditions, to investigate spray effectiveness in pressure suppression. These tests have demonstrated the nonhomogeneity of the spray-steam mixture. These data could be used to partially verify the codes, but complete verification would require data from an interactive test with the plenum coupled to other system elements through typical flow paths. 


\section{TABLE I (contd.)}

BWR MODEL VERIFICATION FOR ECC TIME PEFIOD

\begin{tabular}{|c|c|c|}
\hline Component & Regime & Topic \\
\hline $\begin{array}{l}\text { Upper Plenum } \\
\text { (contd.) }\end{array}$ & $\begin{array}{l}\text { Core S?ray-Refill } \\
\text { (contd.) }\end{array}$ & $\begin{array}{l}\text { Effect of Model } \\
\text { Inadequacies }\end{array}$ \\
\hline
\end{tabular}
Discussion
The major effect of inadequate prediction of events in
the upper plenum will be errors in system flow rates,
as affected by local pressure suppression and entrainment.
These errors in turn will result in errors in core thermal-hydraulic calculations and rod temperature histories.

Conclusions Upper plenum data from an interacting system with core spray are required to assess the limitations of present cote methods and to verify the accuracy of improved codes with UVUT capability.

\section{System}

Interactions

Core Spray-Refill

Fhenomena

cccurring

Introduction of cold core spray into the upper region of the vessel results in several systems interaction phenomena. The core spray wili condense steam in the upper plenum and at the core exit, resulting in a local pressure suppression wich can potentially increase core flow. The core spray can accumu-cte and form a mixture level at the bottom of the ipper plenum if steam updraft is sufficient to prevent penetration intc the core. Once penetration occurs, the core spray will interact $w$-th the hot rod bundles and channel walls resulting in a quench front moving down through the core. Some of the spray may be carried back out of the core to the break by the updraft while a portion will reach the lower plenum, affecting the mixture level and core inlet enthalpy. The time $a t$ which reflood starts is affected by the quantity of core spray accumulated in the lower plenum in addition to the LPCI vater. LPCI penetration to thi lower plenum may be affected by local interactions with the core bypass fluid which conld cause geysering and/or spillover.

The RELAP4 analytical code currently used for system analysis is not capable of iandling the complex two-phase, thermal-hydraulic interactions between BWR components during the ECC time regimes. The limiting assumption in 
TABLE I (contd.)

BWR MODEL VERIFICATION FOR ECC TIME PERIOD

\begin{tabular}{lll}
\hline \multicolumn{1}{c}{ Components } & \multicolumn{1}{c}{ Regime } & \multicolumn{1}{c}{ Topic } \\
$\begin{array}{l}\text { System } \\
\text { Interactions } \\
\text { (contd.) }\end{array}$ & $\begin{array}{l}\text { Core Spray-Reill } \\
\text { (contd.) }\end{array}$ & $\begin{array}{l}\text { Predictive } \\
\text { Model } \\
\text { (contd.) }\end{array}$
\end{tabular}

\section{Discussion}

RELAP4 is that of homogeneous volumes, with no separate calculations of the phase velocities and temperature. As a result, the BWR system interaction studies are presently limited to blowdown regime only, where this assumption can be made. Near-term improvements to RELAP4 are expected to allow limited use for BWR ECC problems but will not fully satisfy the analytical requirements. Advanced codes with UVUT capabilities are currently being developed. These codes, when available, will provide the capability to link the BWR components during ECC and permit calculation of coupled BWR performance history.

Supporting Data. No data base is available to provide verification data for Model on systems interactions for BWRs during the core sprayVerification refill period.

i

Effect of Model With the lack of an accurate interactive systems calInadequacies culation, thermal-hydraulic boundary conditions to and within the core cannot be correctly determined. As a consequence, rod temperature calculations must be made with empirically derived (BWR-FLECHT) core heat transfer correlations. The applicability of this approach to BWRs has not been verified. Confident application of advanced codes with UVUT capabilities depends on their verification through use of systems data typical of BWR-ECC conditions.

Conclusions Systems level ECC tests are necessary to provide a data base to assess the limitations of present codes and to verify new codes presently being developed. These tests are also desired to identify potential unexpected. phenomena:

Core Reflood Phenomena

The core spray is still active during this reglme, and all processes assoclated with core spray, described previously, are superimposed upon the reflooding effects. Core reflooding is initiated when the water level in the lower plenum reaches the core. As the reflood water contacts the hot rods, violent boiling occurs. 
TABLE I (contd.)

BWR MODEL VERIFICATION FOR ECC TIME PERIOD

\begin{tabular}{|c|c|c|c|}
\hline Components & Regine & Topic & Discussion \\
\hline $\begin{array}{l}\text { Core } \\
\text { (contd.) }\end{array}$ & $\begin{array}{l}\text { Eeflood } \\
\text { (contd.) }\end{array}$ & $\begin{array}{l}\text { Phenomena } \\
\text { Occurring } \\
\text { (contd.) }\end{array}$ & $\begin{array}{l}\text { The upward flow of steam and entrained subcooled liqui } \\
\text { will result in cooling atove the reflood front. Turn- } \\
\text { around of the cladding temperature of the hottest rods } \\
\text { is expected to occur after reflooding commences. The } \\
\text { boiling front will advance up the bundle as the lower } \\
\text { regions are quenched until. eventually, the entire. } \\
\text { bundle is quenched. }\end{array}$ \\
\hline
\end{tabular}

Predictive Model

Supporting Data for Mociel

Verification

Effect of Model Inadequacies

Conclusions

Phenomena

Occurring

Predictive

Model
The predictive models used during reflood are similar to those used in core spray-refill analyses. They are based on BWR-FLECHT data and are subject to the same limitations.

As for core spray-refill, BWR-FLECHT is the only available source of reflood data.

Inadequacies affect core fluid conditions and heat transfer coefficient calculations. This directly affects peak clad temperature calculations and time of rod quench.

Assessment of present codes used for core analysis requires confirming reflood data from a separate facility.

During reflood, the lower plenum remains full of subcooled liquid. Flow enters the lower plenum from the LPIS and exits through the core and the jet pumps.

The lower plenum can be modeled as described for the core spray-refill period. 
TABLE I (contd.)

BWR MODEL VERIFICATION FOR ECC TIME PERIOD

Component
Lower Plenum

$\frac{\text { Topic }}{\text { Supporting Data }}$
for Model

Verification

Effect of Model

Inadequacies

Conclusions

Phenomena

Occurring

Predictive

Model

Supporting Data

for Mòdel

Verification

Effect of Model Inadequacies

Conclusions

Phenomena

Occurring

Discussion
No spectfic BWR reflood data are currently avallable.
However, BWR-BDHT, LOFT, and Semiscale blowdown
data can be used for verification.

There will be minor effects on reflood rate.

Model verification can be completed through presently planned programs.

Flow in these elements is generally single phase and readily analyzed.

These elements can be modeled as described for the core spray-ref111 period.

No specific BWR reflood data are currently available. However, BWR-BDHT, LOFT, and Semiscale blowdown data can be used for verification.

There will be minor effects on reflood rate.

Model verification can be completed through presently planned programs.

The reflood flow rate is a function of the eight-foot head of water in the fet pumps and the flow resistance which depends on the interaction of the reflood water and the hot rod bundles. A flow oscillation potential exists, influenced by the opposing forces of pressure generated by flashing in the core and the water head in the 
TABLE I (contd.)

BWR MODEL VERIFICATION FOR ECC TIME PERIOD

\begin{tabular}{|c|c|c|c|}
\hline Component & Regime & Topic & Discussion \\
\hline \multirow[t]{5}{*}{$\begin{array}{l}\text { Systems } \\
\text { Interactions } \\
\text { (contd.) }\end{array}$} & Reflood (cortd.) & $\begin{array}{l}\text { Phenomena } \\
\text { Occurring } \\
\text { (contd.) }\end{array}$ & $\begin{array}{l}\text { jet pumps. Core spray is still active during this time } \\
\text { period., All spray intezactions previously described } \\
\text { continue with an added interaction between the core } \\
\text { spray and the reflood flow within the core. }\end{array}$ \\
\hline & & $\begin{array}{l}\text { Predictive } \\
\text { Model }\end{array}$ & $\begin{array}{l}\text { As for core spray-refill, systems interaction analyses } \\
\text { are not presently conducted for tine reflood time period. }\end{array}$ \\
\hline & . & $\begin{array}{l}\text { Supportire Data } \\
\text { for Model } \\
\text { Verification }\end{array}$ & $\begin{array}{l}\text { The PWR FLECHT-SET } \\
\text { will provide PWR code verification data for the reflood } \\
\text { period. The differences in system design, operating } \\
\text { conditions, as well as she lack of concurrent core } \\
\text { spray, will not allow complete verification of the codes } \\
\text { for BWR application. No information is currently avail- } \\
\text { able to fill this need. }\end{array}$ \\
\hline & & $\begin{array}{l}\text { Effect of Model } \\
\text { Inadequacies }\end{array}$ & $\begin{array}{l}\text { As for core spray-refill, the core model cannot be } \\
\text { coupled to an interactive system model. Resulting core } \\
\text { calculations are based on unverified empirical relation- } \\
\text { ships. }\end{array}$ \\
\hline & & Conclusicr.s & $\begin{array}{l}\text { Systems level ECC tests are necessary to provide a data } \\
\text { base to assess the limitations of present codes and to } \\
\text { verify new codes fresenty being developed. } \\
\text { These tests are also desiret to identify potential } \\
\text { unexpected phenomena. }\end{array}$ \\
\hline
\end{tabular}


Interactions occur in the bypass region where LPCI is injected (geysering and spillover) and in the lower plenum where LPCI mixes with saturated fluid (lower plenum quench). Some unique component data requirements during ECC are also outstanding. These include hydraulic and heat transfer processes within the core and two-phase flow mixing in the upper plenum regions .

The conclusion reached from this review is that the lacking information can only be acquired through additional testing in which systems interaction effects can be simulated. Measurements should be made of these effects simultaneously with measurements of the performance of related components. These experiments can be conducted in a scaled system such as the TLTA in which all major flow elements of the BWR are represented.

\section{TLTA DESIGN CONSIDERATIONS}

Several design features of the TLTA have been identified as potentially capable of distorting TLTA performance during ECC testing with respect to BWR behavior. These features include:

(1) The TLTA jet pump suction is three feet above the core inlet (versus eight feet for the BWR) which would affect head for core reflood.

(2) The upper electrode plate splits the upper plenum into two volumes and physically blocks introduction of core spray at the bundle top. Spray would be injected through the sides of the unheated part of the bundle or above the electrode plate which may affect simulation of spray-system interactions in the upper plenum region.

(3) The TLTA channel wall is much heavier and of a different material than that of the BWR. Wall rewetting would thus be nontypical in the TLTA which could affect rod bundle temperature response.

(4) The core bypass design in TLTA does not simulate BWR geometry. The current TLTA design could affect the timing of reflood coolant reaching the lower plenum.

(5) The TLTA heater rods are limited to $1,500^{\circ} \mathrm{F}$ to prevent damage to the thermocouples. ECC temperatures in the BWR, prior to quench, could exceed this limit.

Modifications to the TLTA to permit the conduct of ECC interaction experiments have been proposed by GE. To cope with the above mentioned problems, while providing information on a timely basis, a three-part program has been formulated. Each part utilizes a specific TLTA configuration and addresses only certain ECC interaction questions. 
The first portion of the proposed program uses the TLTA essentially as now constructed. The only modifications are the addition of high- and low-pressure core spray and low-pressure coolant injection systems. Objectives of the tests with this configuration are to assess, the influence of ECC delivery systems on the fluid flow and heat transfer processes during the early blowdown.

For the second part of the program, the TLTA would be modified to provide more representative upper plenum, channel wall, jet pump, and core geometries. High temperature, low-power heater rods would also be utilized. Tests on this configuration would explore the ECC system interaction processes starting from the latter stages of blowdown through reflood.

During the third portion of the program, integral tests would be conducted from rupture through reflood to provide data in the regime between those covered by the first and second portions of the program. These tests would probably require development of a new high-power heater rod capable of withstanding temperatures in excess of $1,500^{\circ}$.

The proposed three-part program is tentatively endorsed by ANC as an alternidive to complete integral systems tests. However, many potential BWR model verification problems may remain after completion of such a program. The models must be verified over the total integral LOCA regime from data obtained from several nonintegral tests. Subsequently, these models must be extrapolated from a $1 / 560$-scale TLTA facility to predict performance of a full-scale plant.

\section{RECOMMENDATIONS}

The ECC. systems interaction program proposed by GE should bc adopted and schedules established for its completion.

A series of scoping studies should be defined and conductcd to clarify the influences and importances of various factors affecting BWR cladding temperature during the ECC period. Subjects of interest would include core spray pressure suppression effects, flow and pressure oscillation potential, and nonequilibrium steam-water interaction throughout the system. In addition, the studies should scope the magnitude of updraft flow and cooling, the potential for spray entrainment, the potential delay in reflooding due to ECC entrainment, and interaction between LPCI fluid and the core bypass region.

Similar studies for the TLTA should parallel the development of the ECC program plan. These studies should be directed toward obtaining an understanding of TLTA response to various scaling compromises and hardware design options. Results from these studies should be compared with expected BWR behavior during the ECC period to assess typicality of expected TLTA experimental results. 
The proposed test program should be continuously reviewed in light of the results of these studies and, as available, experimental results. Model verification progress and needs should also be continuously reviewed to determine current applicability of the experimental results and future requirements. 


\section{OPERATIONS AND MEASUREMENTS}

One of ANC's primary assignments in connection with the BWR-BDHT program was to independently appraise the capability of the TLTA to provide accurate and meaningful results. This task was carried out by (a) conducting an analysis of the accuracies of selected key TLTA measurements, and (b) witnessing a selected TLTA test and reviewing pre- and posttest operations by the GE test conduction team.

Details of these two activities are covered in the following sections.

\section{MEASUREMENT ACCURACY EVALUATION}

\subsection{Background.}

The primary purpose of this evaluation was to numerically define selected measurement accuracies to assist in the ultimate specification of TLTA data confidence levels and to identify potential problem areas which could be remedied. Emphasis was placed on evaluation of the accuracies of the transient measurements of quality, mass, void fraction, internal energy, mass flow, and density. Since most of these parameters will vary significantly during a typical experiment, their accuracies were evaluated at various time points to determine the effects of flow conditions on the accuracies. TLTA Test 3 , the reference case, was used as a baseline for this study.

Results of these studies wcrc originally presentedin Reference 10 . Since completion of the original analysis, several improvements were incorporated by GE in the measurement approach. These changes have been accounted for by an updated analysis. In addition, a more thorough treatment was given to flow rate uncertainties and bias errors to improve and add to those calculations described in Reference 10.

\subsection{Analysis Description}

The parameters investigated in this study are all derived from one or more direct measurements of pressire or pressure difference $(\Delta \dot{P})$. 'This relationship between measurements and derived quantities is shown in ligure l. The locations of the medsurement stations selected for this evaluation are shown in Figure 2.

Uncertainties exist in the basic measurements as well as in other variables used to calculate the parameter of intcrcst. The cvaluation of the total uncentainty in each parameter follows the approach outlined in Reference 11 for single sample experiments. For a parameter $\mathrm{m}=\mathrm{f}\left(\mathrm{v}_{1}, \mathrm{v}_{2}, \ldots, \mathrm{v}_{\mathrm{n}}\right)$, the uncertainty in $\mathrm{m}, \delta \mathrm{m}$, was determined as a function of the known uncertainties in each of the variables $(\delta v)$ by 


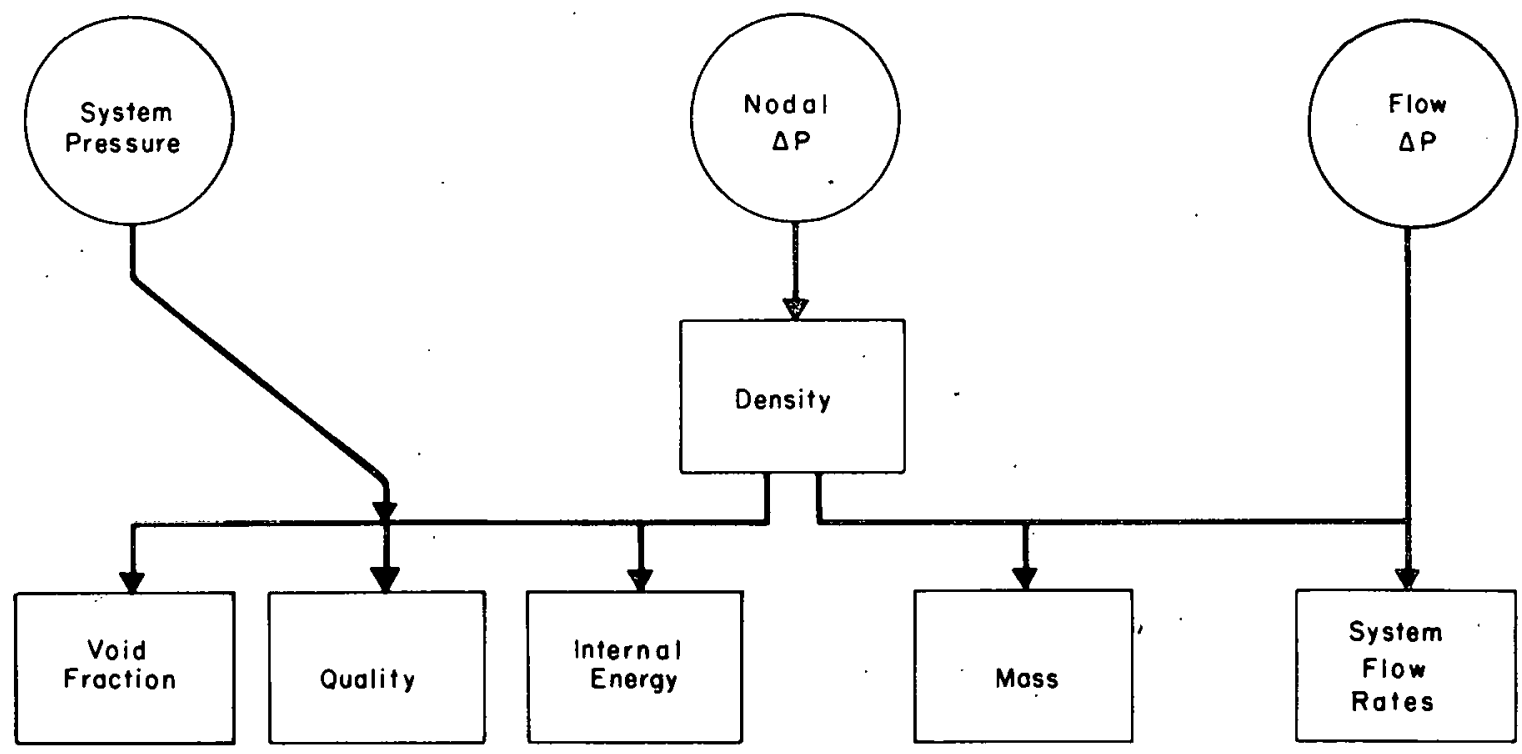

Fig. 1 Calculation of TLTA derived data.

Flow $\Delta P$

Broken Loop

Jet Pump

(DP 46)

Flow $\Delta P$ Bundle

Inlet

(DP 4O)

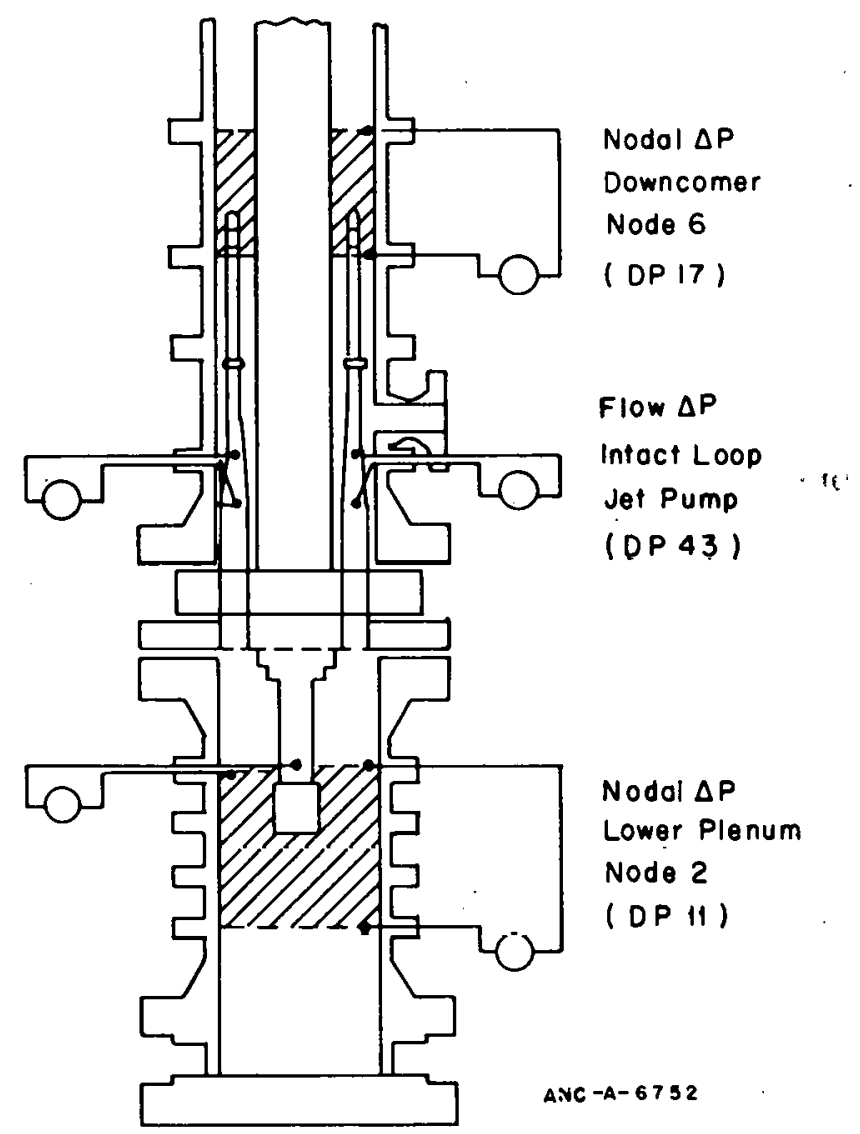

Fig. 2 TLT $\Lambda$ measurement locations. 


$$
\delta m= \pm\left[\left(\frac{\partial m}{\partial v_{1}} \quad \delta v_{1}\right)^{2}+\left(\frac{\partial m}{\partial v_{2}} \quad \delta v_{2}\right)^{2}+\ldots+\left(\frac{\partial m}{\partial v_{n}} \delta v_{n}\right)^{2}\right]^{1 / 2}
$$

In addition to these uncertainties, bias errors will exist in the derived quantities. Typical sources of bias errors are transducer and data system response lags and neglected flow effects. Since these errors were not random, they were treated separately from the uncertainties. The bias errors in $\mathrm{m}, \Delta \mathrm{m}$, were determined from the known functional relationships for $m$, and the known bias errors, $\Delta v$, in each of the variables $v$ by

$$
\Delta m=f\left[\left(v_{1}+\Delta v_{1}\right),\left(v_{2}+\Delta v_{2}\right), \ldots,\left(v_{n}+\Delta v_{n}\right)\right]-f\left(v_{1}, v_{2} \ldots, v_{n}\right) .
$$

Tablc II summarizes the functional relationships used by GE to determine the parameters of interest and the uncertainty and bias error sources considered in this accuracy analysis.

Density is determined in the various TLTA regions through measurement of a pressure difference between two vertically separated points which form the boundaries of the volume (or node) of interest. The equation for density shown in Table II is given in two forms. The first form is derived directly from the momentum equation, assuming one-dimensional homogeneous flow. The three quantities in the bracket represent acceleration, momentum, and friction effects. In the large volumes (lower plenum, downcomer) where density measurements are made, GE assumes that these effects are negligible, and the measured pressure difference is simply the difference between cold leg and volume hydrostatic heads. The density equation then simplifies to the second form:

$$
\bar{\rho}=\rho_{C}-\frac{\Delta P_{T}}{L} .
$$

which is the relationship used to compute local experimental densities.

The evaluation of density accuracy has considered the static and dynamic transducer and data system errors. In addition, uncertainties in the node length ( $\mathrm{I}$ ) and in cold leg density were considered. A scoping analy sis was also made of possible bias errors introduced by neglecting the acceleration, momentum, and friction terms.

With exception of flow rate, all remaining quantities are calculated directly from. measured density as shown in Table II. Uncertainties and bias errors in these parameters are based on the corresponding density uncertainties and biases. In addition,other error sources due to volume uncertainties and measured pressure uncertainties were considered as applicable. 
TABLE II

UNCERTAINTY AND BIAS ERROR SOURCES

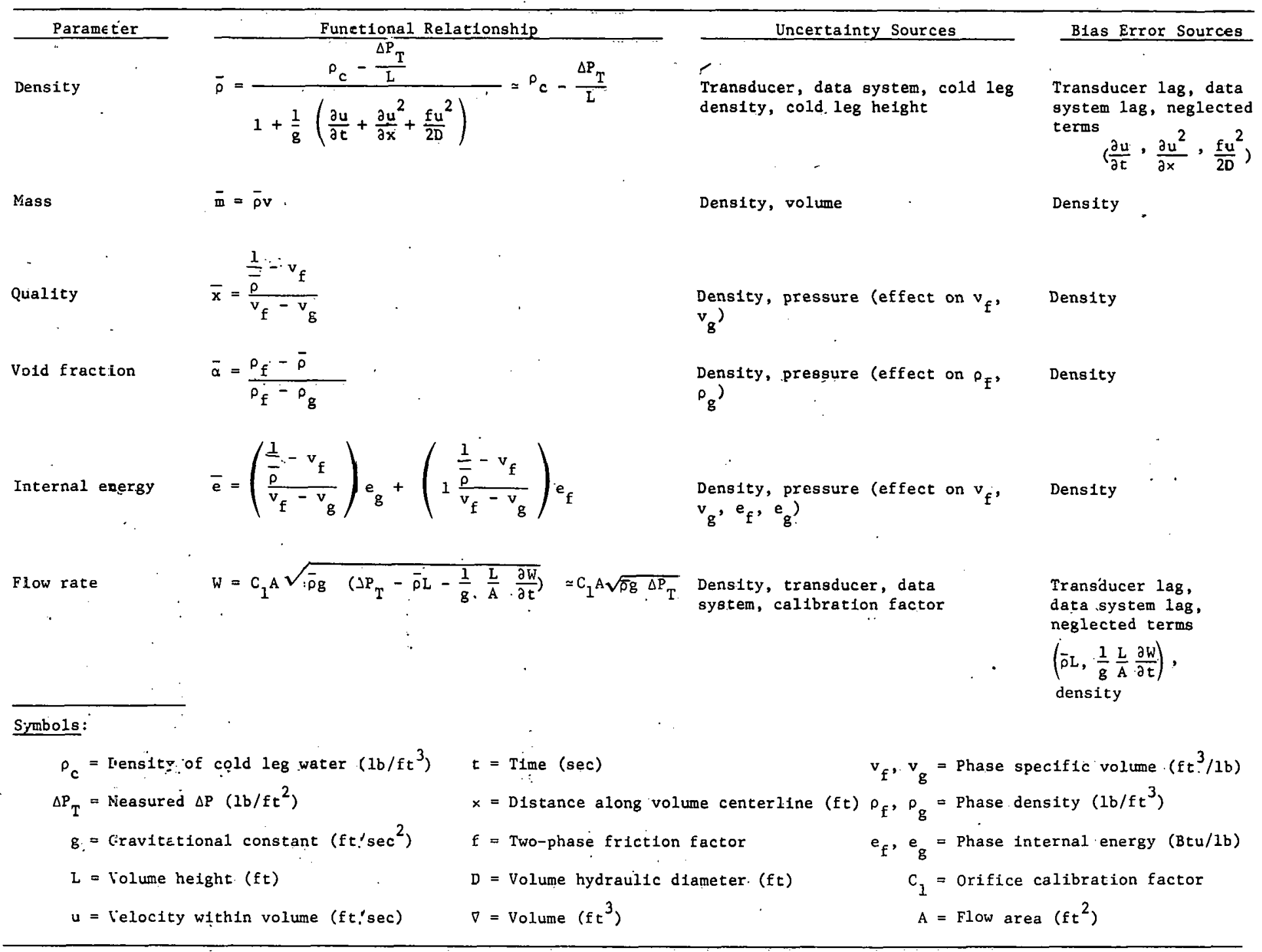


Experimental flow rates in the TLTA are calculated from measured pressure drops through flow resistance or form loss regions. The general relationship used for experimental flow rate is

$$
W=C_{1} A \quad \sqrt{\overline{\rho g} \Delta P_{T}}=\dot{C} \sqrt{\bar{\rho} \Delta P} .
$$

As in the case of the density measurement, this relationship is a simplified case of the complete form shown in Table II. Neglected in this form are effects of elevation head and fluid acceleration on the $\Delta \mathrm{P}$ measurement.

The coefficient $C$ is determined empirically from in-place flow calibration runs at various steady state flow rates, and, for core flow, at various void fractions.

Accuracy of these flow measurements has been evaluated for three flow stations considered most important for code verification. These are the core inlet, the intact loop jet pump, and the broken loop jet pump. The locations of these measurement stations are shown in Figure 2. Accuracics of the flow rates were evaluated at several times in the transient, each representing a unique flow condition.

The uncertainties considered in the analysis included those due to measured local density, measured flow station $\triangle P$, and uncertainties in the calibration coefficient, $C$.

In GE's published calibration description ${ }^{[12]}$ it is recommended that the following calibration coefficents be used:

$$
\begin{array}{ll}
\text { bundle inlet: } & C=2.34 \\
\text { jet pump, forward: } \quad C=0.935+2.45\left(\frac{T}{10,000}\right) \\
\text { jet pump, reverse: } \quad C=0.511+8.4\left(\frac{10 \mathrm{~g} R e}{100}\right)
\end{array}
$$

where

$$
\begin{aligned}
& \mathrm{T}=\text { fluid temperatures }\left({ }^{\circ} \mathrm{F}\right) \\
& \operatorname{Re}=\text { Reynolds number. }
\end{aligned}
$$

The value of $\mathrm{C}$ for corc inlet flow is based on two-phase flow from 5 to $\mathrm{su} \mathrm{lb} / \mathrm{sec}$ with void fractions up to $9 \%$. Locally measured two-phase density is used in solving for flow. Upon examination of the GE two-phase data, it appears that a $\pm 6.2 \%$ scatter exists in various determinations of $\mathrm{C}$ for the bundle. This is assumed to represent the uncertainty in $\mathrm{C}$ for this analysis throughout the transient.

No uncertainty information was available on the jet pump coefficients. However, the jet pump flow calibrations were conducted under conditions similar to the bundle calibrations. It is believed that the resultant jet pump flow calibration accuracy is similar to 
that of the bundle. It is therefore assumed that the jet pump calibration coefficents will also have $\pm 6.2 \%$ uncertainty levels.

Bias errors were also calculated for the flow rate measurements. Sources of these bias errors were transducer and data system response lags and bias errors in the average density. Scoping analyses of the fluid acceleration and elevation effects were also made to determine their influence on the measured flow $\triangle \mathrm{Ps}$.

\subsection{Accuracy of Basic Measurements}

The evaluation of TLTA measurement accuracies was initiated by examining GE's measurement system approach to determine uncertainty levels and bias errors in the basic pressure and $\triangle \mathrm{P}$ measurements. This examination has indicated that $\mathrm{GE}$ did a good job in defining and confirming direct measurement uncertainties and bias errors. The resultant uncertainty and bias levels are also good and agree favorably with the accuracy of other experimental systems with which ANC is familiar.

1.3.1 Uncertainties. Table IIl summarizes the static transducer uncertainties determined in the evaluation. The figures given represent the root-mean-square (RMS) of linearity, hysteresis, repeatability, temperature shift, and excitation accuracy errors. The table includes an error determined from information provided by the supplier. Also included are errors determined from full-scale calibration tests performed by GE on numerous transducers: These latter data confirm the validity of the supplier error specifications for use of the transducer over its full range.

In ANC's previous analysis (Reference 10), the maximum full-scale errors were used in the uncertainty analysis. GE has since updated their calibration approach, defining a calibration factor only over the range of interest. This approach, as shown graphically in Figure 3, can improve the accuracy of individual transducers. The most significant improvements were observed in the Statham $\triangle \mathrm{P}$ transducers, which are used for most flow and density measurements. Typically, these instruments were ranged to approximately twice the maximum measurement. Upon examination of the typical calibration traces available, it appeared that the calibration error could be reduced to about $50 \%$ of the full-scale value using the revised technique. The analysis was thus updated by using an uncertainty of $50 \%$ of the supplier-specified value for the Statham transducers.

Another component of uncertainty not covered by the manufacturer's specifications is zero shift of the differential pressure transducers with system pressure. This uncertainty is found during calibration and is seen in actual data as a measured zero shift from pretest to posttest conditions. GE compensates for zero shift through application of a pressure dependent correction factor in their data reduction code. This approach appears reasonable and, accordingly, zero shift uncertainties are assumed negligible.

Potential errors from the data acquisition system include gain and zero variations and analog-to-digital conversion errors. According to the manufacturer, fixed gain accuracy is 


\section{TABLE III}

STATIC TRANSDUCER UNCERTAIINTIES

\begin{tabular}{|c|c|c|c|c|c|c|c|}
\hline \multirow[b]{2}{*}{ Transducer } & \multirow[b]{2}{*}{ Supplier } & \multirow[b]{2}{*}{ Range (pji) } & \multirow[b]{2}{*}{ Used For } & \multicolumn{4}{|c|}{ Uncercaingy - Percent Full Scale ${ }^{\{a\}}$} \\
\hline & & & & $\begin{array}{c}\text { Supplier } \\
\text { Specificaticn }\end{array}$ & $\begin{array}{l}\text { Measured } \\
\text { Minimum } \\
\end{array}$ & $\begin{array}{r}\text { Measured } \\
\text { Maximum } \\
\end{array}$ & $\begin{array}{r}\text { Measured } \\
\text { Average } \\
\end{array}$ \\
\hline Pressure & Straindyne & 0 to 1,030 & Systen pressure & \pm 0.24 & \pm 0.12 & \pm 0.25 & \pm 0.18 \\
\hline$\dot{\Delta P}$ & Statham & $\begin{array}{lll}0 & \text { to } & 2.5 \\
0 & \text { tc } & 5 \\
0 & \text { to } & 10 \\
0 & \text { to } 25 \\
0 & \text { to } & 50\end{array}$ & $\begin{array}{l}\text { Flcw rrifice } \triangle P s, \text { nodal } \\
\text { densily } \triangle P s \text {, system } \\
\text { pressure drops }\end{array}$ & \pm 0.78 & \pm 0.21 & \pm 0.67 & \pm 0.29 \\
\hline$\Delta \mathrm{P}$ & BLH & 0 to $1 . \varepsilon$ & $\begin{array}{l}\text { Noda1 density } \triangle P s \text {, system } \\
\text { pressire drops }\end{array}$ & \pm 0.60 & \pm 0.29 & \pm 0.53 & \pm 0.39 \\
\hline
\end{tabular}

[a] Errors include repeatability. ccmbired linearity and hysteresis, and temperature sh:ft. Number of transducers analyzed: 7 Straindyne, 22 Statham, 7 Bal doin Lima-Hamilton. 


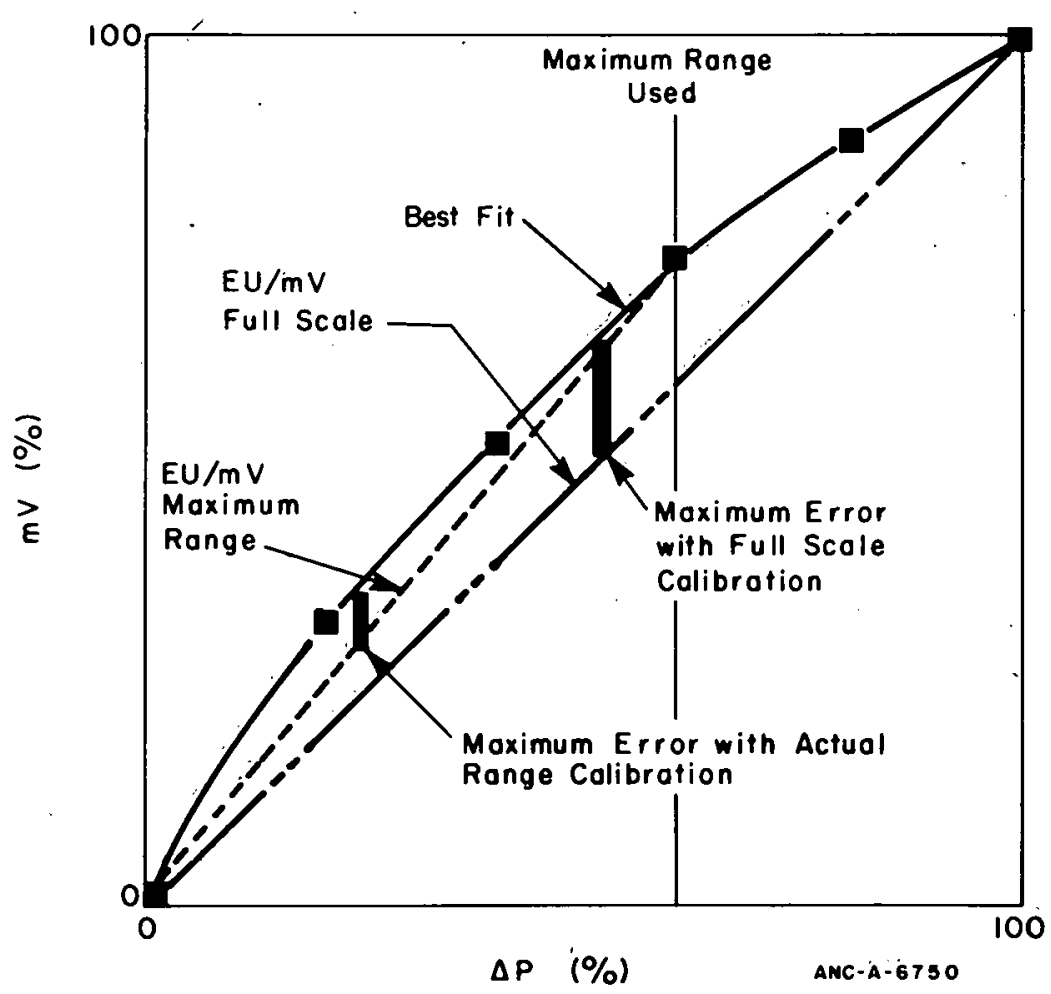

Fig. 3 Transducer calibration options.

$\pm 0.1 \%$ of the reading. Zero variations are believed negligible as they are calibrated out along with the transducer zero shifts. Analog-to-digital conversion errors are also believed to be negligible as the sample rate is generally several times the transducer bandwidth.

The transducer calibration accuracy is dependent upon the accuracy of a group of digital voltmeters and a set of pressure gauges. The RMS accuracy of the calibration tests, taken from manufacturer's specifications on these instruments, is $\pm 0.1 \%$ of full scale. GE maintains the calibration of these instruments through periodic intercomparisons.

All measurements of pressure and $\Delta \mathrm{P}$ must be corrected to remove the head generated by cold water in the vertical transducer lines. An uncertainty can be introduced in this cold leg correction due to uncertainties in the cold leg height $( \pm 1 / 8$ inch assumed) and variations in the cold water density due to ambient temperature changes $\left( \pm 20^{\circ} \mathrm{F}\right.$ assumed $)$. The net effect of these uncertainties was found to be negligible for the pressure measurements. For the $\triangle \mathrm{P}$ measurements, these uncertainties ranged from $\pm 0.27 \%$ for low-range $\Delta \mathrm{P}$ transducers to $\pm 0.10 \%$ for high-range $\Delta \mathrm{P}$ transducers.

1.3.2 Bias Errors. Dynamic bias errors are introduced by the finite response time of the transducers and the data system. These errors can be expressed as the product of the delay time for a ramp input and the slope of the pressure or $\Delta \mathrm{P}$ response:

$$
\text { error }=\text { delay time } \mathrm{x}(-\mathrm{dp} / \mathrm{dt}) \text {. }
$$


These errors will always be biased, either positive or negative depending on the sign of $\mathrm{dp} / \mathrm{dt}$.

The delay time for the data system is calculated to be $9 \mathrm{msec}$ with the filters set at the nominal $30 \mathrm{~Hz}$ bandwidth. The "as installed" transducer delay times were experimentally determined by GE from dynamic response tests. The values obtained were about $2 \mathrm{msec}$ for the Straindyne transducers used for pressure measurement and a maximum of $100 \mathrm{msec}$ for the $\Delta \mathrm{P}$ transducers.

\section{$1.4 \quad$ Accuracy of Derived Quantities}

The results of this measurement accuracy analysis are presented in Tables IV, V, and VI. A summary of these results follows. Note that all results are presented as a percentage of the instantaneous reading. This applies to both the uncertainties and bias errors.

'I'ABLE IV

LOWER PLENUM NODE 2 MEASUREMENT ACCURACIES

\begin{tabular}{|c|c|c|c|c|}
\hline \multicolumn{2}{|c|}{ Volume Condition } & $\begin{array}{c}\text { Subcooled } \\
\text { Liquid } \\
(5 \text { sec }) \\
\end{array}$ & $\begin{array}{c}\text { Flashing } \\
\text { Two-Phase } \text { Mixture } \\
(10 \cdot \mathrm{sec}) \\
\end{array}$ & $\begin{array}{c}\text { Gradual Boiloff } \\
\text { Two-Phase Mixture } \\
(15 \mathrm{sec}) \\
\end{array}$ \\
\hline Density & $\begin{array}{l}\text { Value }\left(1 \mathrm{~b} / \mathrm{ft} \mathrm{t}^{3}\right) \\
\text { Uncertainty }(\%) \\
\text { Bias }(\%)\end{array}$ & $\begin{array}{l}47 \\
\pm 1.8 \\
-4.8\end{array}$ & $\begin{array}{l}40 \\
\pm 2.1 \\
10.6\end{array}$ & $\begin{array}{r}30 \\
\pm 2.8 \\
0.2\end{array}$ \\
\hline Mass & $\begin{array}{l}\text { Value }(1 b) \\
\text { Uncertalnty }(\%) \\
\text { Dias }(\%)\end{array}$ & $\begin{array}{l}45 \\
\pm 4.6 \\
-4.8\end{array}$ & $\begin{array}{l}38.3 \\
\pm 4.7 \\
10.6\end{array}$ & $\begin{array}{r}28.7 \\
\pm 4.7 \\
0.2\end{array}$ \\
\hline Quality $\cdots$ & $\begin{array}{l}\text { Value } \\
\text { Uncertainty (\%) } \\
\text { Bias }(\%)\end{array}$ & 0 & $\begin{aligned} & 0.008 \\
& \pm 15.4 \\
&-78.8\end{aligned}$ & $\begin{array}{l}\quad 0.015 \\
\pm 5.6 \\
-5\end{array}$ \\
\hline $\begin{array}{l}\text { Void } \\
\text { Fraction }\end{array}$ & $\begin{array}{l}\text { Value } \\
\text { Uncertainty (\%) } \\
\text { Bias (\%) }\end{array}$ & 0 & $\begin{aligned} & 0.142 \\
\pm & 13.4 \\
- & 66.4\end{aligned}$ & $\begin{array}{l}0.428 \\
\pm 3 \\
-0.2\end{array}$ \\
\hline $\begin{array}{l}\text { Lnternal } \\
\text { Energy }\end{array}$ & $\begin{array}{l}\text { Value }(B+u / 1 b) \\
\text { Uncertainty }(\%) \\
\text { Bias }(\%)\end{array}$ & $\begin{array}{c}525.3 \\
\pm 0.8 \\
0\end{array}$ & $\begin{array}{l}543 \\
\pm 0.2 \\
-0.7\end{array}$ & $\begin{array}{l}433 \\
\pm 0.2 \\
-0.1\end{array}$ \\
\hline
\end{tabular}

1.4.1 Lower Plenum Node 2. The accuracy of parameters associated with Node 2 in the lower plenum is contained in Table IV. It is shown that these measurements are within acceptable limits throughout most of the transient. Exceptions are observed in density, quality, and void fraction bias errors during the flashing period. Though relatively large in 
TABLE V

DOWNCOMER NODE 6 MEASUREMENT ACCURACIES

\begin{tabular}{|c|c|c|c|c|}
\hline \multicolumn{2}{|c|}{ Volume Condition } & $\begin{array}{c}\text { Two-Phase Mixture } \\
\text { Low Qual1ty } \\
(6 \mathrm{sec}) \\
\end{array}$ & $\begin{array}{c}\text { Partially Full } \\
\text { Two-Phase Mixture } \\
(9 \text { sec }) \\
\end{array}$ & $\begin{array}{c}\text { Two-Phase Mixture } \\
\text { H1gh Qual1ty } \\
(30 \text { sec })\end{array}$ \\
\hline Density & $\begin{array}{l}\text { Value }\left(1 \mathrm{~b} / \mathrm{ft}^{3}\right) \\
\text { Uncertalnty }(\%) . \\
\text { Blas }(\%)\end{array}$ & $\begin{array}{l}42 \\
\pm 1.1 \\
-1.2\end{array}$ & $\begin{array}{r}22 \\
\pm 2.1 \\
+15.4\end{array}$ & $\begin{array}{r}0.9 \\
\pm 55.6 \\
+14.4\end{array}$ \\
\hline Mass & $\begin{array}{l}\text { Value (1b) } \\
\text { Uncertainty (\%) } \\
\text { Bias (\%) }\end{array}$ & $\begin{array}{l}90.2 \\
\pm 2.6 \\
-1.2\end{array}$ & $\begin{array}{r}42.2 \\
+3.2 \\
+15.4\end{array}$ & $\begin{array}{r}1.7 \\
\pm 55.7 \\
+14.4\end{array}$ \\
\hline Qual1ty & $\begin{array}{l}\text { Value } \\
\text { Uncertainty }(\%) \\
\text { Blas }\end{array}$ & $\begin{aligned} & 0.005 \\
\pm & 11.8 \\
+ & 12.9\end{aligned}$ & $\begin{array}{l}0.056 \\
\pm 4 \\
-25.5\end{array}$ & $\begin{aligned} & 0.98 \\
\pm & 56.6 \\
- & 12\end{aligned}$ \\
\hline $\begin{array}{l}\text { Void } \\
\text { Fraction }\end{array}$ & $\begin{array}{l}\text { Value } \\
\text { Uncertainty }(\%) \\
\text { Blas }(\%)\end{array}$ & $\begin{aligned} & 0.098 \\
\pm & 10.6 \\
+ & 11.2\end{aligned}$ & $\begin{aligned} & 0.552 \\
& \pm 1.9 \\
&-13.9\end{aligned}$ & $\begin{array}{l}0.999 \\
\pm 1 \\
-0.1\end{array}$ \\
\hline $\begin{array}{l}\text { Internal } \\
\text { Energy }\end{array}$ & $\begin{array}{l}\text { Value (Btu/1b) } \\
\text { Uncertainty (\%) } \\
\text { Blas }(\%)\end{array}$ & $\begin{array}{r}541.3 \\
\pm 0.1 \\
+0.1\end{array}$ & $\begin{array}{r}570.4 \\
\pm 0.2 \\
-1.4\end{array}$ & $\begin{array}{c}1,096.2 \\
\pm 36.9 \\
-6.7\end{array}$ \\
\hline
\end{tabular}

magnitude, these errors only persist for a few seconds as influenced by fluid acceleration effects during flashing.

1.4.2 Downcomer Node 6. The results for Node 6 are shown in Table V. It is noted that uncertainties for the downcomer parameters are relatively small during the first part of the transient. Later in the transient when this volume contains saturated steam, substantial uncertainties are observed in measurements of density, because the density of the steam approaches the resolution limit of the transducers. The resultant large uncertainties in density are propagated into large uncertainties in most of the other derived quantities. These large uncertainties are not considered a major problem, however, since it is possible to use a backup measurement of local pressure to determine saturated steam properties.

Bias errors were found to be moderate for several of the parameters at various points in the transient. Most noticeable of these are the $-25.5 \%$ bias error in quality as Node 6 is emptying. This error does not appear, however, to pose a significant problem in code verification studies. The errors only persist for a brief time and are in parameters of secondary importance in code comparisons .

1.4.3 Flow Rates. Table VI presents the calculated measurement accuracies for bundle flow rate and flow rates in both jet pumps. The results indicate that. initially, the accuracies 
TABLE VI

FLO'N RATE MEASUREMENT ACCURACIES

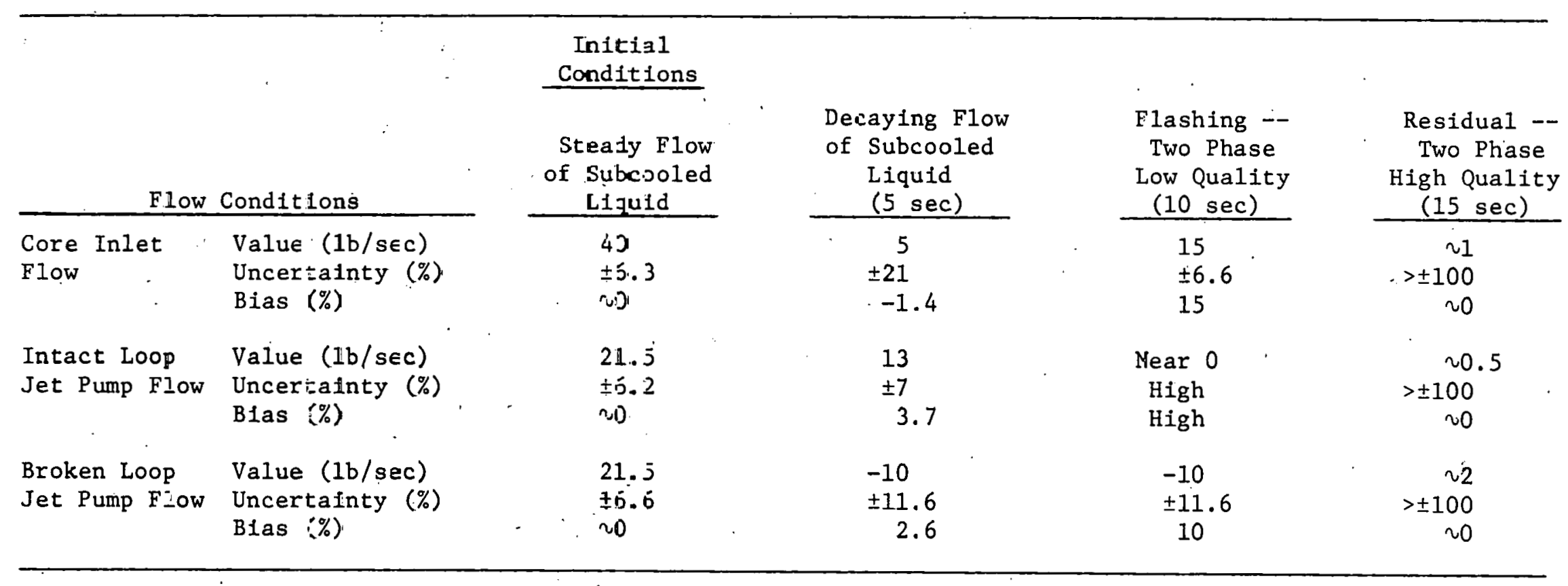


are relatively good. However, as the transient progresses, many of these flow measurements develop significant uncertainties as the absolute values of the measurements drop. At five seconds, a moderate uncertainty of $21 \%$ was calculated in core flow which had dropped from 40 to about $5 \mathrm{lb} / \mathrm{sec}$. During flashing, the flow has increased and the calculated uncertainty drops to $6.6 \%$. Up through 10 seconds, uncertainties in the jet pump flow rates are moderate, with the exception of the intact loop jet pump during flashing. Flow stalls in this jet pump and remains near zero during flashing. The calculated uncertainties are thus a high percentage of the absolute flow rate.

Beyond 15 seconds, none of the flow rates can be measured within any reasonable uncertainty band, when the $\triangle W P$ measurements fall below the transducer sensitivity limits. ANC considers this area to be the most significant TLTA measurement problem. Lack of the postflashing flow information has restricted diagnosis of code problem areas.

Bias errors in the flow rates were not generally found to be serious. Most persist only for short periods of time during conditions of rapid flow rate change. A typical bias error, calculated for core inlet flow during the flashing period, is put into perspective in Figure 4. The error is shown as a difference between measured flow and a corrected flow where the bias was analytically removed. As shown, the maximum error is only $15 \%$ and appears only for a brief period. ANC does not consider errors of this type a serious detriment to the code verification activity.

\section{OBSERVATION OF TESTS}

An ANC representative witnessed Matrix Test 6 , which was designated by NRC as Standard Problem $4^{[a]}$.

In addition to witnessing the actual Test 6 ,experiment, the pretest and nosttest operations were also viewed. In general, it was observed that the entire procedure was conducted quite professionally, with no obvious problems which would affect the quality of the data. GE has developed a systematic procedure for setting up and conducting the tests. The Hewlett-Packard computer in the control room is used extensively prior to the test to monitor and verify the measurements and initial flow conditions. This computer is also used to record the test data for immediate playback in engineering units. Specific procedures are summarized in the following paragraphs.

[a] The Standard Problems are a continuing series of code predictions made by the reactor vendors for various experinitents to provide a basis for code evaluation and comparison. 


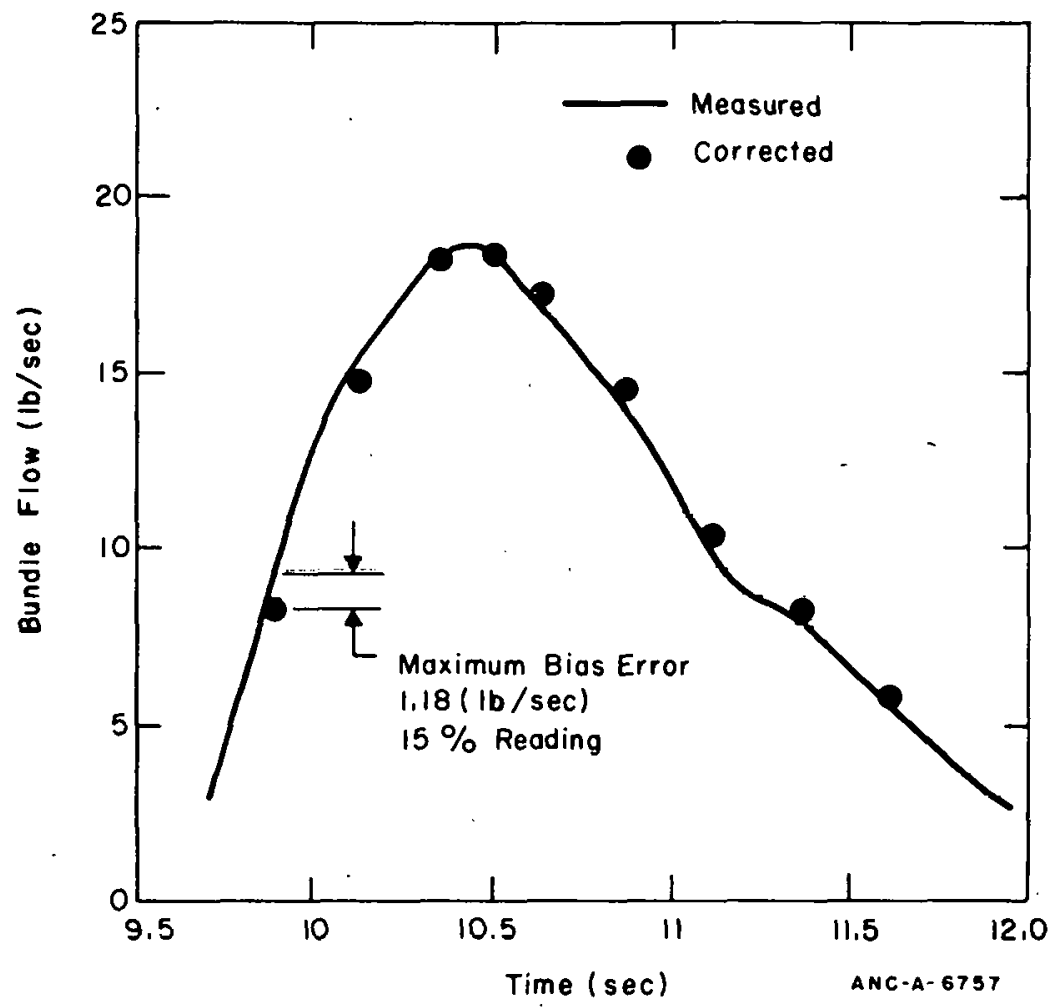

Fig. 4 TLTA bundle flow bias error.

\section{(1) Measurements}

(a) With the transducers on balance (valved off from the TLTA), the zero readings are recorded before and after the test. These zero readings are used to corrcct the transient experimental measurements, assuming a linear variation between pre- and posttest zero readings.

(b) Measurements are checked several times during the hours leading up to the experiment, while the TLTA is hot and pressurizer The procedure includes a comparison of actual and expected nodal $\Delta \mathrm{Ps}$ and comparison of supposedly equal $\Delta \mathrm{P}$ sums taken over several paths. In the Test 6 procedure, this careful double-checking revealed a faulty $\Delta \mathrm{P}$ channel amplificr which was subsequently replaced to eliminate a potential problem.

\section{(2) Operations}

(a) Automatic control systems are used to maintain proper system pressure and subcooling and to coordinate the 
timing of all test initiation events. These systems were all checked several times prior to the tests.

(b) Initial system flows are established by adjusting flow in both jet pumps until bundle flow reaches the desired value. This adjustment is accomplished with manual control values in each of the jet pump drive lines.

(c) Downcomer mixture level starts to fall in the 60 seconds or so prior to initiation of the test when full power is applied to the bundle and steam generation rate increases. To achieve the proper initial mixture level, the test is started when the falling level reaches the desired value. This action is taken by the operator, based on his observation of a control room $\Delta \mathrm{P}$ gauge indicating downcomer elevation head.

\section{(3) Blowdown Experiment}

A typical experiment lasts 45 to 60 seconds. The progress of the blowdown can be followed by observing numerous control room displays which include mixture level, system pressure, flow rates, and bundle power. In addition, alarm bells are used to signal critical mixture level points and bundle temperature thresholds.

(4) Posttest

Within five minutes after the test, data retrieval operations begin with the printing of transient data on the control room printer. These data appear in engineering units. Quick-look examinations may be made of bundle flow, bundle temperature levels, and timing of various blowdown events as desired. A preliminary evaluation of the test results is also possible from this information.

\section{CONCLUSIONS AND RECOMMENDATIONS}

This evaluation has led to the following conclusions:

(1) The accuracy of the various transducers used has been well defined and verified.

(2) The conduct of the experiments was very thorough with numerous checks for measurement anomalies. No obvious problem areas are evident in these procedures. 
(3) Most of the measured parameters are considered to be of acceptable accuracy.

(4) Bias error problems were found in several measurements of flow, dénsity and void fraction, and quality during or near the flashing period. Inasmuch as these errors are short lived and not extremely high, they are not considered a major problem in using TLTA data for code verification:

(5) Uncertainties were found to be relatively high in measured density and related parameters in steam-filled regions. These unccrtaintics posc no major problem in model verification, because propcrtics of saturated steam are known from backup measurements of local system pressure.

(6) System flow rates beyond the lower plenum flashing period are below the threshold of measurement system sensitivity. This is considered a significant problem area in utilizing TLTA performance data to assess, diagnose, and verify LOCA computer codes.

Based on this final conclusion, it is recommended that GE continue to seek improved me thods of measuring these low flow rates. 


\section{ANALYTICAL SUPPORT}

Several analytical tasks have been completed to further the understanding of TLTA performance. These studies have focused on the relationship of TLTA performance to that of a BWR as affected by various scaling compromises and techniques. Consideration has been given to wall heat transfer effects, elevation effects, and effects of fluid inertia. An additional study has examined potential TLTA performance differences due to an alternate lower plenum geometry planned for use later in the test program.

These studies were all conducted with the RELAP4 ${ }^{[4]}$ transient thermal-hydraulic computer code. A typical TLTA analytical model used in conjunction with RELAP4 is shown in Figure 5. Numerous, similar versions were developed during the course of these studies and in the code evaluation studies discussed in Section VI. A thorough description of the TLTA model is given in Section VI.

\section{WALL HEAT TRANSFER EFFECTS}

In thermal-hydraulic analyses of BWR systems during a postulated LOCA, wall heat effects are generally ignored. This assumption is believed to be valid, as the full-scale plant has a relatively low heat transfer surface area-to-fluid mass ratio. (In typical plants, this ratio is about $0.008 \mathrm{ft}^{2} / 1 \mathrm{bm}$.) As a consequence, heat transfer to the fluid from the vessel structure is expected to be negligible. In the TLTA, which is a 1/560 scaled version of a BWR, this assumption may no longer be valid, as the TLTA surface-to-mass ratio is about $0.09 \mathrm{ft}^{2} / 1 \mathrm{bm}$, an order of magnitude larger.

The purpose of this study was to evaluate the significance of TLTA wall heat effects to aid in interpreting TLTA performance and to provide guidance in modeling the TLTA system. The study was-conducted with a version of the TLTA model which consisted of 14 volumes and 22 flow junctions connecting the volumes. Sensible wall heat effects were represented in the model by ten one-dimensional wall conduction models, interfacing with one or more of the TLTA regions through appropriate heat transfer correlations. These correlations are selected by RELAP4 to correspond to the instantaneous wall and fluid conditions prevailing in each region.

The model was set up to represent a typical TLTA blowdown experiment. Initial power, flow, pressure, and enthalpy distribution for Matrix Test 3, the reference case, were selected to initiate the problem. The blowdown analysis was based on expected TLTA valve phasing, which simulates a double-ended recirculation loop pipe break. The analysis was conducted with RELAP4/Mod 1, version 64.

Figure 6 presents the calculated wall heat flux to the fluid in the lower plenum. Also included is the calculated wall to fluid temperature difference $\left(\Delta T_{w}\right)$. The response shows a relatively low heat transfer rate early in the transient when a low $\Delta T_{W}$ exists. A threshold 


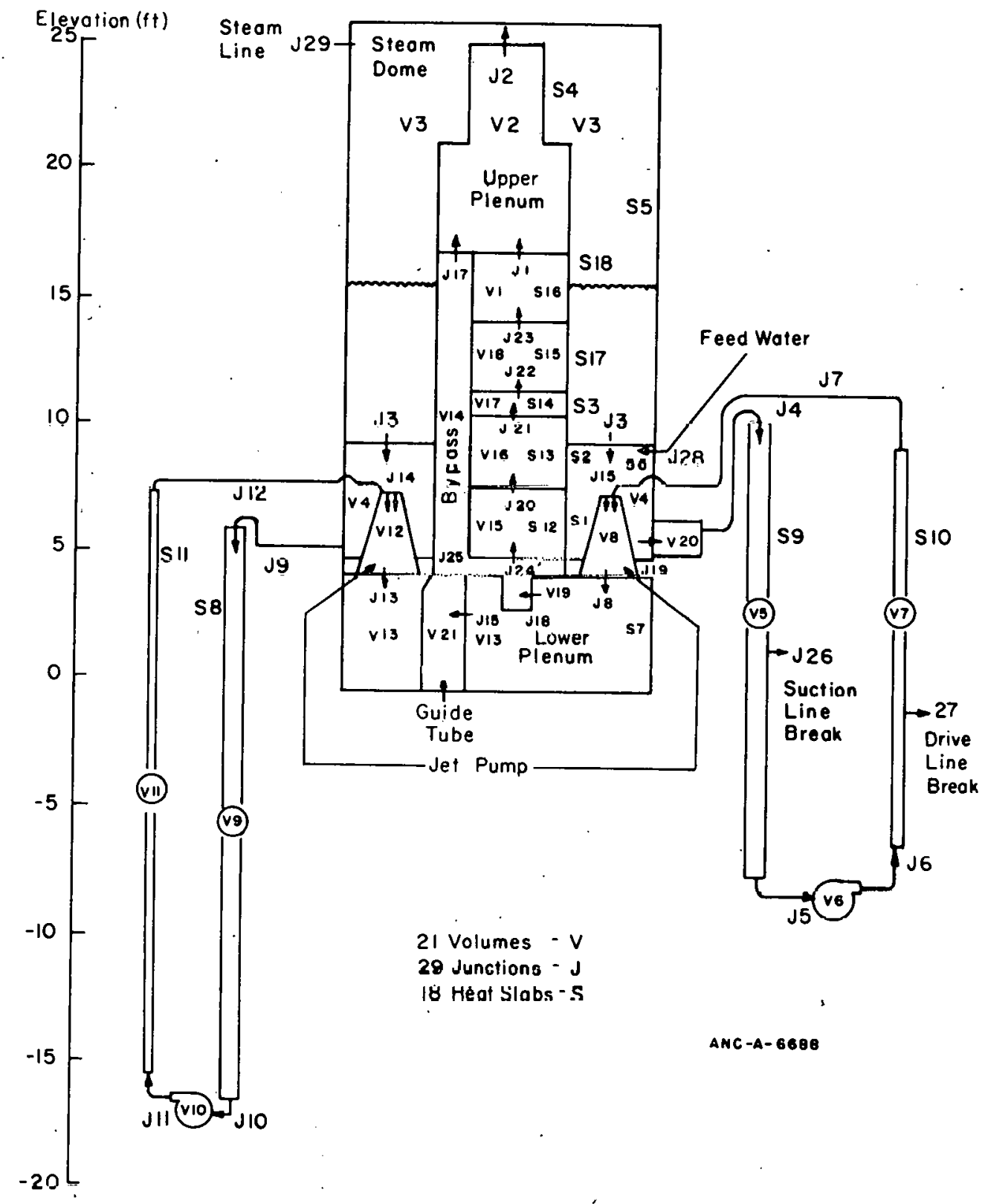

Fig. 5 GE-BDHT-TLTA base case analy tical model.

point is observed at about seven seconds when the suction line uncovers and the vessel begins to rapidly depressurize. As the pressure falls, the local fluid temperatures follow the saturation line, resulting in a rapid buildup of $\Delta T_{w}$, hence increasing rates of heat transfer.

A forced convection heat transfer mode is predicted in the initial few seconds, when $\Delta \mathrm{T}_{\mathrm{W}}$ is low, with relatively low heat transfer rates. At about five seconds, the heat transfer mode is predicted to switch into a nucleate boiling regime, where it remains for the duration of the 30 seconds analyzed. Heat transfer rates increase throughout this period as $\Delta \mathrm{T}_{\mathrm{w}}$ increases, reaching a peak of $85,000 \mathrm{Btu} / \mathrm{ft}^{2}$-hr at 30 seconds. 


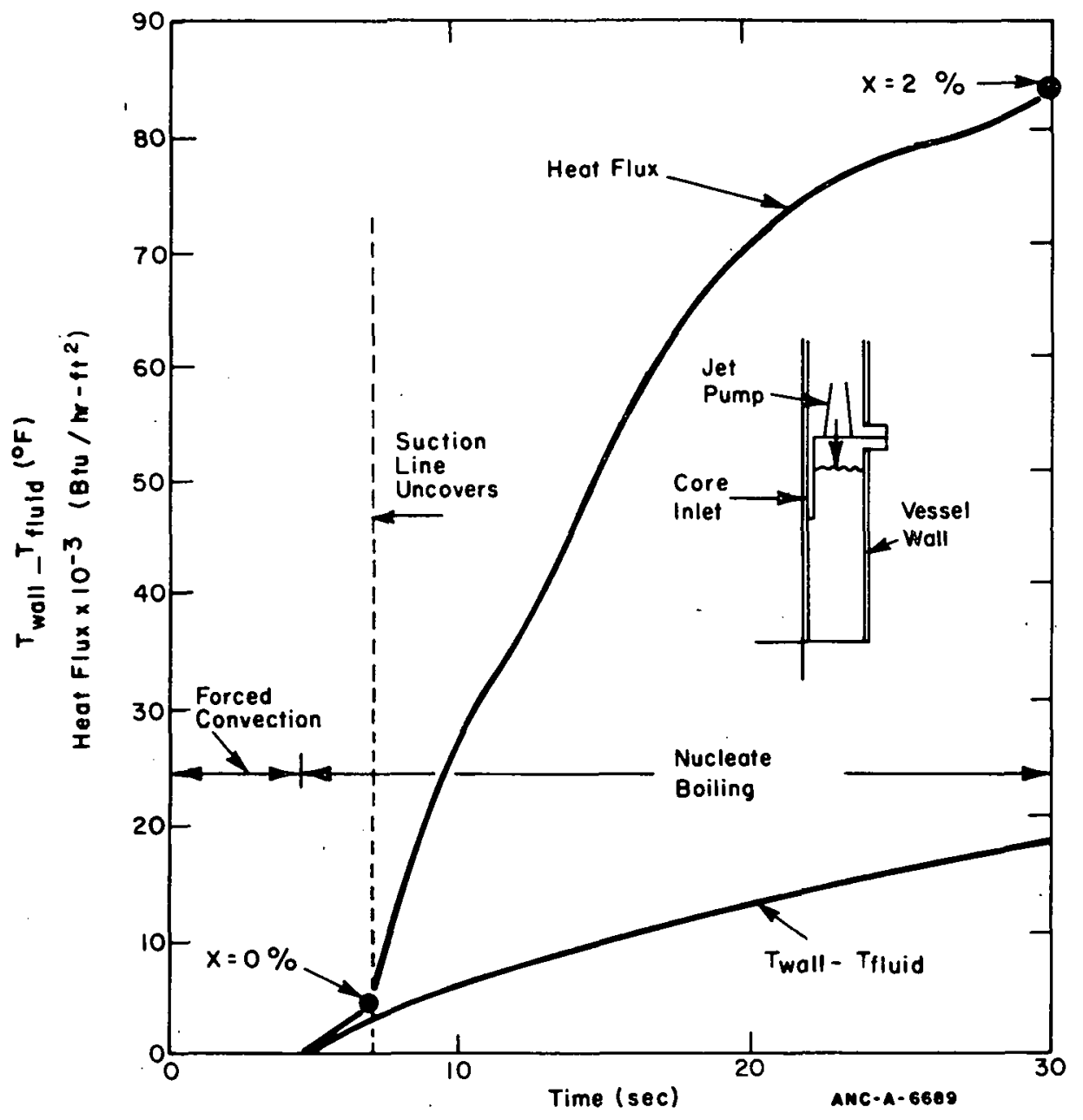

Fig. 6 Heat transfer-lower plenum vessel wall.

The relative effect of the lower plenum wall heat transfer can be determined from the quantity of liquid boiled off by the wall heat compared to the total vapor generated in the lower plenum. The integral of energy transferred from the lower plenum walls in the 30-second interval, with the Figure 6 fluxes, was 7,300 Btu. This energy transfer is sufficient to boil off about 10 pounds of lower plenum water. This quantity is about one-third of the total of 30 pounds of vapor generated in the lower plenum during this interval.

The relative effect of wall heat on TLTA performance was established through two comparative runs, one with and one without the wall heat option. The calculated steam dome pressure decay and core flow rate for these two cases are shown in Figure 7.

Figure 7 shows that the predicted wall heat effects on system performance are significant. Wall heat transferred to the fluid contributes to the vapor generation rate, which holds vessel pressure up relative to the case with no wall heat. This effect is seen to become significant at about seven seconds when the wall heat transfer rates begin to rise. This difference in pressure increases with time and reaches about 130 psi at 30 seconds, 


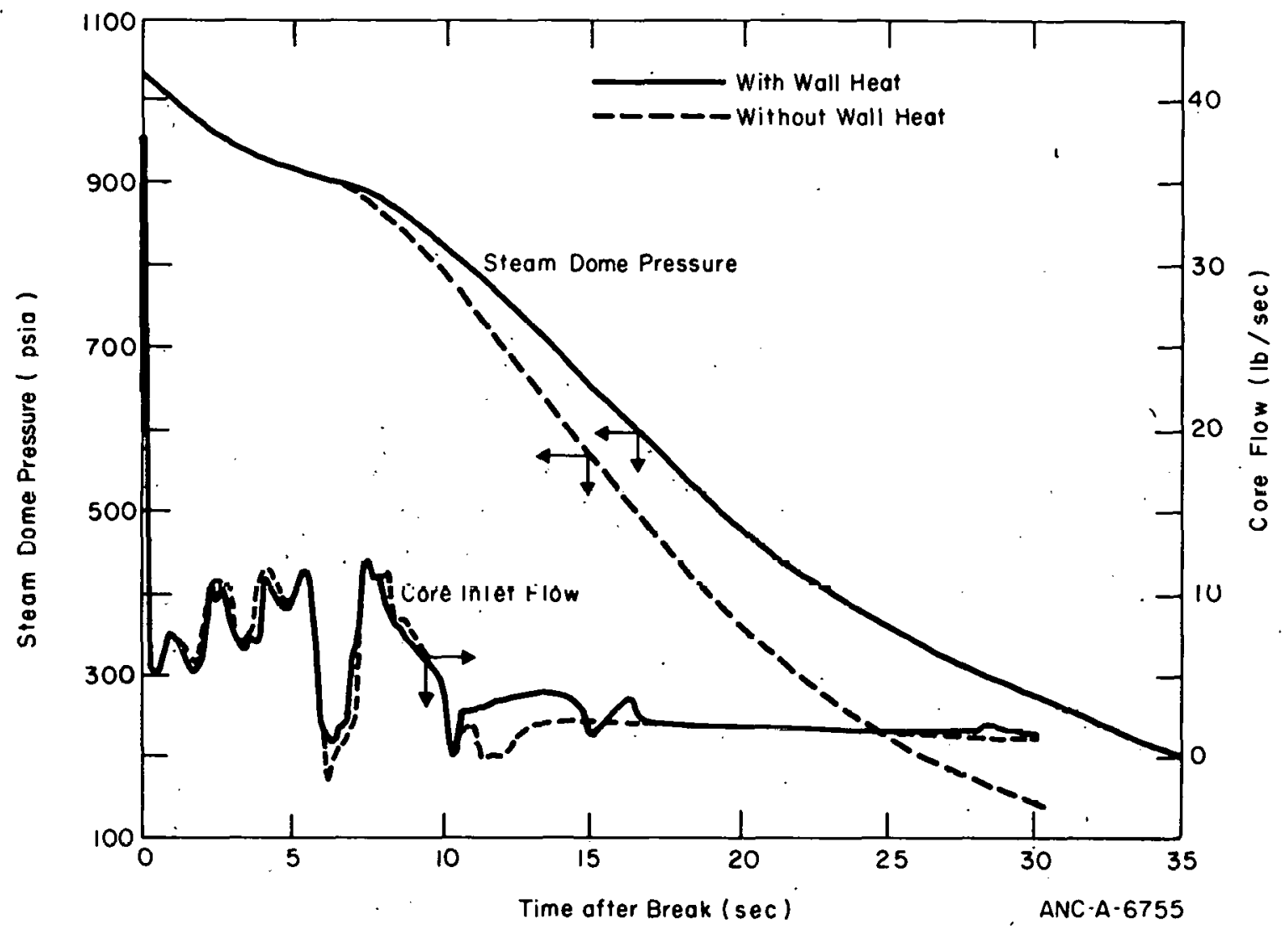

Fig. 7 Wall heat effect on TLTA.

lengthening the blowdown time by six to eight seconds. Core flow is also influenced by the wall heat. The most obvious difference occurs in the 10- to 15 -sècond time period, where the local wall heat transfer effects are increasing rapidly. The heat addition to the lower plenum fluid results in local boiloff which forces more fluid through the core.

\section{TLTA ELEVATION EFFECTS}

In scaling the TLTA from the reference BWR, certain distortions in elevations were apparently unavoidable. Of particular interest are those elevation differences between the TLTA and the BWR which may affect core flow simulation in the TLTA. Specifically, these include the relative height of the jet pump suction and downcomer mixture level with respect to the core. Both elevations are significantly higher in the BWR.

To isolate and evaluate the potential effect of these differences, two comparative RELAP4 /Mod 3, version 66 computer runs have been used. One run representing a base case was made for TLTA Test 3 , the reference test. The model used to make this run was then modified and rerun representing BWR rather than TLTA elevations, volume heights, and mixture levels for regions above the beginning of the bundle heated length. These regions include the jet pumps, downcomer, steam dome, upper plenum, and upper portions of the recirculation loops. Friction losses, inertias, heat transfer geometries, and initital fluid masses were kept the same as in the base case. 
The results of the TLTA analytical model with BWR elevations are compared to those from the TLTA base case model results in Figures 8 and 9. The effect of the higher BWR elevations was to increase core flow as shown in Figure 8. The higher BWR elevations increase the head in the broken loop jet pump which decreases the flow from the lower plenum through the broken loop jet pump. The decrease in flow from the lower plenum through the broken loop jet pump results in the corresponding increase in core flow.

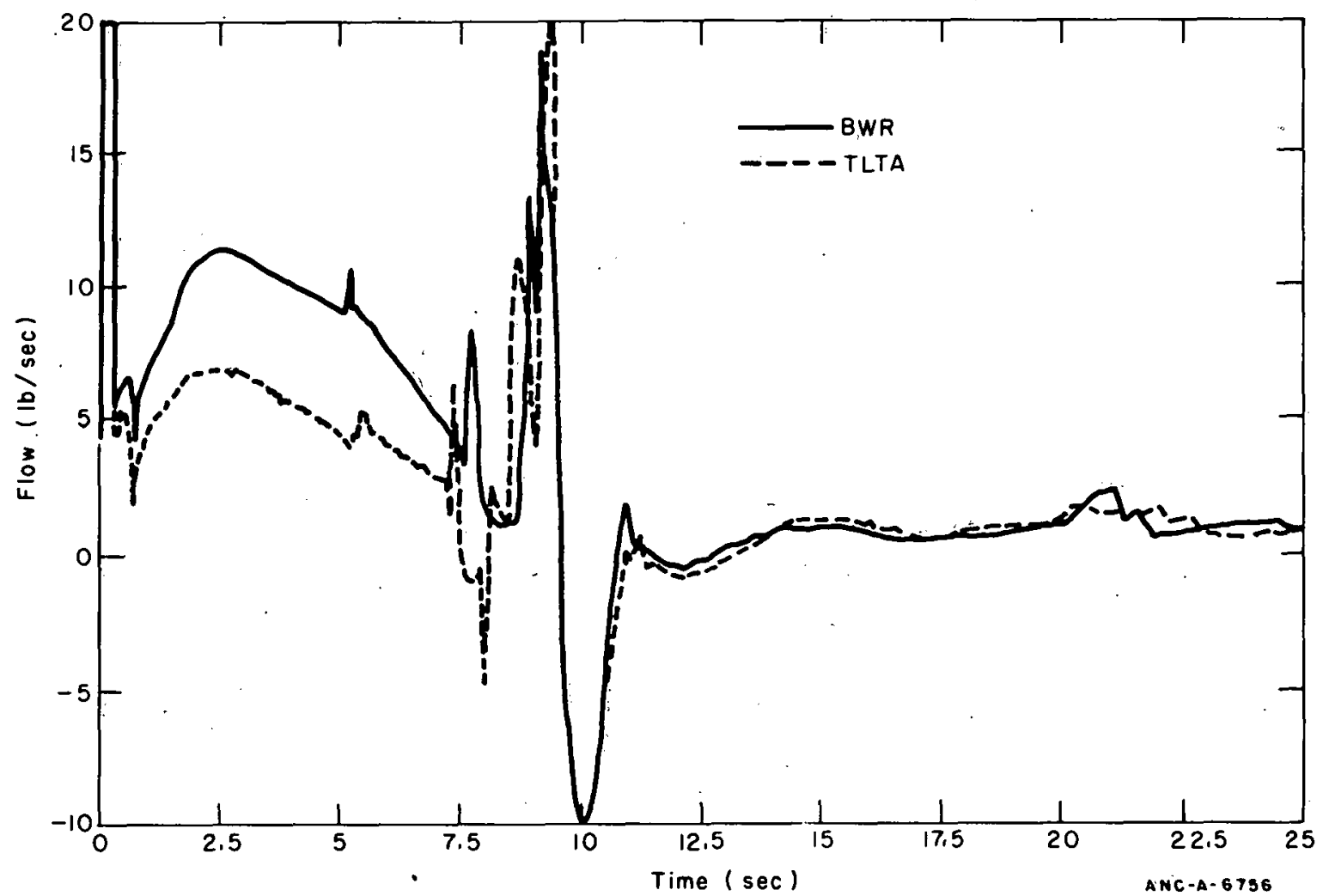

Fig. 8 TLTA-BWR elevation comparison - core flow.

Soon after the jet pump suction is uncovered, the core flows from both analytical models converge to nearly equal values. The flows remain nearly the same during the rest of the transient because the liquid level in the downcomer and jet pumps is depleted which negates any elevation differences between the two systems.

Surface temperatures of an average power rod at the axial center of the core are compared in Figure 9. The high core flow with the BWR elevation provides better cooling and keeps the temperature about $40^{\circ} \mathrm{F}$ lower than the base case during the initial 8 to 9 seconds. Although the rod surface temperatures converge at about 9 seconds, the stored energy and the average temperature of the rod in the base case is higher at this time. Dryout occurs slightly earlier for the base case which, along with the higher stored energy, results in the slightly higher surface temperature. 


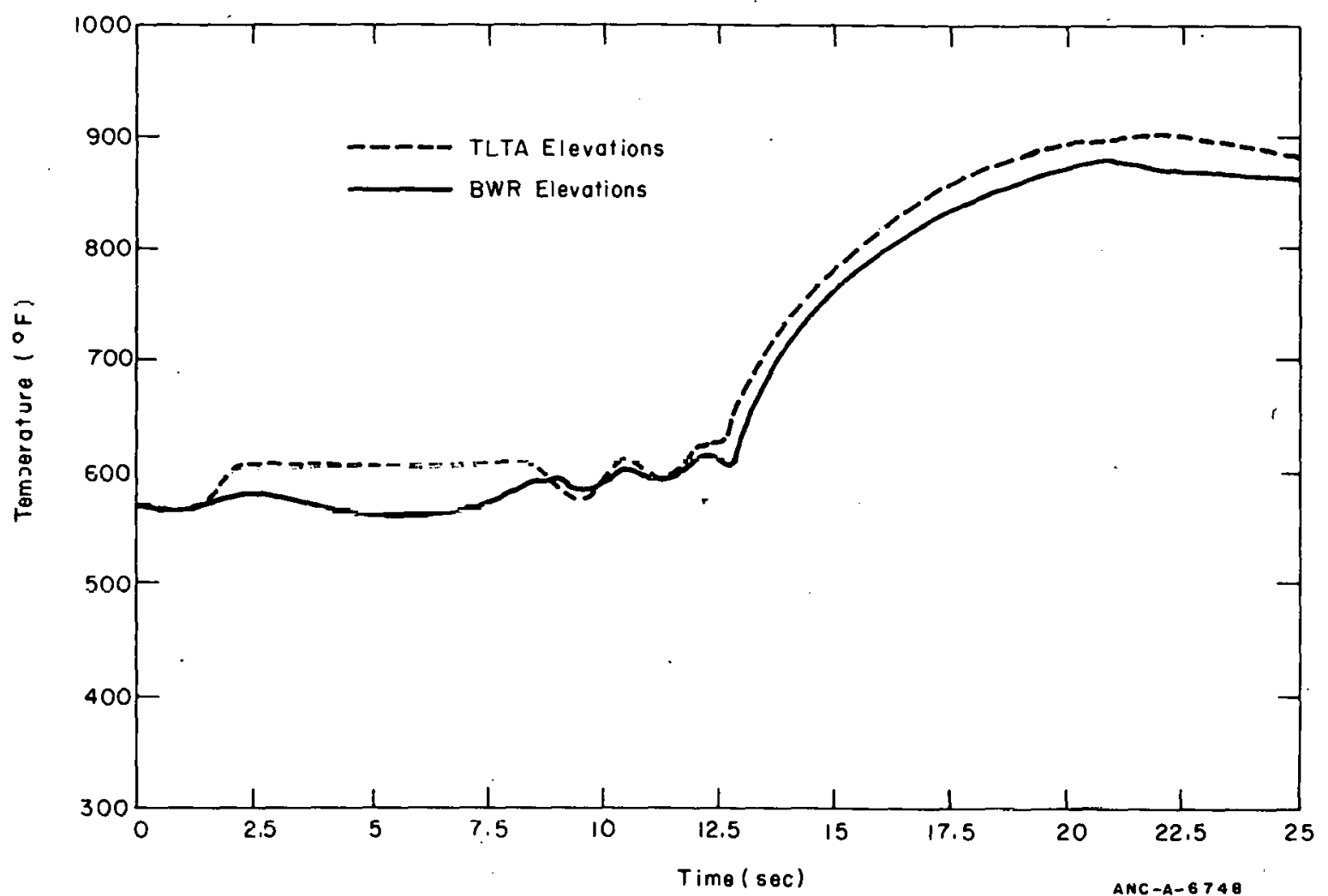

Fig. 9 TLTA-BWR elevation comparison - rod temperature.

\section{TLTA FLUID INERTIA EFFECTS}

Another potential distortion in TI.TA simulation results from scaling compromises in the design of the TLTA recirculation loop. These compromises in TLTA piping and jet pump lengths and relative flow areas were necessary to avoid unacceptably high friction losses. These geometrical distortions result in lower initial TLTA fluid velocities and stored momentum. As an example, the initial fluid velocity in the TI.TA intact loop suction line is about $4.6 \mathrm{ft} / \mathrm{sec}$, whereas in a BWR it is about $27.4 \mathrm{ft} / \mathrm{sec}$. The lower stored momentum would be expected to allow transient flow events in the TLTA to occur much faster than in the BWR.

The evaluation of the fluid inertia effects has been made through a comparison of RELAP4 core flow predictions for the TLTA and a BWR. The TLTA calculation used was that described as the base case in Section 2. Results from previous BWR analyses, described in Reference 13, were used for BWR core flow.

This comparison is shown in Figure 10 for the first 6 seconds of blowdown. The differences in flow rate are due to the combined effects of inertia and elevation differences. During the first second, the comparison shows the TLTA core flow rate decreasing much more rapidly than that for the BWR due to the lower TLTA inertias. The TLTA broken 


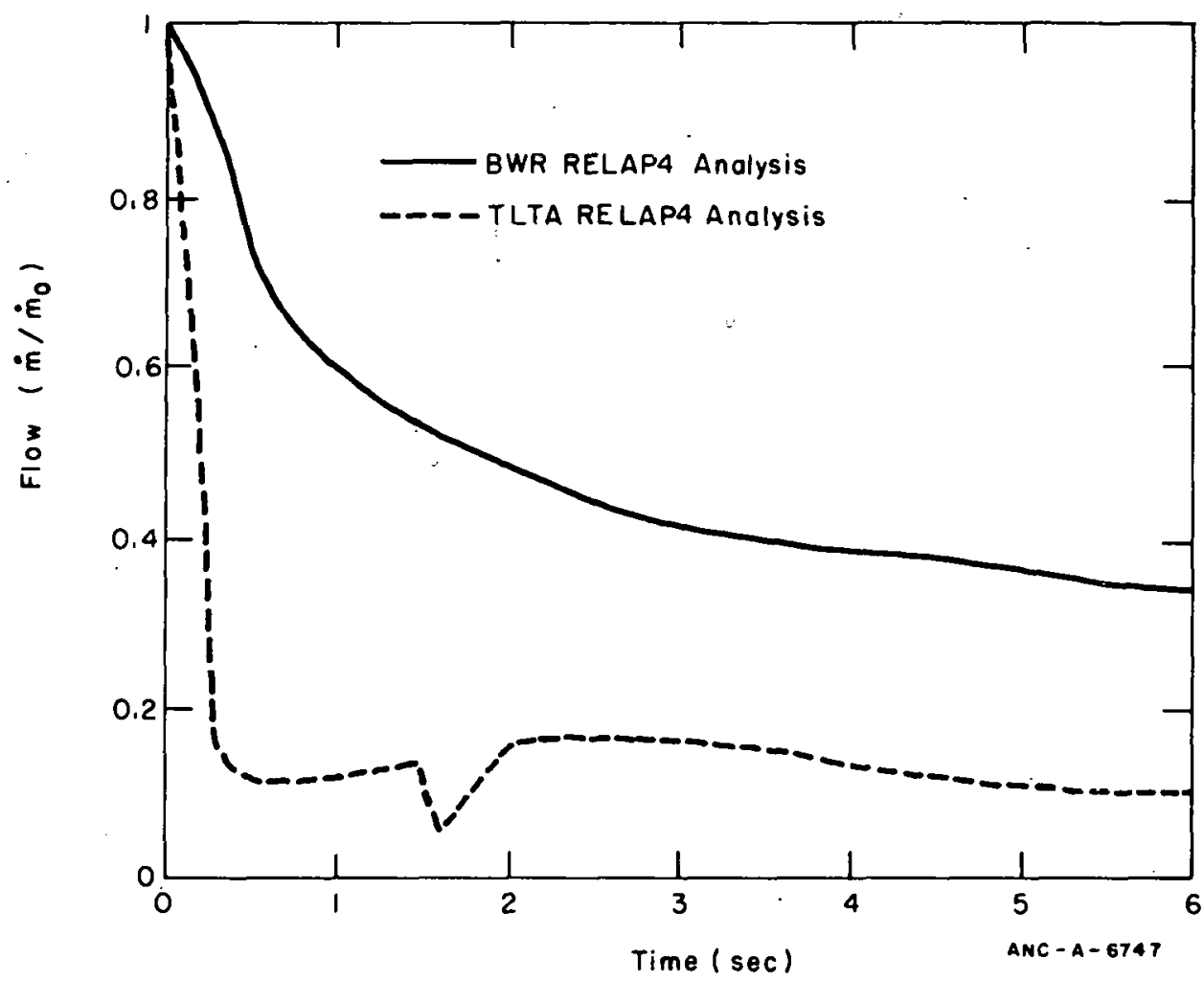

Fig. 10 TLTA-BWR loop momentum comparison - core flow.

loop jet pump reverses flow direction more rapidly than it does for the BWR, which is the primary cause of the sharper decrease in core flow rate. Once the inertia effects are dissipated, the higher elevations of the BWR maintain a higher core flow, consistent with the results discussed in Section 2.

\section{ALTERNATE LOWER PLENUM GEOMETRY}

TLTA Test 18 , to be conducted with the second bundle, will utilize an alternate lower plenum and guide tube configuration. The primary objective of this test will be to assess experimentally the sensitivity of TLTA performance to a variation in lower plenum and guide tube geometry.

The alternate lower plenum and guide tube configurations are shown in Figure 11, alung with the reference design. The alternate configuration has a higher length-to-diameter (L/D) ratio as compared to the reference configuration. In addition to a different $L / D$, the alternate lower plenum volume is substantially higher. It was originally intended that the lower plenum and guide tube volumes be identical for both designs. An apparent design change resulted in the larger alternate configuration volume. 


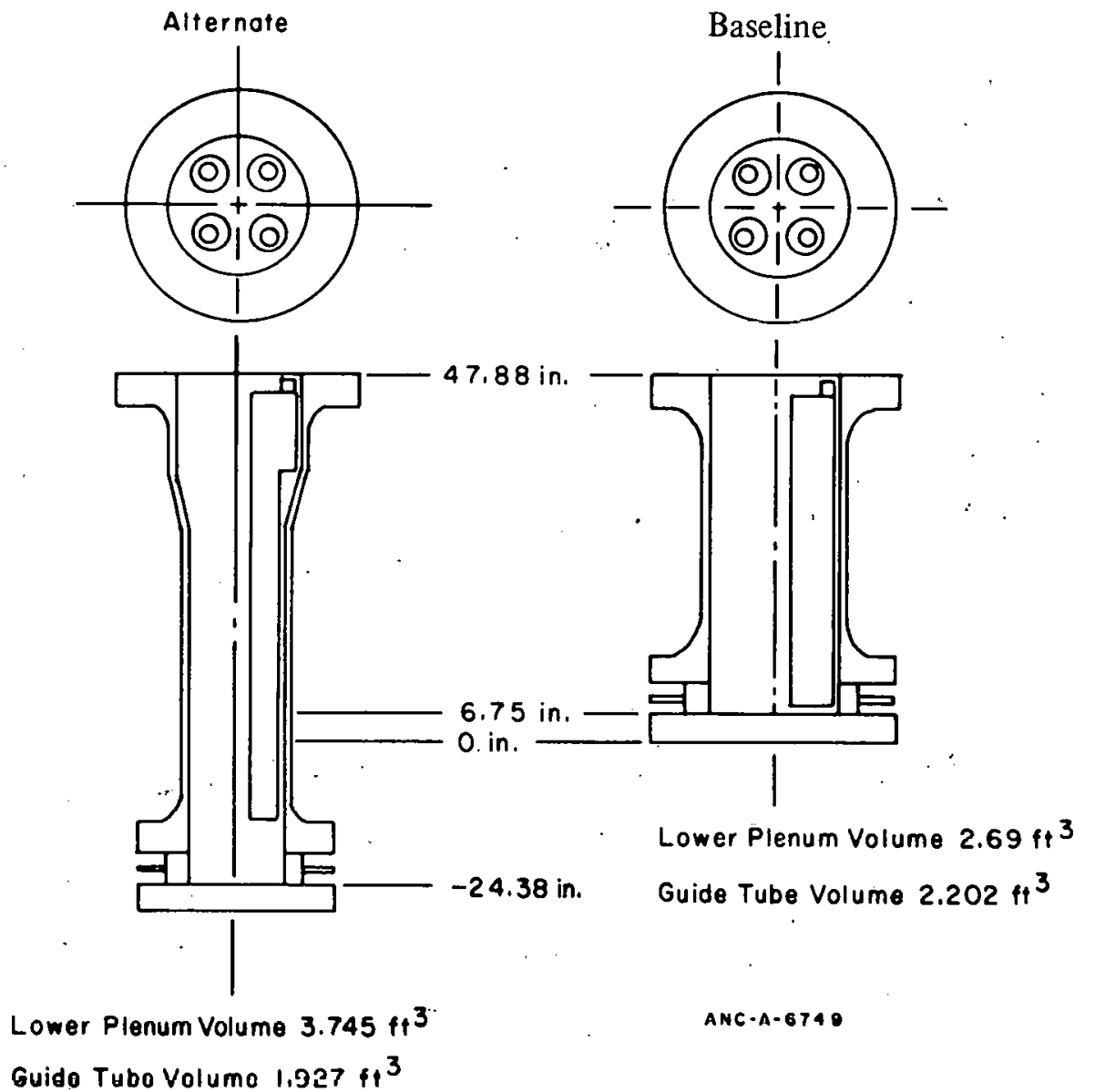

Fig. 11 Lower plenum and guide tube configurations.

The RELAP4 analysis described herein was conducted to determine the effect of the alternate lower plenum geometry on TLTA system performance. Three RELAP4/Mod 3, version 66 blowdown calculations were compared for the following conditions:

(1) Baseline case with nominal lower plenum and guide tube geometry

(2) Alternate lower plenum and guide tube geometry with $\mathrm{L} / \mathrm{D}$ and volume as shown in Figure 11

(3) Alternate geor: etry with L/D changed, but with. volumes maintained identical to the baseline case.

The baseline case was generated for the Test 3 posttest calculation as described in Section 2. The two change cases were analyzed with an identical model except for minor changes to account for the alternate lower plenum and guide tube flow area, length, and volume. 
The primary feature of RELAP4 affected by changes to the lower plenum and guide tube geometry is the bubble rise model. This model calculates a vertical distribution of bubble mass and enthalpy and an overall bubble mass balance in vertically oriented volumes.

' The following paragraphs contain a discussion of the results obtained in the analysis.

Figure 12 compares the predicted average lower plenum quality for the three cases. The lowest quality occurs in the baseline case, with higher values in the change cases. This behavior is attributedl to the smaller lower plenum cross-sectional area of the two change cases. Using the same bubble rise velocity ( $3 \mathrm{fps}$ ), a lower bubble mass escape rate is calculated in the change cases, leaving behind a higher percentage of voids in the lower plenum mixture. Where only the $L / D$ is changed, the effect on average quality is more pronounced due to the reduced lower plenum liquid mass in this case.

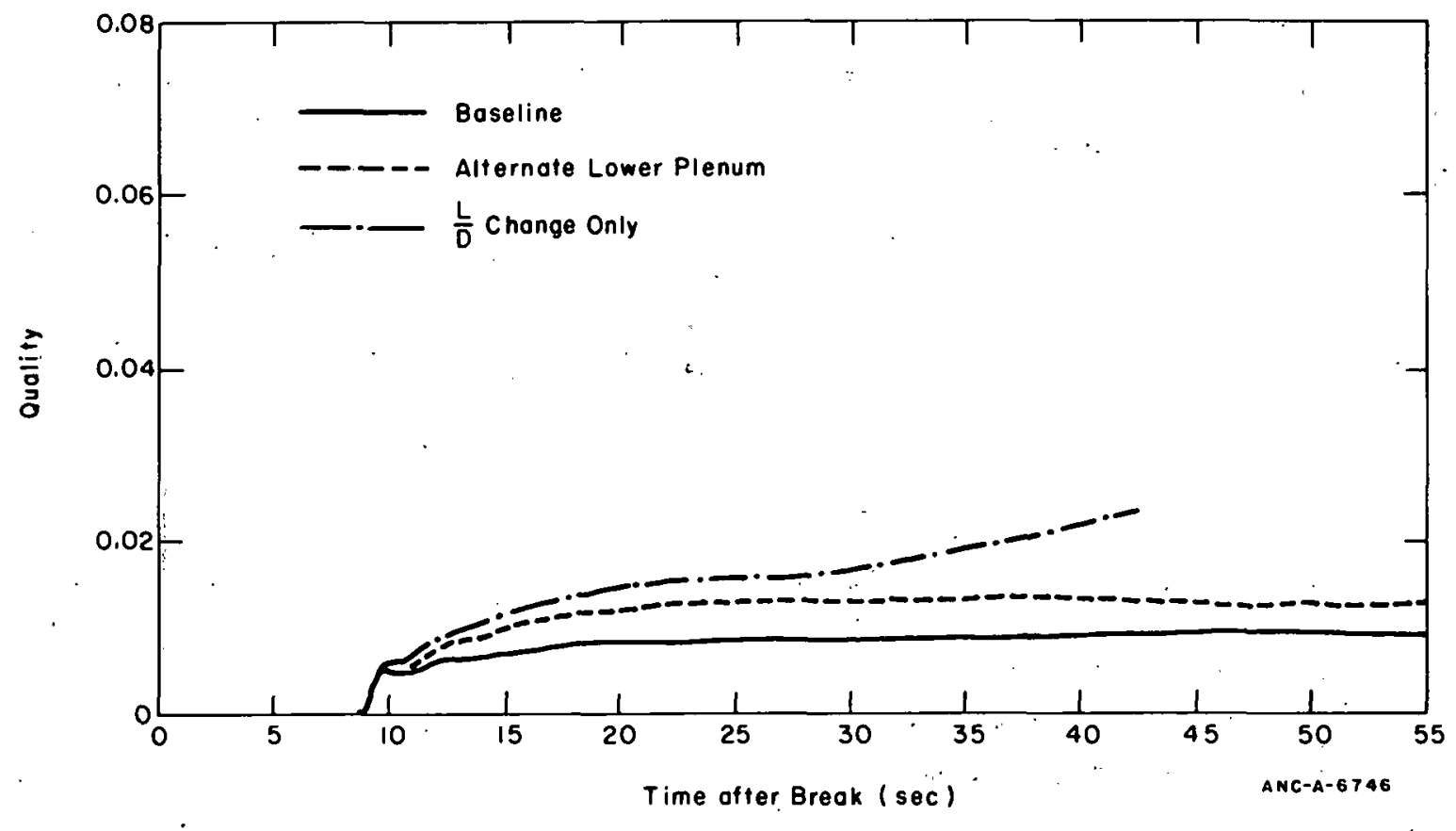

Fig. 12 Lower plenum study - average lower plenum quality.

Figure 13 compares core inlet flow predictions for the three cases. The differences in quality discussed above affect core flow only to a minor degree. :

Figure 14 compares the magnitude of flows in the broken loop jet pump. The two change cases both predict a lower quality fluid entering the jet pump due to the reduced bubble escape rate from the lower plenum. The lower quality entering the jet pump results in a higher mass flow in the change cases as shown in the figure. This is expected because the flow is choked in the broken loop jet pump at the drive nozzle and critical flow rate is strongly dependent on quality.

Figure 15 presents the predicted lower plenum pressure history for the three cases. The combined effects of slightly different predictions of wall heat transfer, break flow, and 


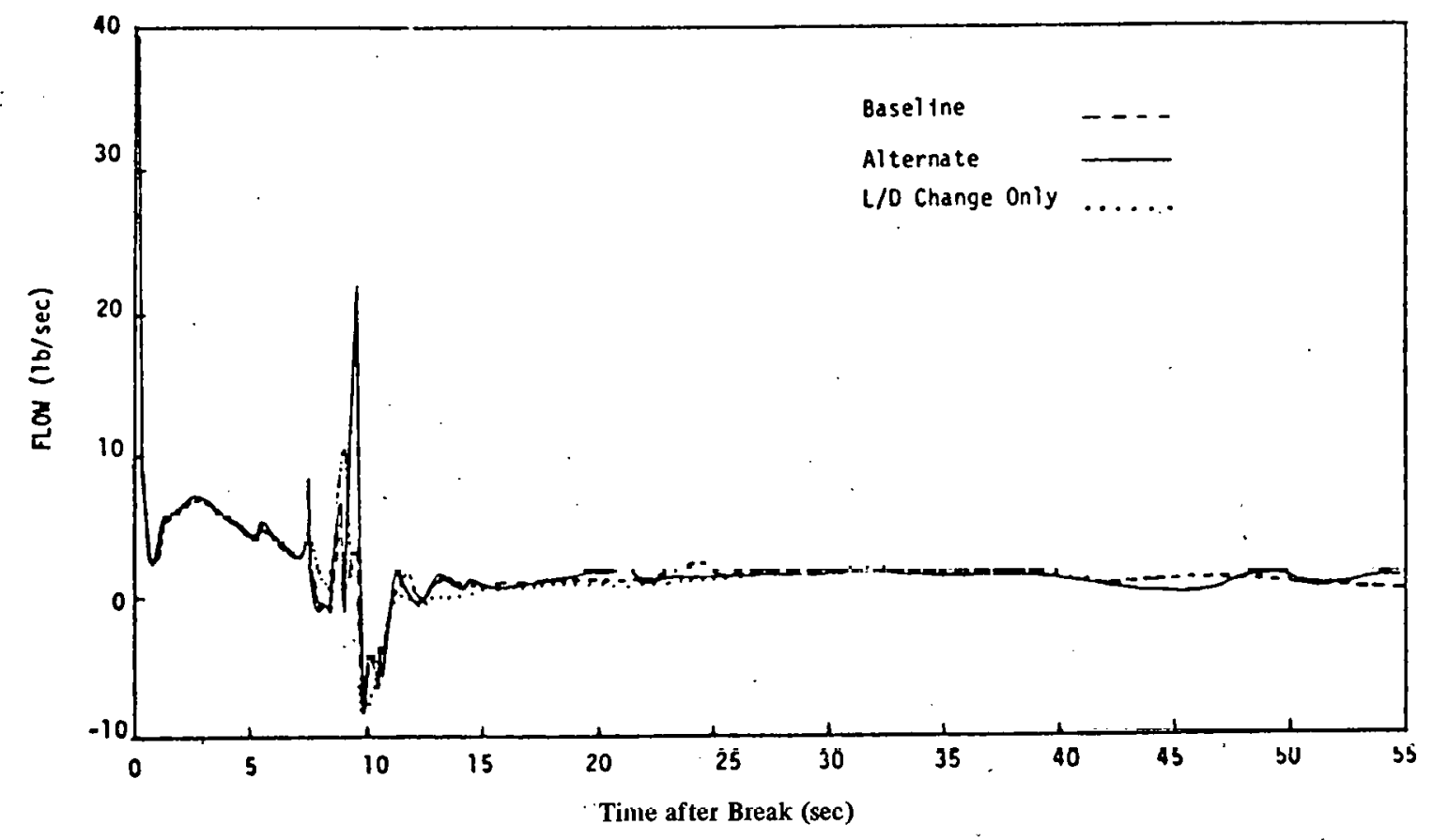

Fig. 13 Lower. plenum study - core inlet flow.

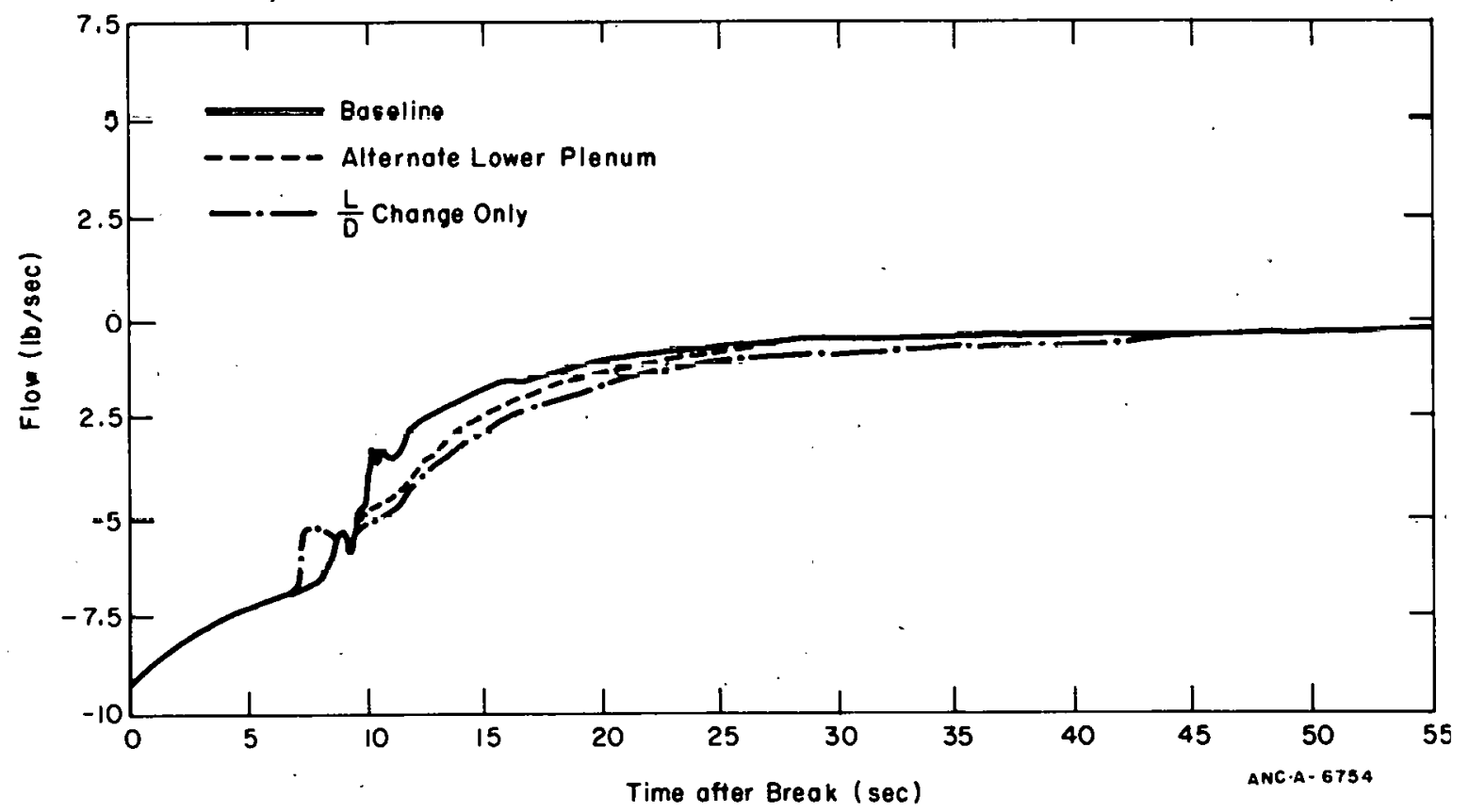

Fig. 14 Lower plenum study - broken loop jet pump flow. 


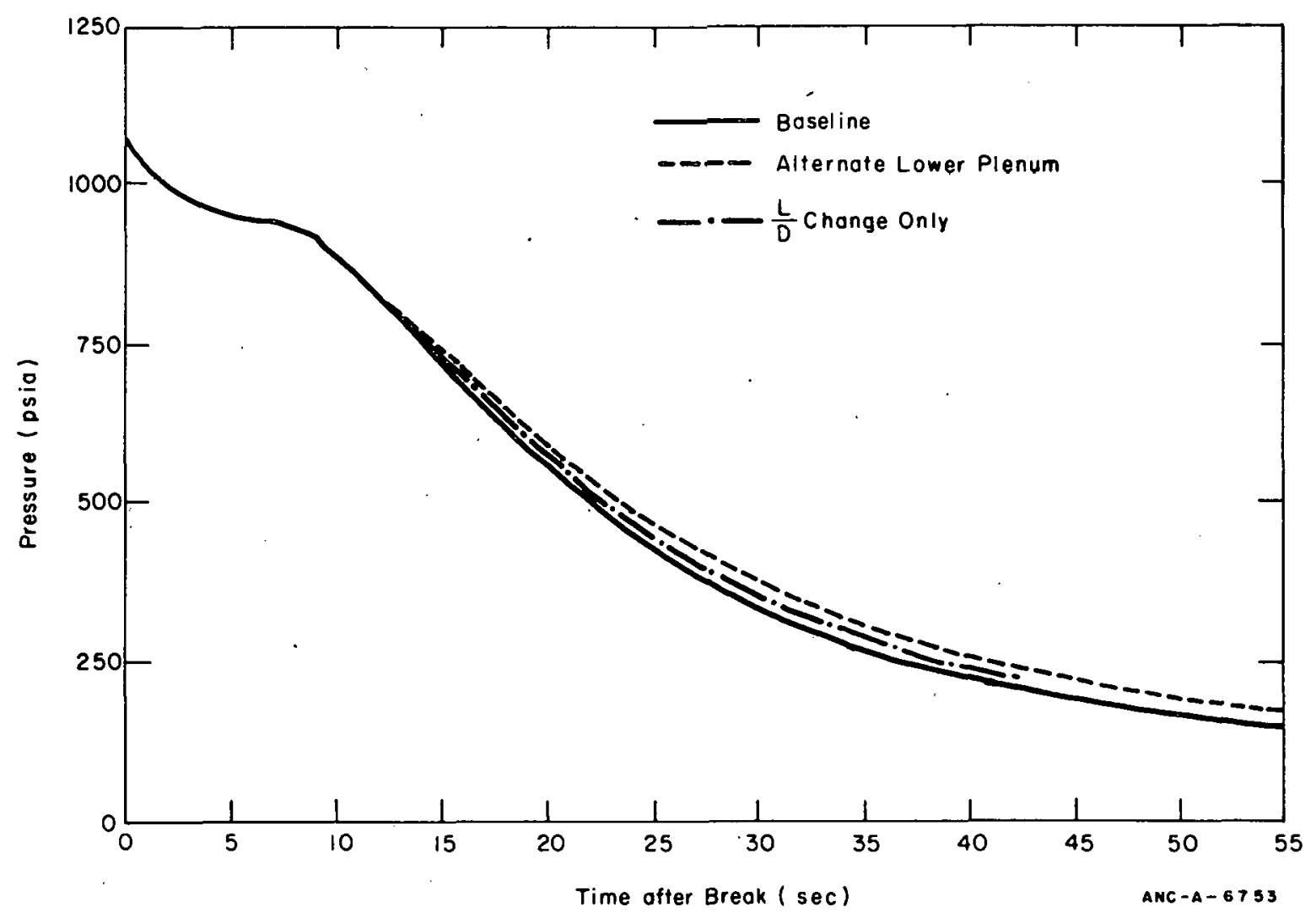

Fig. 15 Lower plenum study - lower plenum pressure.

swer plenum bubble escape rate result in only relatively minor differences in predicted ystem depressurization time.

These results show several minor performance differences between the two alternate ower plenum designs and the baseline case. With respect to the baseline, both alternate design cases show somewhat higher average lower plenum qualities, but only minimal changes in resultant flow rates out of the lower plenum. Slight differences in the system depressurization rate are also observed in the change case predictions.

In comparing the predictions for the two alternate configurations, it appears that the case with just the L/D changed results in the greatest departure in predicted performance from the base case. 


\section{CONCLUSIONS AND RECOMMENDATIONS}

The studies described in Section 1 through 4 have led to the following conclusions regarding TLTA performance:

(1) Wall heat transfer effects in the TLTA will be significant. The resultant effect on TLTA performance must be accounted for analy tically.

(2) The elevation and component height differences between the TLTA and a BWR significantly affect TLTA core flow simulations during the initial part of the transient. The lower TLTA core flow would tend to cause higher peak heater rod surface temperatures in the TLTA, compared to those in a BWR.

(3) Fluid inertias are lower in the TLTA and result in a faster intial core flow rate decay relative to a BWR. This faster decay would tend to cause higher peak heater rod surface temperature in the TLTA.

(4) The influence of the alternate lower plenum geometry on TLTA system behavior is expected to be small. To maximize the behavior difference, an alternate design is recommended in which $L / D$ is the only parameter changed. 


\section{REVIEW OF TLTA DATA}

The experimental program developed for the TLTA by GE revolves about a reference test. Conditions of the reference test were selected to represent an average power bundle experiencing a double-ended offset shear BWR recirculation line break. In the remaining tests in the TLTA series, a single parameter was usually varied from the reference test to isolate the influence of each parameter on TLTA performance. This section presents the results of a review of the data from all tests conducted on the first TLTA bundle. Emphasis was placed on determination of: (a) influence of each parameter on TLTA system behavior, (b) significance of the influence with respect to future model development and verification plans, and (c) potential improvements or additions to the GE test program to provide more useful results relative to code verification.

\section{BUNDLE 1 TEST CONDITIONS}

The conditions of the tests from the first TLTA bundle are summarized in Table VII. The major parameters which have been varied include:

Bundle power (Tests 1, 3, 4, and 10)

Break area (Tests 2, 3, and 6)

Power decay (Tests 4 and 7).

Tests 8 and 9 were dropped from the test matrix, as their objective (determination of power decay rate sensitivity) had been judged fulfilled by Test 7 . An additional consideration by GE in developing the test plan was test-to-test repeatability. This question was addressed through a second run of the reference test, shown in the table as Matrix Test 5.

The data for the first bundle tests were obtained from GE in References 12 and 14 through 20 .

\section{EFFECT OF BUNDLE POWER}

The effect of bundle power on system and bundle performance was assessed by comparing the results of Tests $1,3,4$, and 10 which had bundle powers of $3.0,4.55,6.1$, and 6.5 MW, respectively. An additional experiment, Test 4903, Run:16 (designated Test 3R) was also considered. This test, which was not included in the test matrix, was a rerun of Matrix Test 3 with a revised steam line valve closing time. All other test parameters were 
TABLE VII

BUNDLE 1 TEST CONDITIONS

\begin{tabular}{|c|c|c|c|c|c|}
\hline $\begin{array}{l}\text { Matrix Test } \\
\text { Number } \\
\end{array}$ & Description & $\begin{array}{c}\text { Test and Run } \\
\text { Number } \\
\end{array}$ & $\begin{array}{c}\text { Bundle Power } \\
\text { (MW) }\end{array}$ & $\begin{array}{c}\text { Relative } \\
\text { Break Area }\end{array}$ & $\begin{array}{l}\begin{array}{c}\text { Power Decay } \\
\text { Rate }\end{array} \\
\end{array}$ \\
\hline 1 & Low Power, Nominal Bzeak & 4901 Run 13 & 3.0 & $100 \%$ & Nominal \\
\hline 2 & Nominal Power, Intermediate Break & 4902 Run 9 & 4.55 & $50 \%$ & Nominal \\
\hline 3 & Reference & 4903 Run 9 & 4.55 & $100 \%$ & Nominal \\
\hline 4 & Peak Power, Nominal Break & 4904 Run 45 & 6.1 & $100 \%$ & Nominal \\
\hline 5 & Repeatability Test & 4903 Run 4 & 4.55 & $100 \%$ & Nominal \\
\hline 6 & Nominal Power, Orersize Break & 4906 Run 14 & 4.55 & $120 \%$ & Nominal \\
\hline 7 & Peak Power, ANS $+20 \%$ Power Decay & 4907 Run 10 & 6.1 & $100 \%$ & ANS $+20 \%$ \\
\hline 8 & Nominal Fuwer, Alis $+20 \%$ Power Decay & Not Run & 4.55 & $900 \%$ & ANS $+20 \%$ \\
\hline 9 & $\begin{array}{l}\text { Nominal F zwer, Irtermediate Ereak, ANS }+20 \% \\
\text { Power Decay }\end{array}$ & Not Run & 4.55 & $50 \%$ & ANS $+20 \%$ \\
\hline 10 & Overpower, Nominal Break & 4910 Run 10 & 6.5 & $100 \%$ & Nominal \\
\hline
\end{tabular}


essentially the same in this group of experiments with the exception of initial downcomer mass. This parameter did not appear to be repeatable from test to test.

System performance parameters such as depressurization rate and system flows were not significantly affected by bundle power. Those differences that were observed between the tests are explained by other factors. For example, differences are observed in timing of lower plenum flashing, shown by bundle inlet flow in Figure 16. Flashing occurs earliest in Test 10 , followed in succession by Tests $3,4,3 \mathrm{R}$, and 1 . Flashing occurs in exactly the same order as increases in initial downcomer masses for these five tests. Obviously, the quantity of initial mass determines the time to suction line uncovery and subsequent lower plenum flashing.

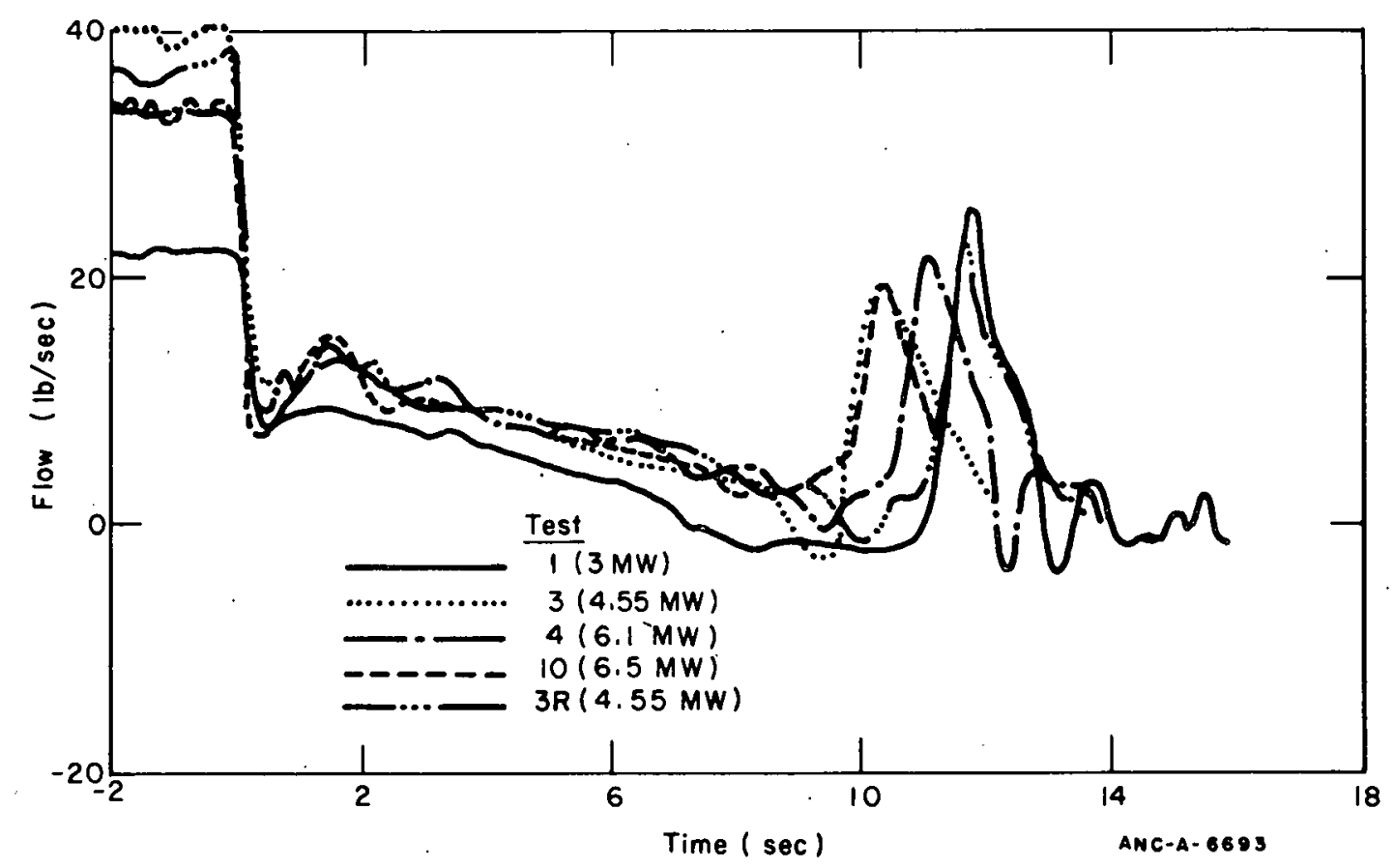

Fig. 16 Effect of bundle power on bundle inlet flow.

Rod temperatures did show marked differences among the tests at varying power level. Temperatures in the 6.1 and $6.5 \mathrm{MW}$ tests ran at consistently higher levels than the nominally powered cases, and the $3 \mathrm{MW}$ test temperatures were consistently lower - both effects as expected. Of primary interest is the effect shown in Figure 17. Here, the rods in the high-powered tests experienced a rapid temperature rise immediately, whereas the temperatures of the rods in the lower power tests did not rise until after lower plenum flashing, when dryout occurred. This indicates a threshold bundle power, where an early critical heat flux occurs causing a change from nucleate to film boiling. It would be of interest to compare results of tests at intermediate bundle powers between 4.55 and $6.1 \mathrm{MW}$ to closer determine the CHF threshold. 


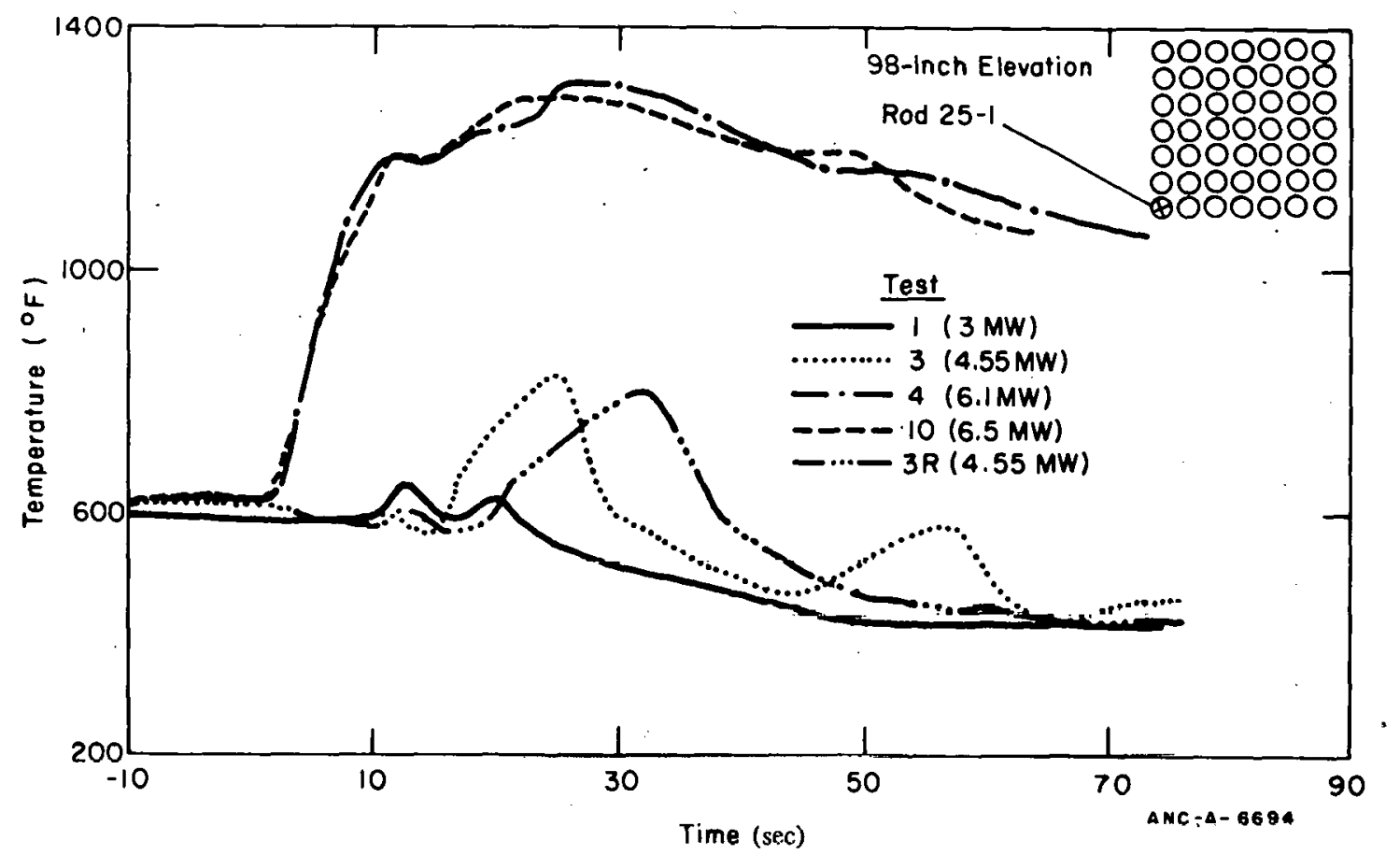

Fig: 17 Effect of bundle power on iod temperalures.

\section{EFFECTS OF BREAK AREA}

The effects of break area have been examined by comparing the results of Tests 2,3 , and 6 . These tests had break areas of 50,100 , and $120 \%$ with respect to the reference case. Break area was found to have a significant effect on system performance as shown in Figure 18. The depressurization rate was much slower in the 50\% break area test than in the nominal test and slightly faster with the $120 \%$ break area. The differences in break flow also affected downcomer mixture level history, time of suction line uncovery, and subsequently, the timing of lower plenum flashing. This difference is shown by the bundle inlet flows in Figure 19. In the 50\% break area test the lower plenum fluid flashed several seconds later than either the $1 \cup 0$ or $120 \%$ cases. I'he nearly identical time of flashing for these latter cases is attributed to compensating differences in break area and initial downcomer mass.

In comparing rod temperatures, few consistent trends were found with respect to break area. Typical rod temperature results are shown in Figure 20. Generally, the rods dried out later in the small $(50 \%)$ break case as expected from the later flashing and dryout in this test. The nominal break test had consistently higher rod temperatures than the 50\% case, which follows from the differences in dryout times. However, at many locations the nominal test also showed higher rod temperatures than did the $1.20 \%$ case. This trend is not readily explained but could be attributed to the randomness of the rewetting process due to fallback, coupled with the limited quantity of thermocouple measurements available:for comparison. 


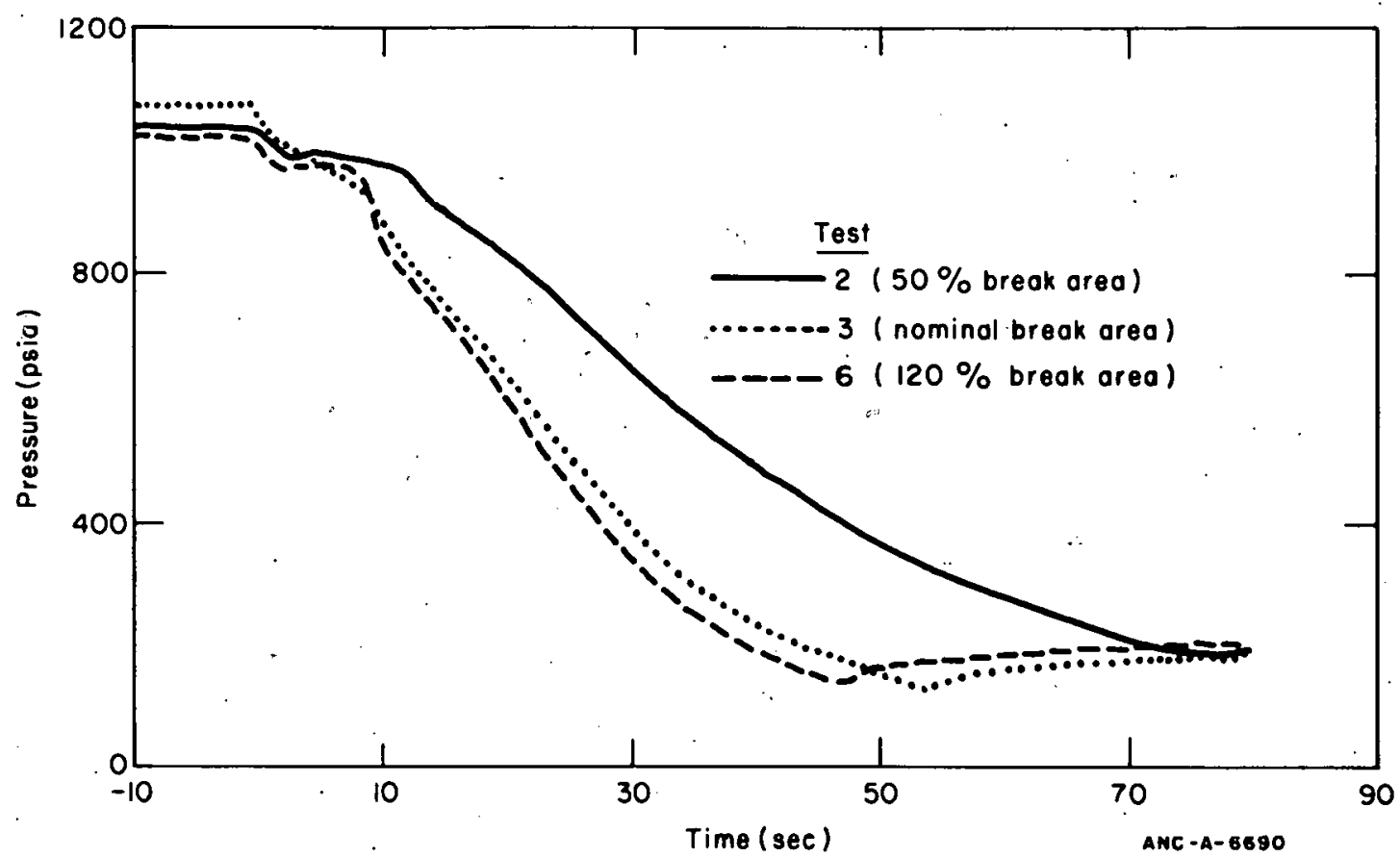

Fig. 18 Effect of break area on depressurization rate.

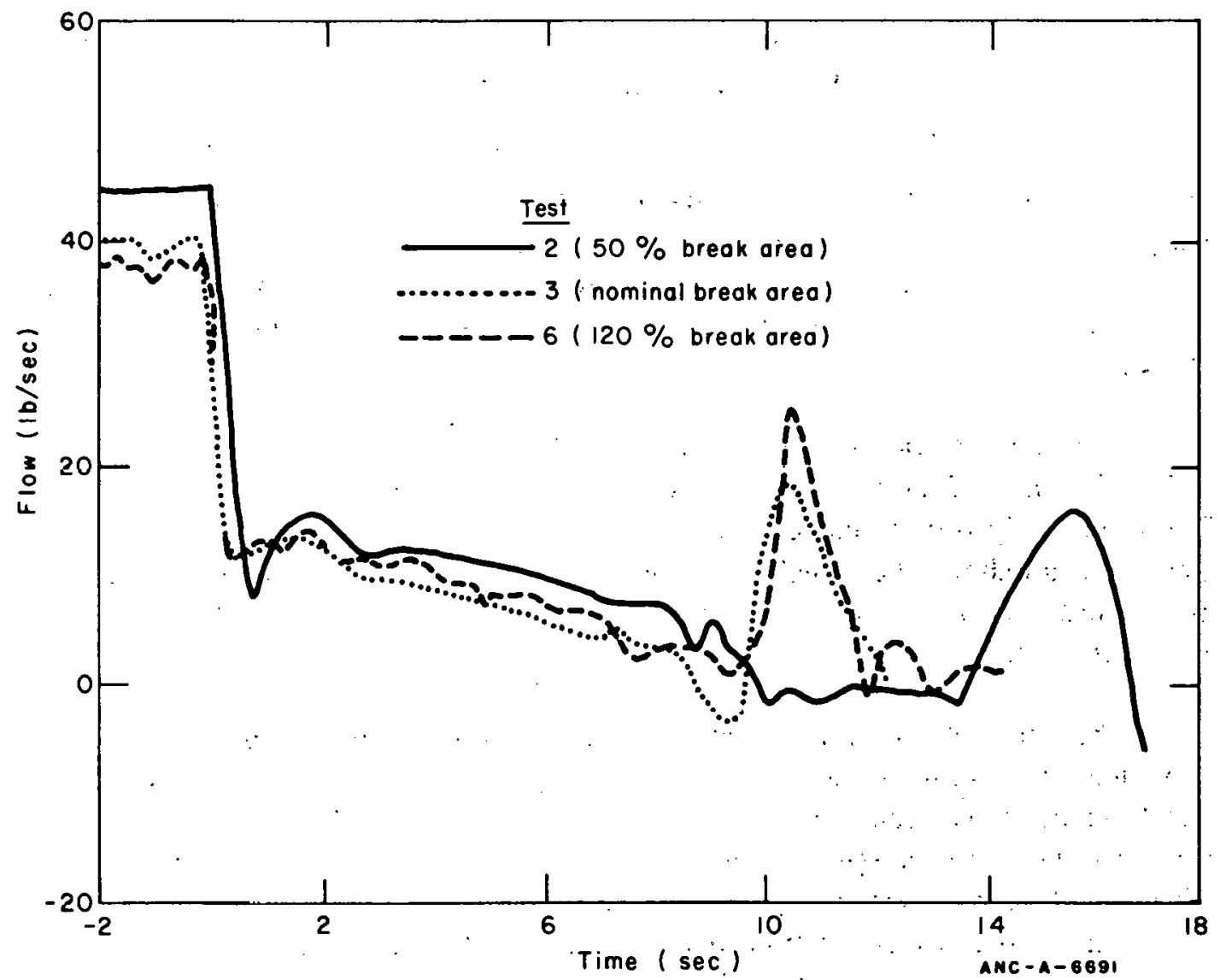

Fig. 19 Effect of break area on bundle inlet flow. 


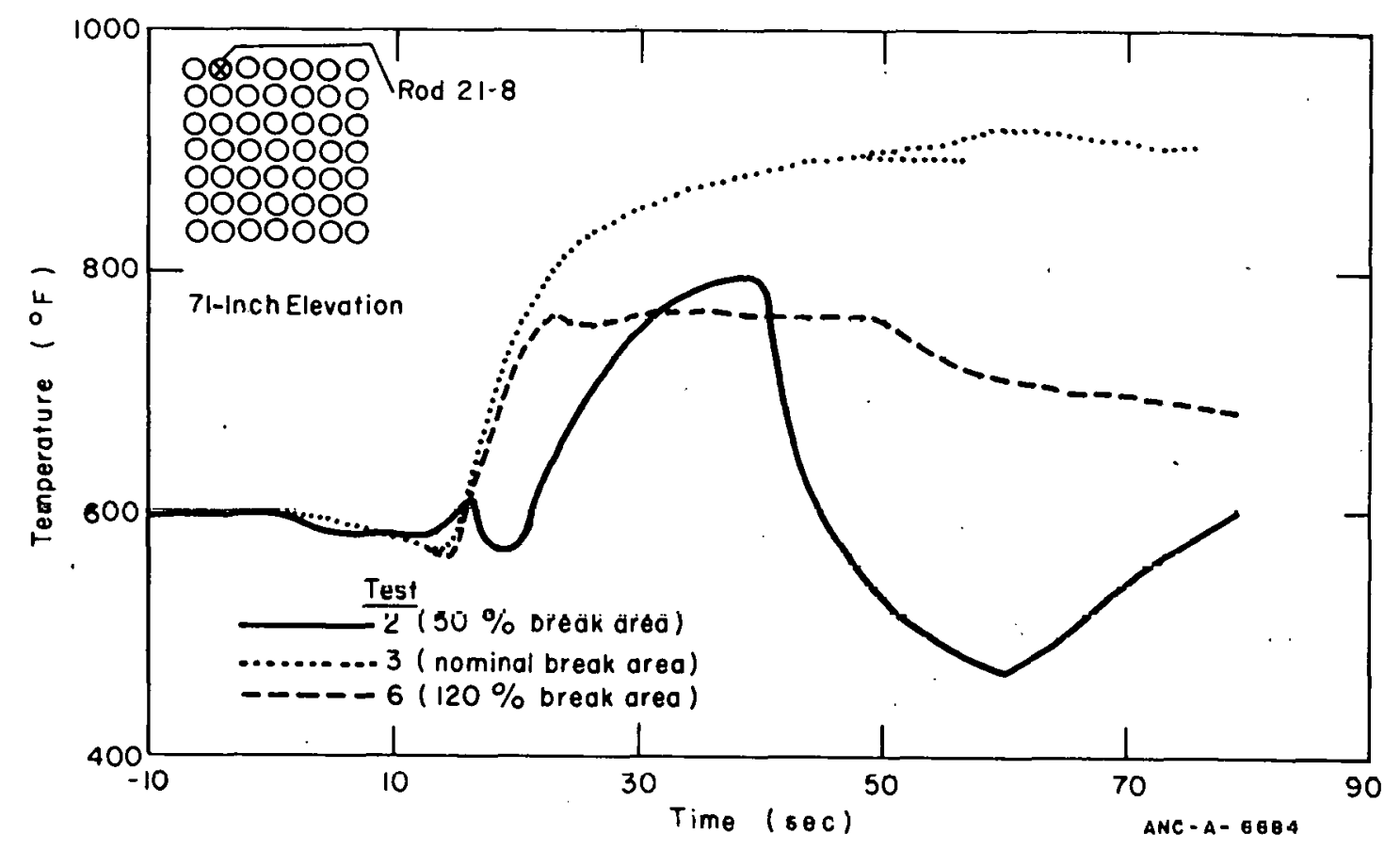

Fig. 20 Effect of break area on rod temperature.

\section{EFFECT OF POWER DECAY RATE}

In establishing the nominal power decay for the TLTA heater rods, GE used their own design values for decay heat based on BWR scram characteristics. To simulate the fuel rod, the heater rod must be programmed to follow a decay profile that combines both stored and decay heat of the fucl. The approach used in deriving this power profilo is described in Reference 21.

The alternate decay profile was based on the ANS $+20 \%[22]$ curve for decay heat rather than the GE design values. Stored energy considerations were identical in both cases. The resultant heater rod power profiles for the two cases were found to differ by only a few percent throughout the transient as shown in Figure 21. On the basis of this comparison, one would expect only a minor difference between tests programmed with the two power decay profiles.

The effect of power decay rates was evaluated by comparing the results of Tests 4 and 7 , which used nominal and ANS $+20 \%$ decay heat assumptions, respectively. The decay heat had no perceptible effect on system performance depressurization, and bundle flow rates matched very closely. However, rod temperatures showed a very definite trend; the ANS $+20 \%$ power decay curve test resulted in consistently higher rod temperatures. In several cases, such as shown typically in Figure 22, the temperatures in the ANS $+20 \%$ test seemed disproportionately higher. It does not seem reasonable that such large temperature differences could be caused by the very small power difference. This apparent anomoly is thus far unexplained. 


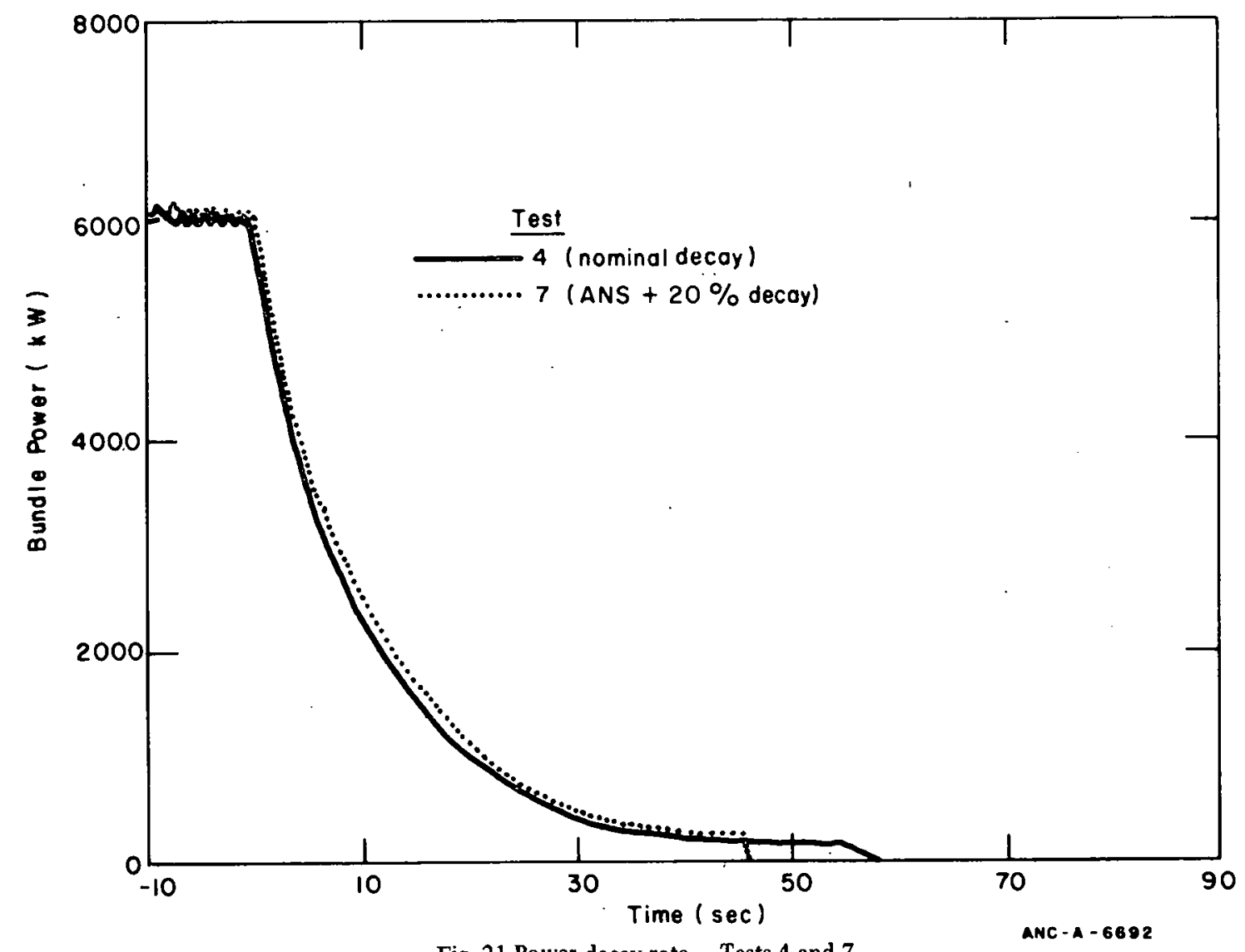

Fig. 21 Power decay rate - Tests 4 and 7.

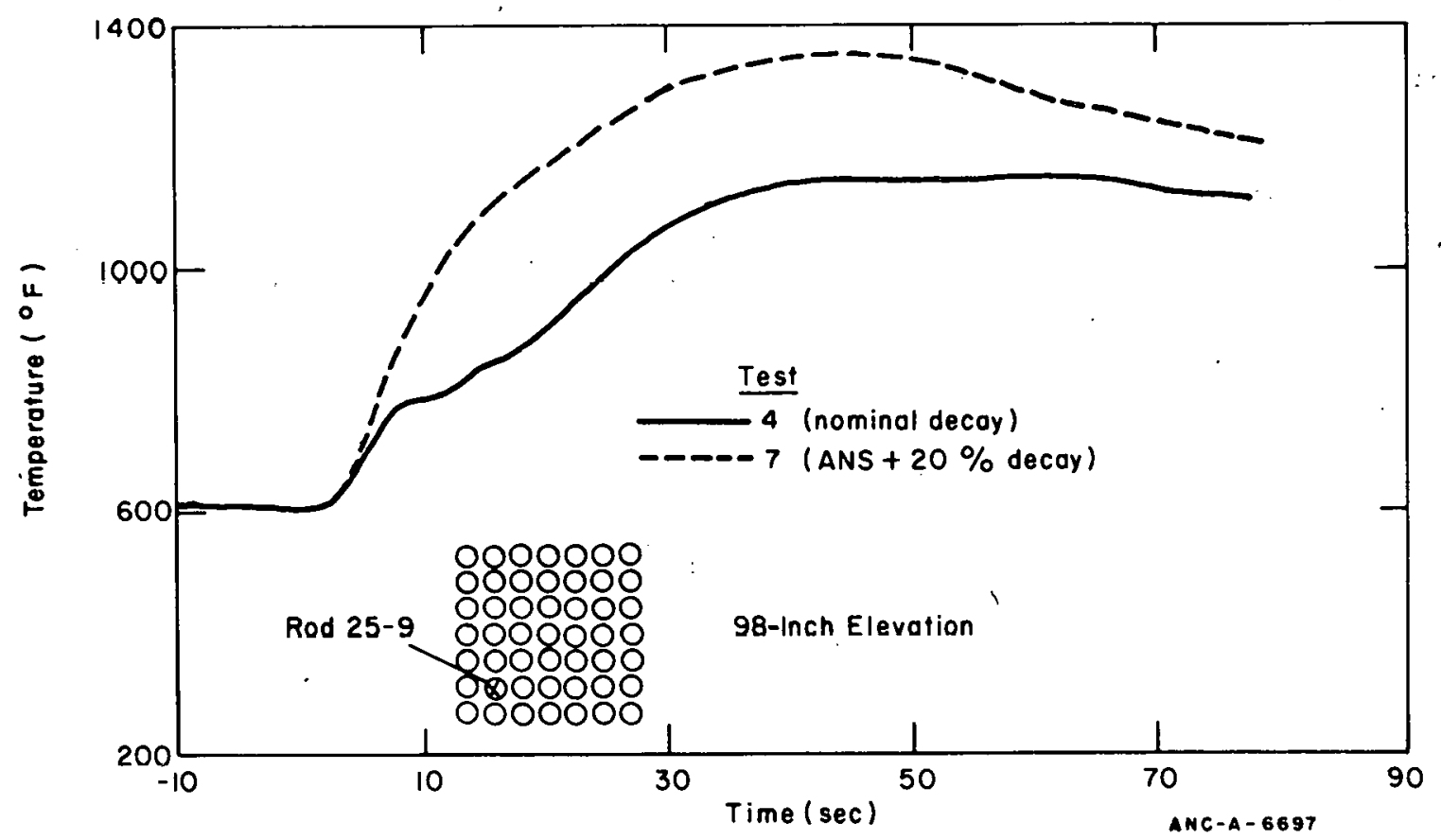

Fig. 22 Effect of power decay rate on rod temperature. 
The power decay test is considered inconclusive due to the apparent inconsistency of the results and the relatively minor differences between the programmed decay rates. It is thus suggested that power decay rate be considered again as a parameter in future tests. In running these tests, a wider difference in programmed decay rates is recommended to better establish rod temperature performance differences.

\section{EFFECT OF THERMOCOUPLE LOCATION}

In view of the apparent inconsistencies observed in bundle performance, the effect of thermocouple location on measurement values was examined. Two such comparisons are shown in Figures 23 and 24. The figures each present several temperature measurements frum Tesl 3 laken al cummun axial pusiliuns and puwer levels. These results isulate the effect of radial position on rod thermal performance. Both figures show that temperature differences in excess of $400^{\circ} \mathrm{F}$ exist on rods with identical power levels and axial elevations. These results clearly indicate a three dimensionality and randomness in the bundle dryout and rewetting processes.

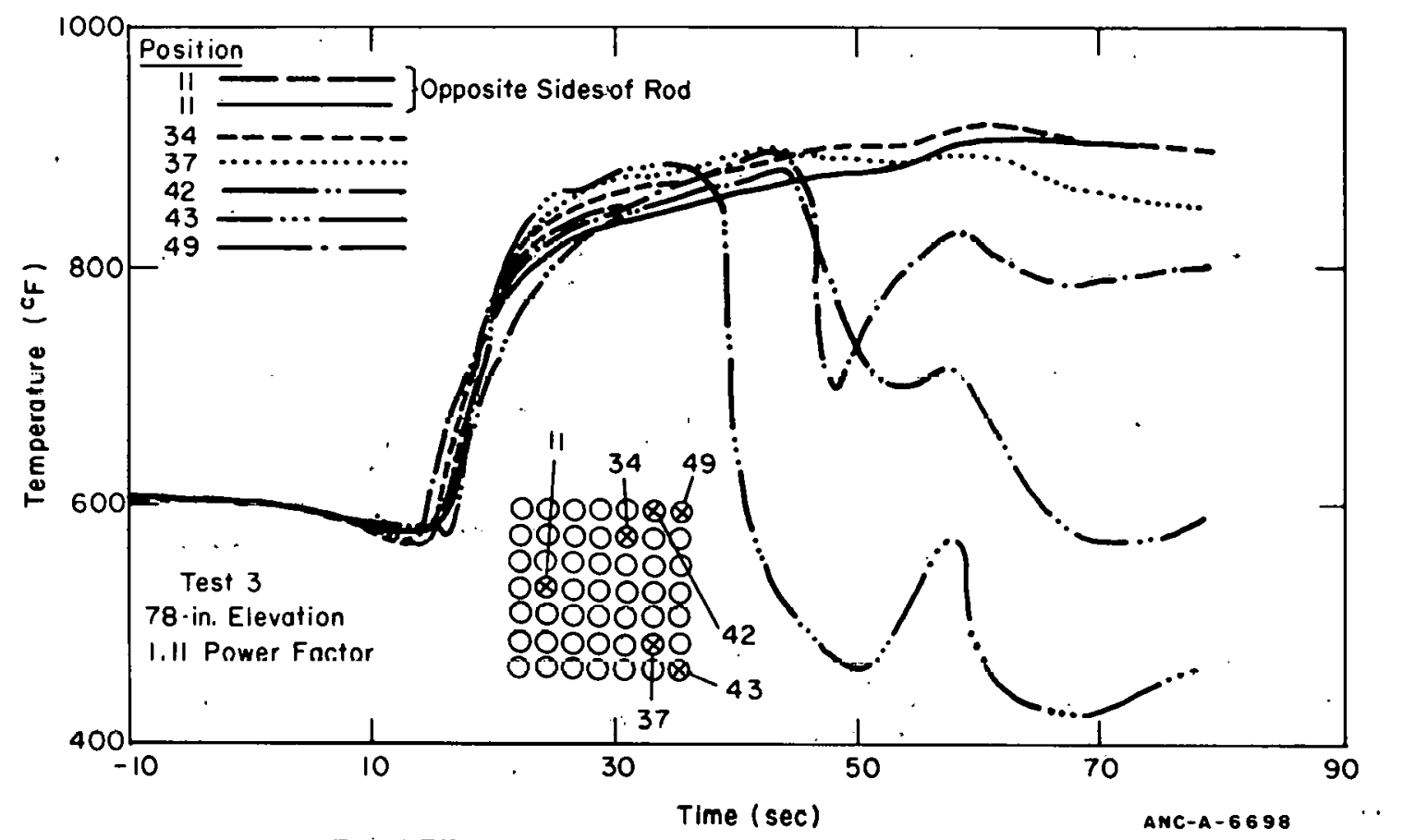

Fig: 33 Effeot of thermocouple location - 1,11 power factor. 


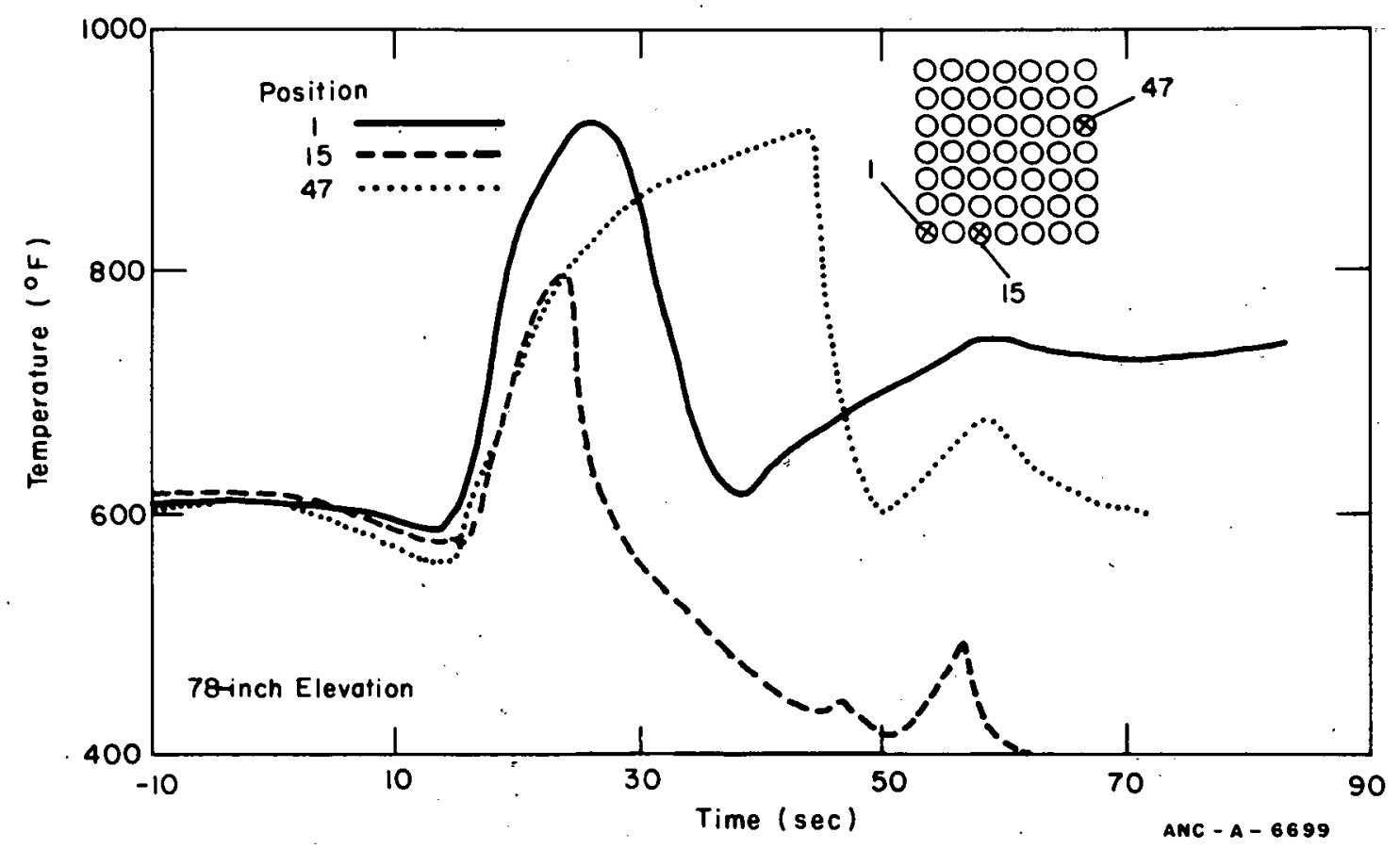

Fig. 24 Effect of thermocouple location -1.25 power factor.

\section{REPEATABILITY}

Test-to-test repeatability was assessed by reviewing the data from Tests 3 and 5 . These tests started from nearly identical initial conditions and were operated under similar valve phasing and power decay profiles.

Depressurization rates in the two tests were found to match almost exactly. Some minor differences in system flow rates were observed between the two tests, as shown by bundle flow in Figure 25. This difference is apparently due to slight differences in initial downcomer mass, initial bundle flow, and timing of the transient initiation.

Bundle performance was also found to be generally repeatable between these two tests as evidenced by Figure 26. The minor temperature differences shown are attributed to the bundle flow difference. In a few instances, some notable differences were observed in bundle temperatures. Typical of these are the results presented in Figure 27. The rod dryout and rewetting process does not appear to be consistent, demonstrating certain randomness in this phenomenon.

Some inconsistencies which could not be readily explained have been pointed out in comparisons in previous sections. Further, the repeatability tests were conducted within a few days of each other, whereas all other tests were conducted from several days to months apart. One question which has not been fully resolved is experiment repeatability over periods of times approaching the bundle lifetime. Lack of repeatability should be eliminated as a possible cause of data inconsistencies by running identical tests several months apart. 


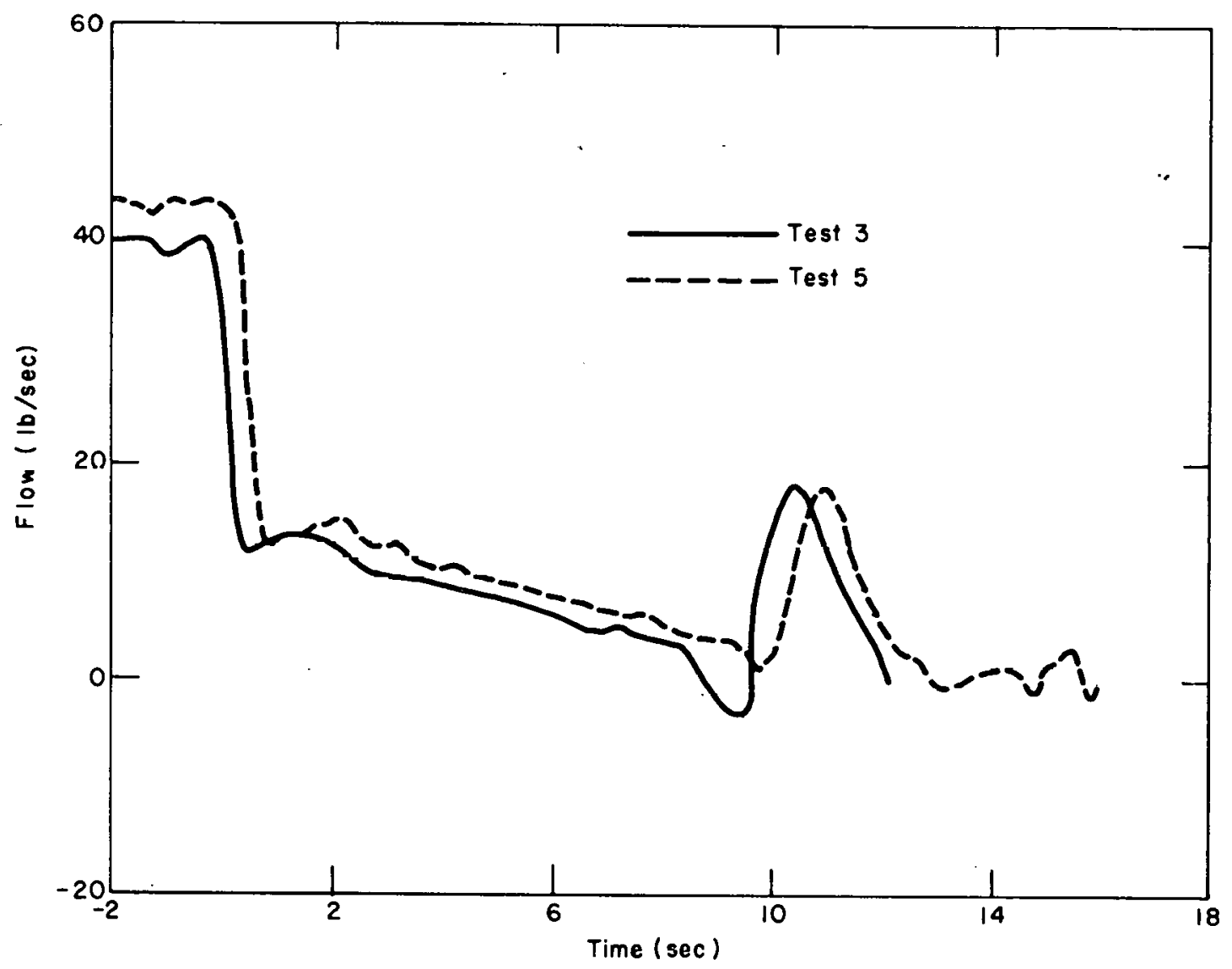

Fig. 25 Bundle flow repeatability.

ANC-A- 6700

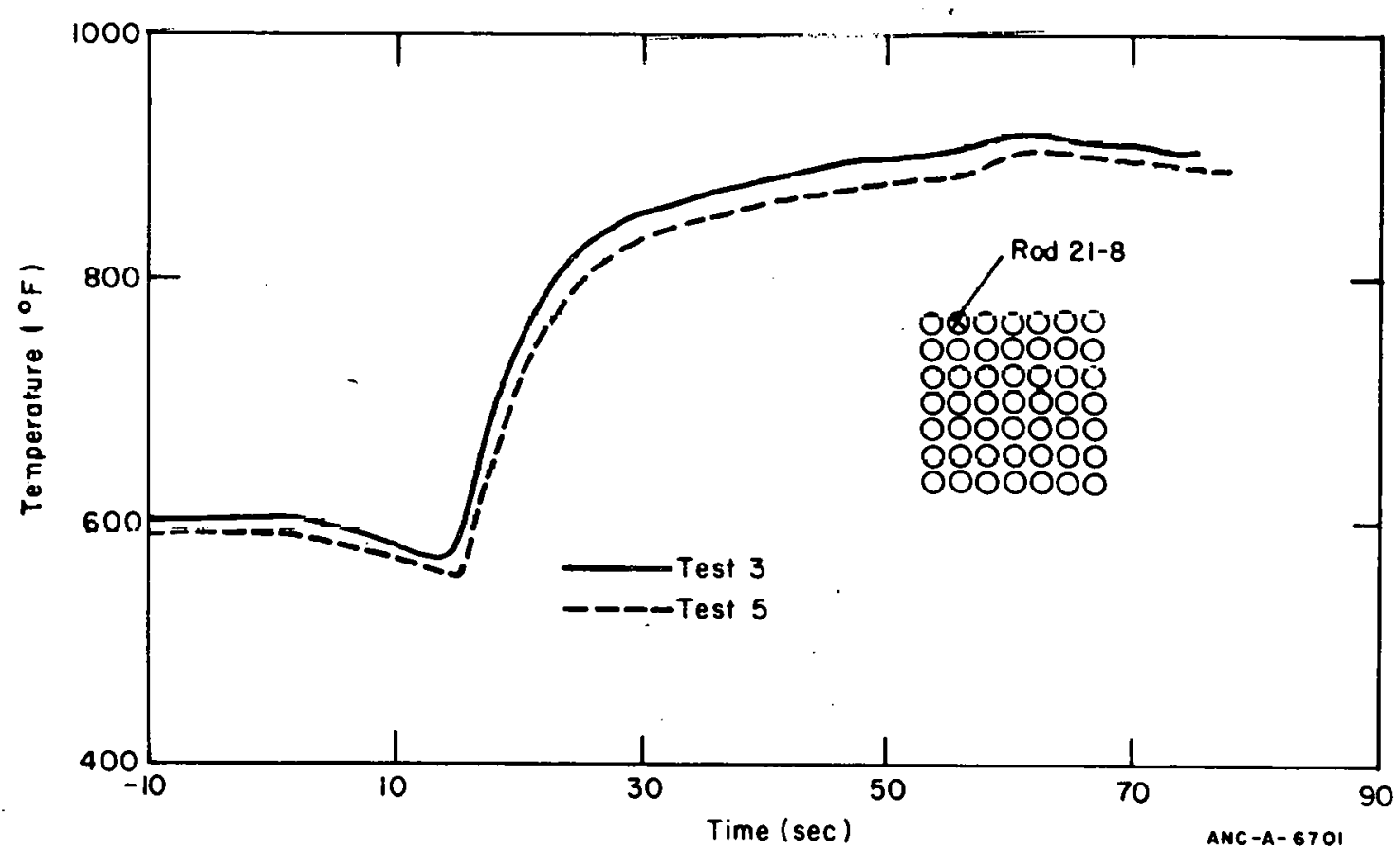

Fig. 26 Bundle temperature repeatability - 71 -inch elevation. 


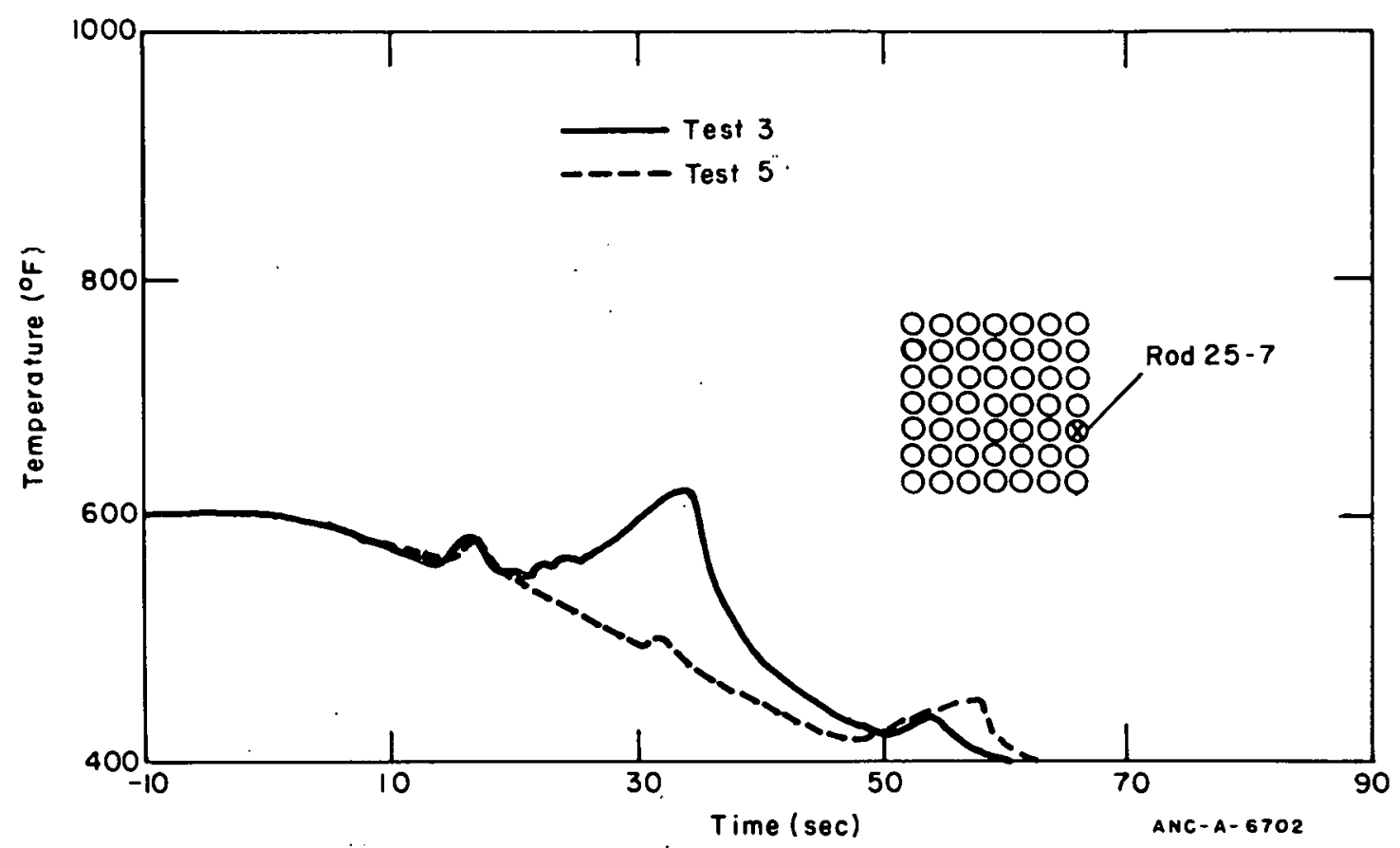

Fig. 27 Bundle temperature repeatability - 118-inch elevation.

\section{CONCLUSIONS AND RECOMMENDATIONS}

This review of the TLTA data has led to the following direct conclusions:

(1) Bundle power level has only a minor effect on TLTA system performance.

(2) Initial downcomer masses, which were not repeatable from test to test, have a significant effect on system behavior. The most severe bundle temperature conditions were associated with the lower initial mass values.

(3) Rod temperatures were significantly affected by bundle power; a CHF threshold exists at initial powers some place between 4.55 and 6.1 MW.

(4) Break area impacts system performance in an expecled mainer, influencing depressurization rates, flows, and mass inventories.

(5) Results of the power decay profile tests are considered inconclusive. 
(6) Many inconsistencies are observed in bundle heat transfer processes. Some of the inconsistencies may be explained by the random nature of rod rewetting due to liquid falling back into the bundle from the upper plenum. Other inconsistencies defy explanation and indicate, perhaps, a high system performance sensitivity to an unknown variable.

(7) Test-to-test repeatability was judged to be good for tests run close together in time. Repeatability over longer time intervals has not been established.

Based on these observations, it is recommended that the following steps be taken:

(1) A criterion (such as $\pm 5 \mathrm{lb}$ ) should be established within which downcomer initial masses should be constrained on all future tests. Failure to meet the criterion should be cause to rerun the test.

(2) Additional testing to precisely establish the CHF power threshold in TLTA should be considered.

(3) A new alternate power decay profile which provides a significant departure from the reference case should be established and used.

(4) A repeatability test to examine test-to-test consistency over the life of a bundle should be scheduled.

(5) Analytical efforits to provide iniproved analyses of BWR rod bundle thermal-hydraulic perlomance should be expanded. Such models will require phase slip and distribution capability to account for fallback effects and standing bundle mixture level. The models should also consider three-dimensional interactions within the bundle combined with channel wall effects. 


\section{RELAP4 CODE EVALUATION}

This section presents the results of comparisons of data from selected TLTA tests with corresponding RELAP4 calculations. The objective of these comparisons was to evaluate the RELAP4 code and user methodology as applied to conditions similar to the blowdown portion of a BWR LOCA. The evaluation has been conducted in a systematic manner, concentrating on performance of individual TLTA components. Components considered include the break, downcomer, recirculation pump, jet pump, lower plenum, and the core.

Three tests were considered in the code evaluation process. These were Matrix Tests 1 , 3 , and 6, which were described generally in Table VII.' Test 1 was the initial TLTA blowdown. It represented a low-power, low-flow rate bundle typical of those found on the periphery of a BWR core. Some measurement problems, unique to this test, were encountered in the data. These problems, which limited some of the Test 1 RELAP4 comparisons, were corrected by GE for subsequent tests. Test 3 represented the "reference case," in which all test parameters and initial conditions were at their nominal values. The flow and power conditions were representative of those in an average BWR bundle. Test 6 was designated as Standard Problem 4 by the NRC. Initial conditions and most other test parameters were similar to those of Test 3 . The relative break area was $120 \%$ of the reference break area which resulted in a more rapid blowdown transient.

The bulk of the data comparisons were made with data from Test 3. However, Test 1 and 6 data were used in several instances to check and verify conclusions reached from the Test 3 comparisons. Sources of the data used are listed as References 12 and 14 through 20.

\section{RELAP4 MODEL DESCRIPTION}

\subsection{System Model}

The analytical model of the TLTA, illustrated in Figure 5, was derived by considering current large BWR modeling methods as they apply to the test facility. The physical model, including volumes, flow areas, elevations, flow rates, pressure, and enthalpy distribution was derived primarily from drawings supplied by GE and the Prelimịnary System Design Description ${ }^{[1]}$.

In general, Figure 5 is self-explanatory; however, the following items are considered pertinent to understanding the model and evaluating the results of the data comparisons:

(1) The upper plenum and steam separator volumes arc modeled as a common volume (Volume 2). The volumes surrounding the steam separator deflector and collector and a portion of the downcomer were included in the steam dome volume (Volume 3 ). 
(2) The junction (Junction 3) between the steam dome (Volume 3) and downcomer (Volume 4) separates a step change in initial downcomer fluid enthalpy at the feedwater injection location.

(3) The blowdown and recirculation lines in the break loops were combined into common volumes (Volumes 5 and 7) using the blowdown line flow resistance.

(4) Momentum flux has been included at all junctions except the core inlet (Junction 24) and outlet (Junction 1) as required to permit separate single channel analyses in the core.

(5) Choking criteria are tested at the jet pump mixing junctions (Junctions $7,12,14$, and 15), the break junctions (Junctions 26 and 27), and the venturi (Junction 4).

(6) The bypass is modeled by a single volume (Volume 14) which contains the total volume of the four bypass tubes. The hydraulic diameter of the volume and connecting junctions (Junctions 16 and 17) is that of the actual hardware, and hence the flow resistance and pressure drop are.conserved in the model.

(7) Several heat slabs have been provided to account for sensible wall heat transfer to the ILTA fluid. To minimize the number of inputs for the heat slabs, some of the vessel structural elements have been combined into single heat slabs. Heat Slabs 1, 2, 3, 17, and 18 are the ceramic and stainless steel channel wall. These heat slabs interface with both the core and main vessel volumes. The surface areas and volumes of the upper plenum and steam separator were combined into Heat Slab 4. Heat Slabs 5, 6, and 7 represent the combined main vessel wall. The break loop recirculation pump and the suction side piping are represented by Hcat Slab 9 . Ileat Slab 10 represents the break loop jet pump and the discharge side piping. Heat Slabs 8 and 11 represent the intact loop. The recirculation pump and the jet pump were combined with the piping as in the break loop. Heat Slabs 12, 13, 14,15 , and 16 represent the corc hratrer rods at five axial locations. Each of these heat slabs represents an axial segment of 49 rods. The resultant calculation of temperature response is that of an average radial power rod.

\subsection{Core Model}

An analytical model of the core was developed to investigate the thermal-hydraulic response of single TLTA rods and the adjacent fluid. The model, shown in Figurc 28, 


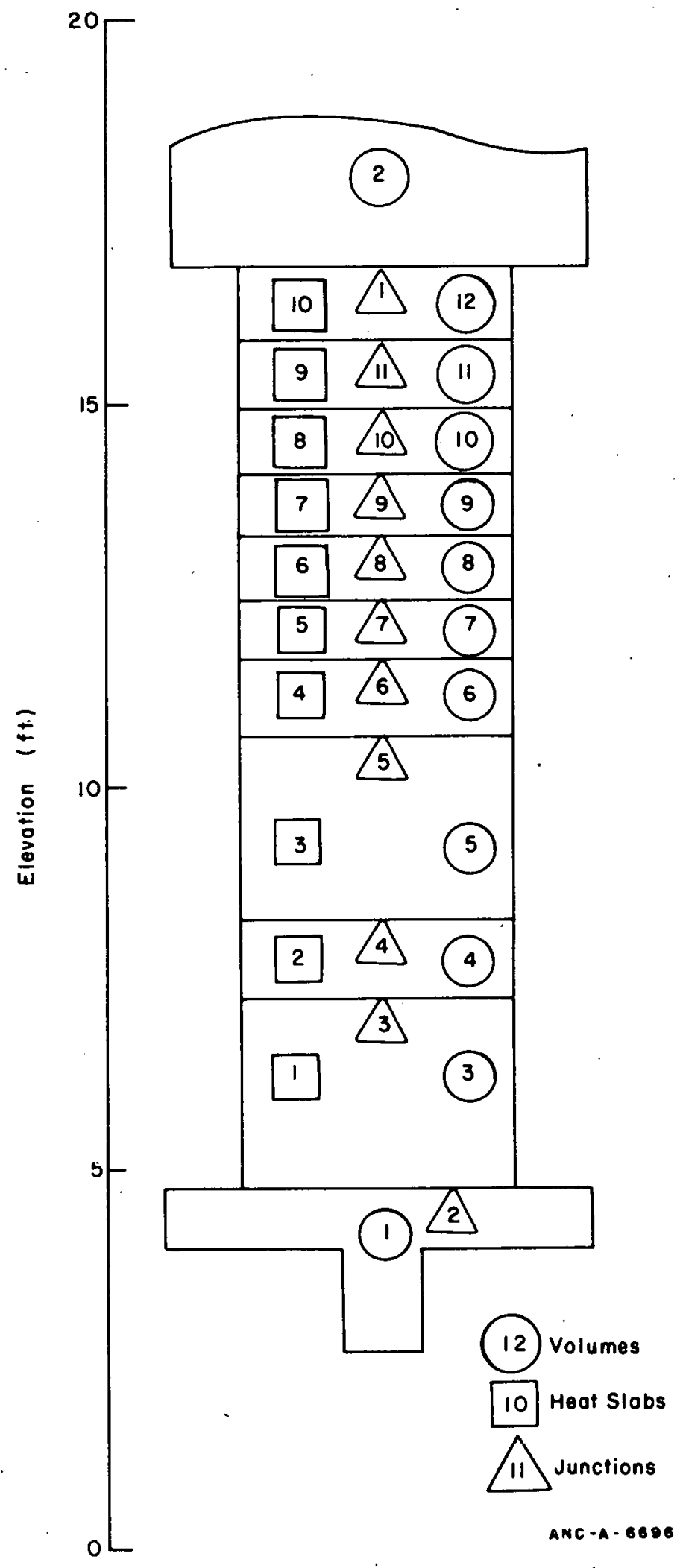

Fig. 28 GE-BDHT-TLTA heater rod model. 
permits a more detailed evaluation of a rod than is economically justified in the system analysis. The subchannel model uses the results of the system analysis as boundary conditions. Separate versions of this model were used to represent rods with different radial peaking factors. The following items are considered pertinent to understanding the heater rod model and evaluating the results of the data comparisons:

(1) Volume 1 represents the unheated inlet section to the core.

(2) Volume 2 represents the upper plenum.

(3) The pressure and temperạture or quality of Volumes 1 and 2 are taken from a system analysis and are used as boundary conditions for the core analysis.

(4) Heat transfer is confined to the heater rods and the circulating fluid. Heat transfer to the channel wall is neglected.

(5) The centers of Volumes 4,6,8,10, and 12 correspond to the axial location of the thermocouples in the rods.

\subsection{Model Evolution}

The code comparisons described herein were based on an "evolutionary" code and user input model. Both the code and the TLTA model were changed several times during the course of the study to incorporate better modeling and techniques, to eliminate code errors, and, in some cases, to aid the diagnosis of problem areas. These changes are documented in References 23, 24, and 25. It is emphasized that the vast majority of these changes were minor in nature and had little impact on the TLTA calculations. Those that were of significance to the code evaluation are summarized in Table VIII.

Generally, the changes to the model were made to improve the calculations in a specific region of the TLTA. The CHF correlation change, the jet pump drive flow modification, and the critical flow model revisions were made to correct an indicated calculational problem. These changes are discussed in more detail in the following sections.

The core model described in Section 1.2 was not available when the Test 1 prediction was made but was available later for Tests 3 and 6 . This model provided additional detail in rod temperature calculations. The Test 1 and 6 calculations worc made prior to the test and used GE-prescribed initial and trip conditions. 


\begin{tabular}{|c|c|c|c|}
\hline & Test & Test & Test \\
\hline & 1 & 3 & 6 \\
\hline CHF Correlation Used & Barnett & $\mathrm{x}_{\mathrm{CHF}}=0.95$ & $\mathrm{x}_{\mathrm{CHF}}=0.95$ \\
\hline $\begin{array}{c}\text { Jet Pump Model Used } \\
.\end{array}$ & As Coded & $\begin{array}{l}\text { Modified } \\
\text { Drive } \\
\text { Flow }\end{array}$ & $\begin{array}{l}\text { Modified } \\
\text { Drive } \\
\text { Flow }\end{array}$ \\
\hline Critical Flow & $\begin{array}{l}\text { Moody } \\
C=0.6\end{array}$ & $\begin{array}{c}\text { Match Test } \\
3\end{array}$ & $\begin{array}{l}\text { Moody } \\
C \doteq 0.6\end{array}$ \\
\hline Core Model & $\begin{array}{l}\text { Integral } \\
\text { Average } \\
\text { Rod }\end{array}$ & $\begin{array}{l}\text { Separate } \\
\text { Local } \\
\text { Rod }\end{array}$ & $\begin{array}{l}\text { Separate } \\
\text { Local } \\
\text { Rod }\end{array}$ \\
\hline When Run & Pretest & Posttest & Pretest \\
\hline RELAP4 Version Used & $\begin{array}{c}\text { MOD 2, } \\
\text { Version } 3\end{array}$ & $\begin{array}{l}\text { MOD 3, } \\
\text { Version } 66\end{array}$ & $\begin{array}{c}\text { MOD 3, } \\
\text { Version } 56\end{array}$ \\
\hline
\end{tabular}

\section{DATA COMPARISONS}

\subsection{Break}

2.1.1 Design and Performance Considerations. The simulation of a BWR LOCA is initiated by two quick-opening valves in the TLTA broken loop. As these valves open, flow in the loop very quickly departs from the initial conditions, as mass is forced out both sides of the loop into the suppression tank. Choking occurs at two points in the system: (a) at the broken loop jet pump drive nozzle and (b) at a venturi placed in the broken loop suction line. The areas of these two choking points were scaled from the BWR so that the relative mass expulsion rate would be simulated in the TLTA.

2.1.2 Model Considerations. The critical flow calculations for the Test 1 and Test 6 predictions utilized the Moody model with multipliers of 0.6 and 0.14 , respectively. 'Ihese calculations were considered unsatisfactory because they did not properly account for the relatively high flow rates observed during the subcooled portion of the blowdown. As a result of the improper break flow calculation, the timing of events during the transient was not properly predicted, and comparisons in other parts of the system were made with difficulty.

To overcome this problem in evaluating RELAP4 calculations for Test 3, the break flow was forced to match roughly the trends observed in the data. This was accomplished . with the following critical flow model:

(1) Subcooled - Henry model x 1.4

(2) Saturated low quality - Moody model x 0.9

(3) Saturated high quality - Moody model x 0.74. 
2.1.3 Data Comparisons. Figure 29 presents information extracted from a GE analysis of net mass depletion in the TLTA for conditions similar to Test $3^{\text {[a] }}$.

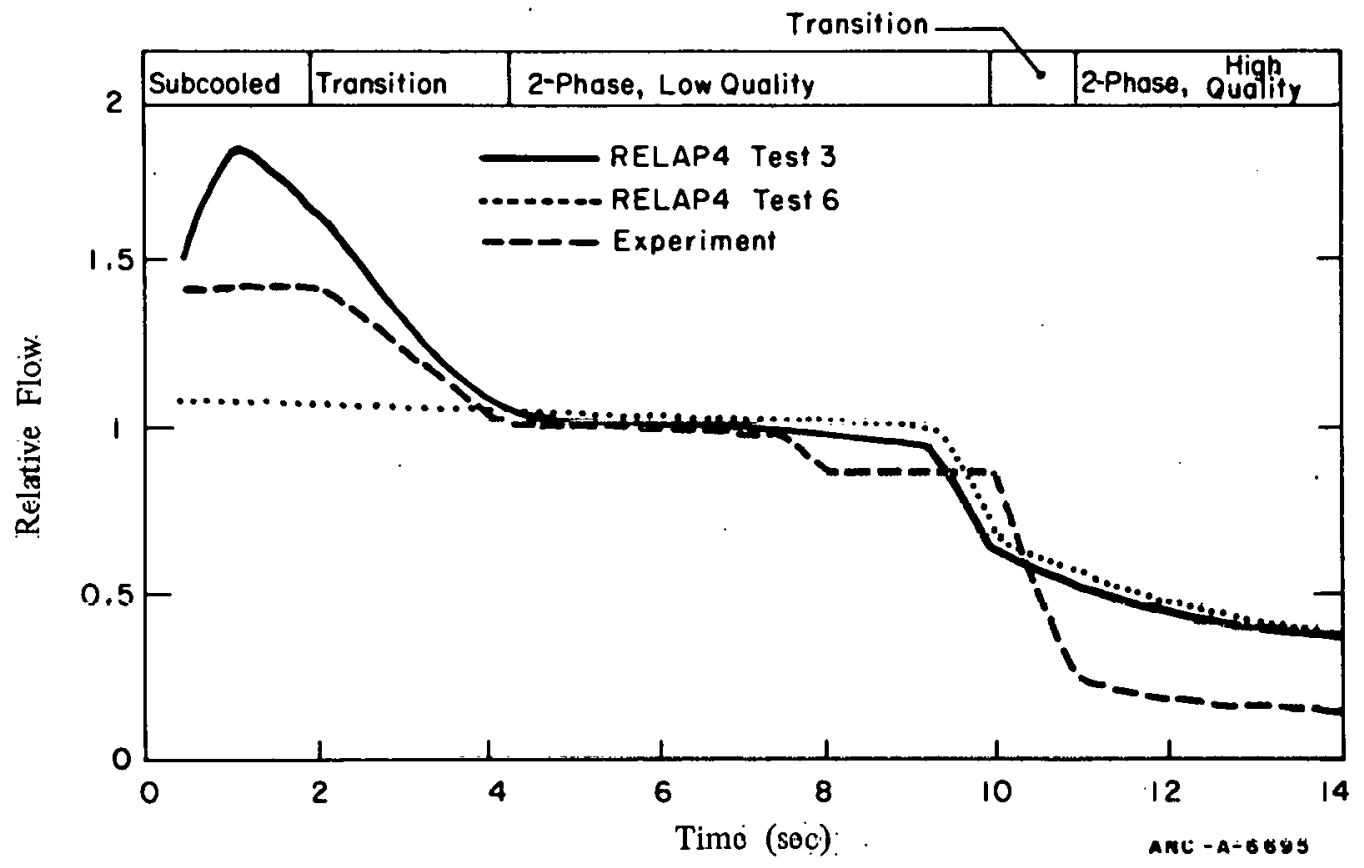

Fig. 29 Tests 3 and 6 break flow.

These results were obtained by summing instantaneous local masses throughout the transient from numerous individual local density measurements. The figure represents total break flow, combining flows through the suction line and jet pump drive nozzle. The results of the RELAP4 calculations made for Tests 3 and 6 are also shown with the experimental data. Since actual break flows differed in these two tests, relative rather than actual flow is plotted.

The experimental trends in Figure 29 show several interesting effects. Initially, the experimental flows are high as subcooled liquid flows out of the system. The transition to low quality break flow is seen in the 2- to 4-second period as a substantial drop in the total break flow. At about 8 seconds, the flow again drops abruptly as the jet pump suction uncovers, and break flow through the drive nozzle changes from low to high quality. At 10 seconds, the sharp drop in flow is observed as the suction line uncovers, and flow here changes from low to high quality.

The degree of compliance of the Tests 3 and 6 calculations with these data is also evident in Figure 29. In Test 6, where a constant multiplier was used with the Moody

[a] The information presented in Figure 29 was taken from Test 4903, Run 16, which was very similar to Test 3 . 
model, the agreement was poor during the early, subcooled portion. The Test 3 case with adjusted models a and multipliers exhibits more consistent trends throughout the transient.

Figures 30 and 31 show comparisons of Test 3 downcomer mass and steam dome pressure. Both parameters are directly affected by the break flow calculation. The calculated and experimental downcomer mass inventories, compared in Figure 30, indicate that the prescribed critical flow is reasonable. The calculated mass inventory is shown to be very close to the Test 3 data except for the 7-to 10-second time period, during which the mixture level in the downcomer is near the suction line opening. This discrepancy is partially attributed to drawdown: within the test apparatus and the lack of a horizontal slip flow model at the suction line inlet. As the mixture level reaches the suction line opening, drawdown near the break is thought to allow high quality flow before the average volume mixture level has reached the opening. This effect, which would reduce the rate of change of the mixture level and mass inventory, is not accounted for in the analysis. During the uncovering process, significant slip between phases is expected at the suction line inlet, which would also reduce the mass inventory rate of change.

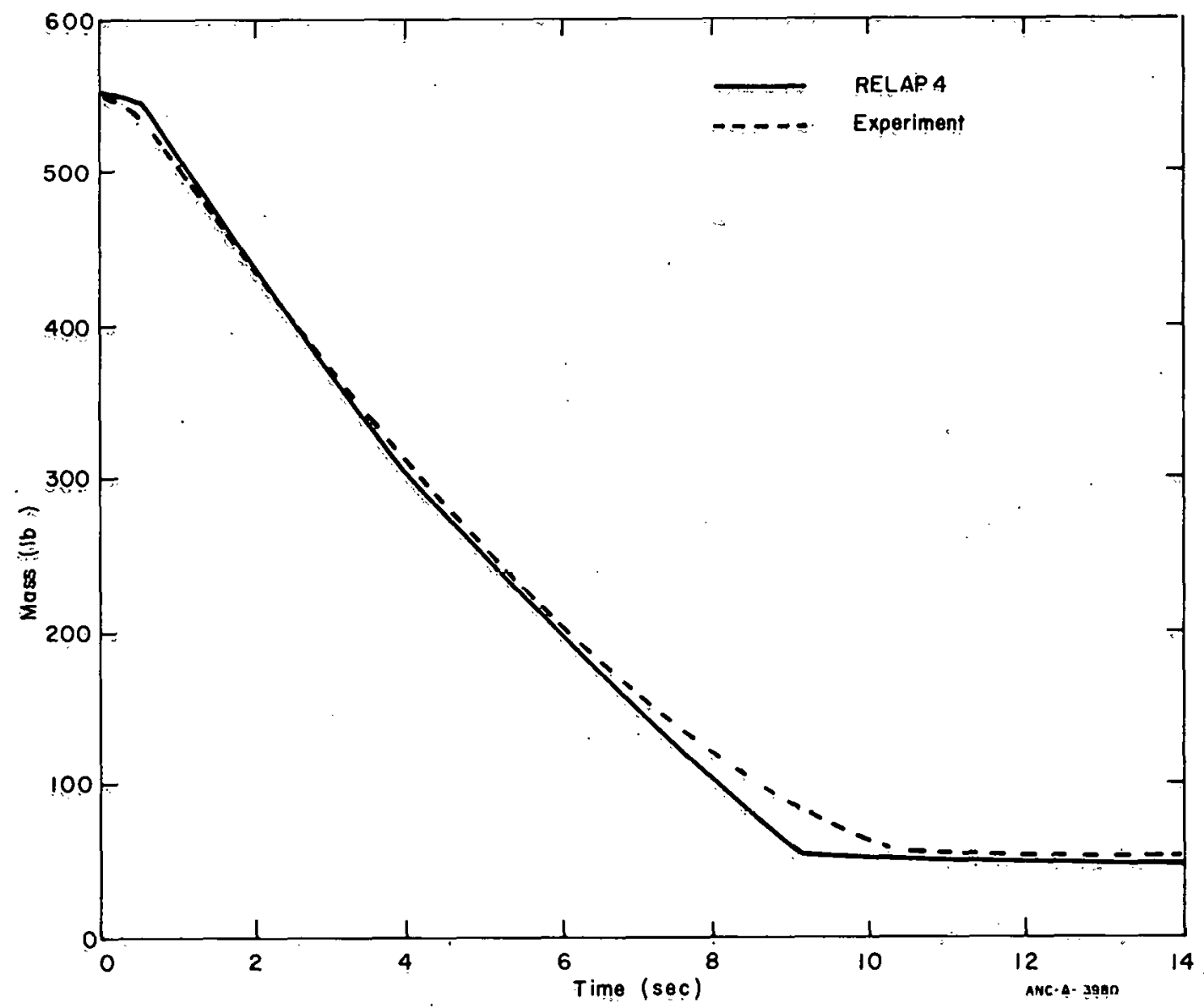

Fig. 30 Test 3 downcomer mass. 


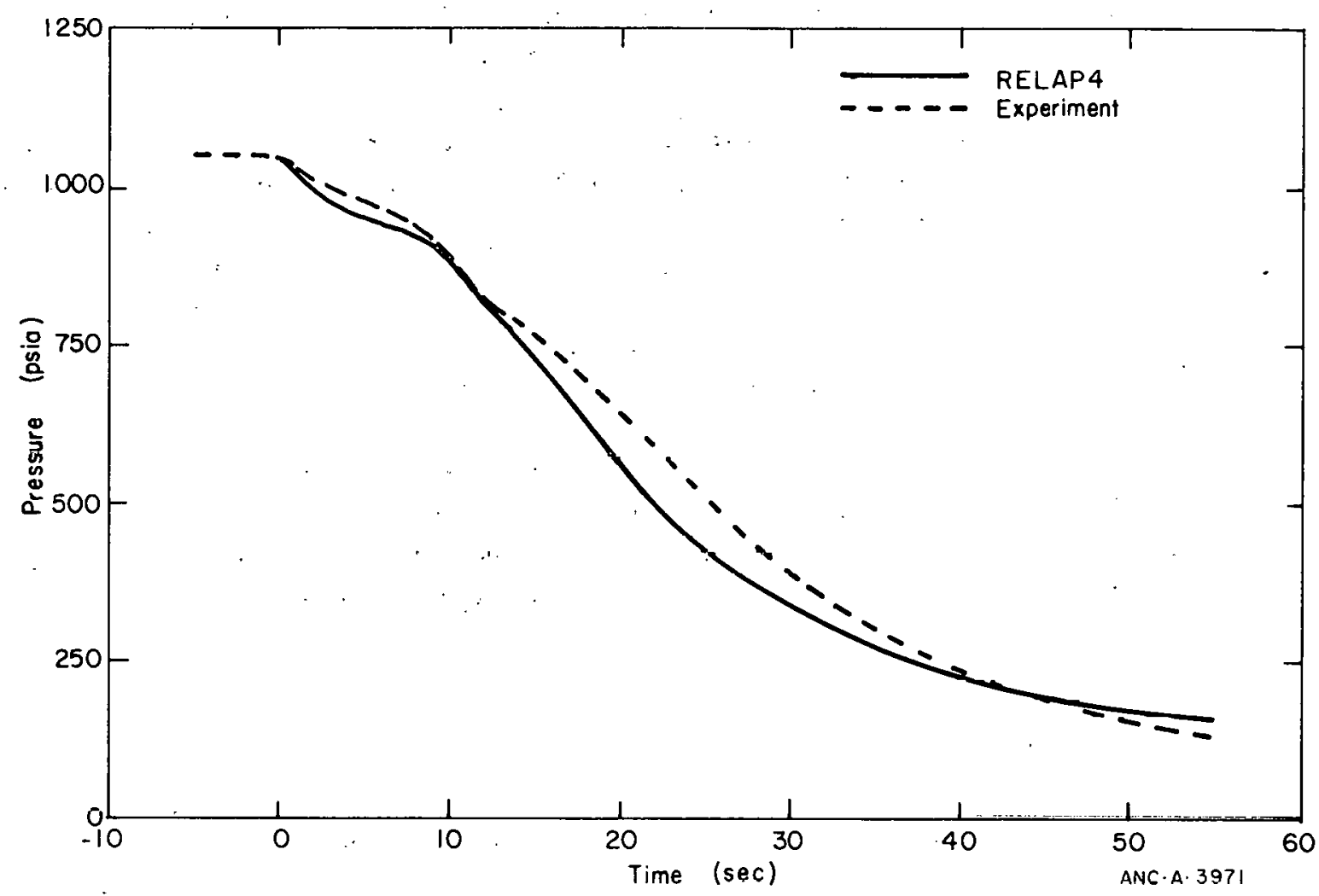

Fig. 31 Test 3 steam dome pressure.

The predicted steam dome pressure decay generally agrees with the test data as shown in Figure 31. The small difference in pressures in the 0 - to 10-second time period may indicate that the prescribed break flow was slightly high. The minor differences in the latter part of the transient may also be due to the break flow calculation and/or wall heating effects. The effect of overpredicting wall heat or underpredicting break flow would be identical in their influence on steam dome pressure. Experimental wall temperature measurements, planned in future testing, are expected to provide additional information, which can be used to verify or improve the wall heat.transfer model.

2. 14 nissussinn. It is generally conceded that improvements were required in the RELAP4 critical flow model. This problem was treated in a recent version of RELAP4 $[26]$. Until this model improvement was available, the approach used in the Test 3 analysis was followed. This procedurc allowed a propor oaloulation of break flow-dependent variables such as steam dome pressure and dowmcomer mass, eliminating several problems in the evaluation of other code variables.

One area which should be examined further is the potential effect on break flow of drawdown and slip in the vicinity of the flow tube inlet. Neither is : presently accounted for in the RELAP4 model but may be significantly affecting break flow. These effects may be even more pronounced in a BWR where flow exits the vessel through a 28-inch pipe. 


\subsection{Downcomer}

2.2.1 Design and Performance Considerations. The downcomer is an annular region bounded by the outer vessel wall and the core channel wall. The jet pumps are submerged in the lower portion of the downcomer. During normal operations, steam separator effluent enters the downcomer in the upper portion of the vessel and exits through the suction line and jet pump suction. Highly subcooled feedwater is introduced into the downcomer, at an elevation which separates saturated liquid from subcooled liquid.

The downcomer mixture level is initally 10 to 15 feet above the bottom of this region. As the simulated LOCA is initiated, flow out the break begins to deplete the downcomer liquid inventory. At about 10 seconds, the liquid level has fallen below the suction line elevation, where it remains for the duration of the blowdown.

2.2.2 Model Considerations. The RELAP4 bubble rise model is used in the downcomer to determine local enthalpy, bubble escape rate, and mixture level. Userspecified inputs of bubble rise velocity and a bubble gradient parameter control the calculated conditions in the downcomer region. In the TLTA analysis, the recommended

values of these parameters have been used ${ }^{[4]}$, as determined from analyses of various vessel blowdowns.

The downcomer region is modeled with two separate volumes. One represents the initially subcooled region below the feedwater sparger. The other combines the upper portion of the downcomer with the steam dome region.

2.2.3 Data Comparisons. The predicted downcomer mixture level, shown in Figure 32; agrees with the data except at the initial time and for a few seconds thereafter. This difference is due to a minor modeling anomaly related to the nonuniform cross section of the test vessel in the upper flange region. Once the level falls below this region, the experimental and predicted levels agree closely, consistent with the downcomer mass comparison. Most importantly, the level is predicted to reach the jet pump suction and recirculation loop elevations at essentially the corrcet time.

The downcomer average fluid density comparison in Figure 33 shows the RELAP4 predicted value for the region below the feedwater sparger and the volume average values calculated from the three density measurements in this region. The initial values agree quite well. However, from shortly after the break until six seconds, when the mixture level in the downcomer drops below the feedwater spargers, a discrepancy exists which is believed to be due to temperature stratification related to carryunder. From six seconds until the mixture level is near the suction line, good agreement is shown. During the time the suction line is uncovering, the discrepancy is related to the drawdown effect and the lack of a slip flow model, as discussed in Section 2.1.

2.2.4 Discussion. The primary discrepancy shown in the downcomer calculations lies in predicted density in the first six seconds. This discrepancy could affect local enthalpy and 


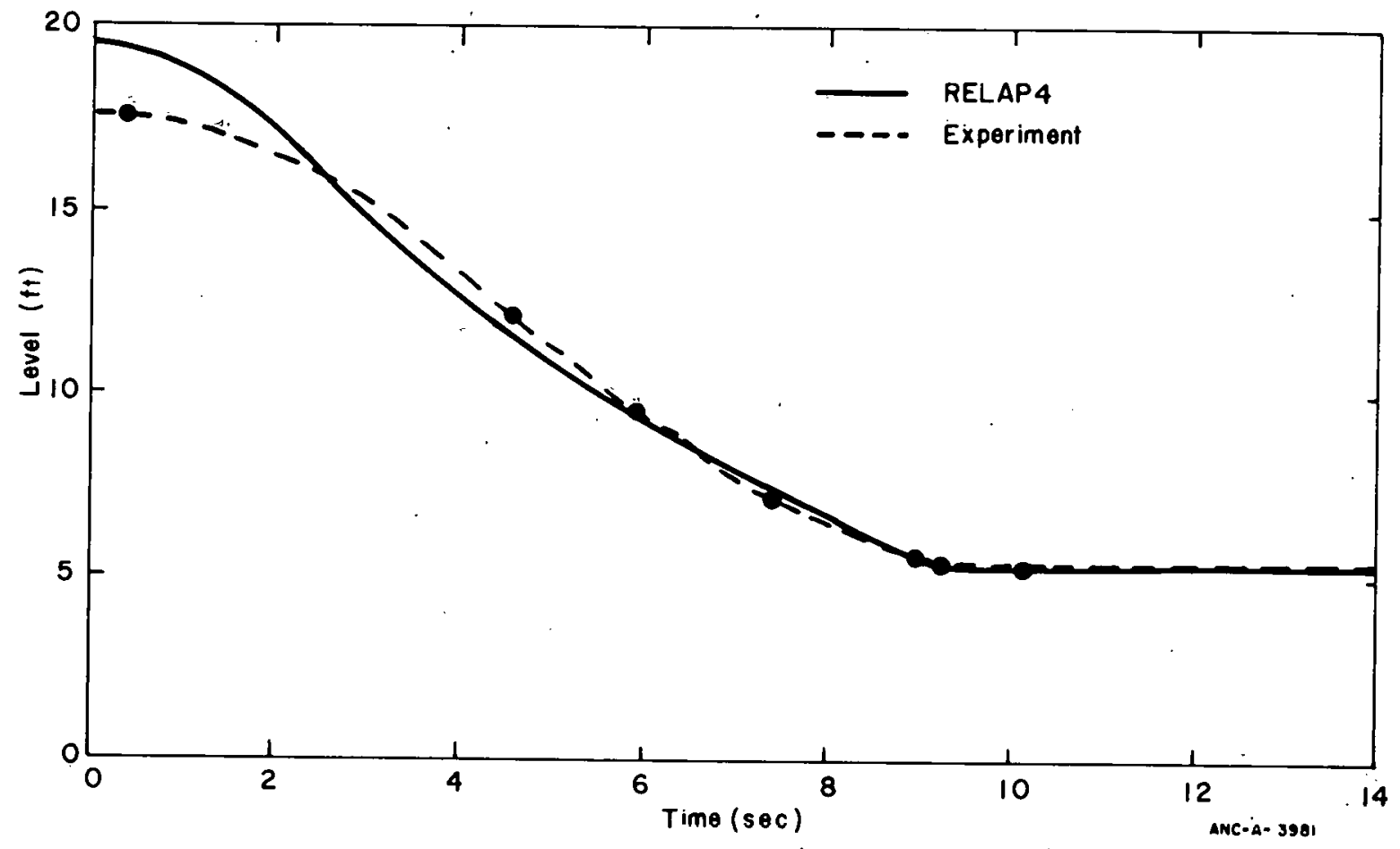

Fig. 32 Test 3 downcomer mixture level.

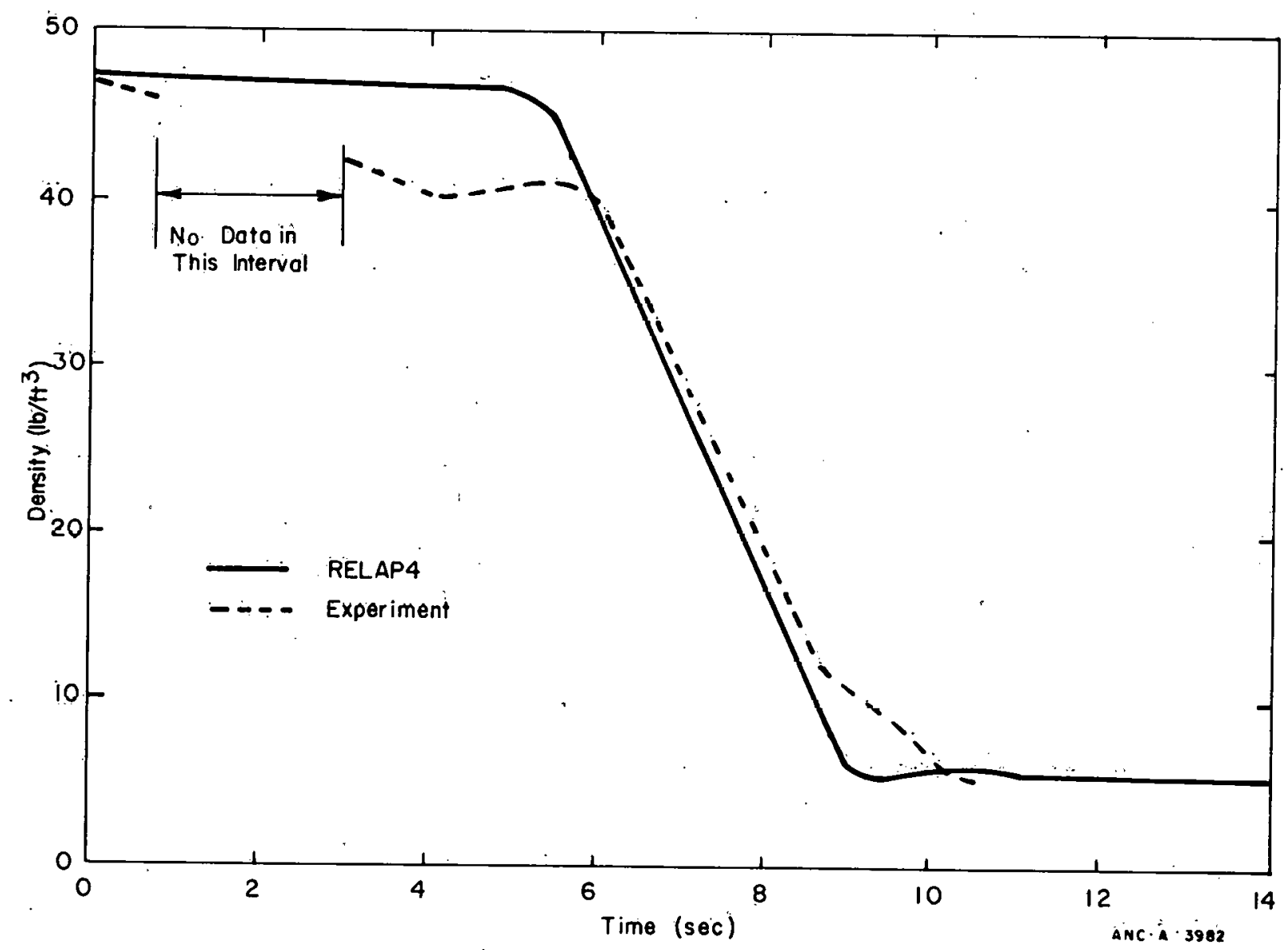

Fig. 33 Test 3 downcomér average fluid density. 
resultant flow rate calculations at the jet pump suction and flow tube inlet. The discrepancy is apparently due to unaccounted stratification in the lower part of the downcomer. It is currently believed that the calculation could be improved if more detail were provided in the downcomer model. It is recommended that follow-on studies be conducted to investigate this potential by additional volumes in this region.

\subsection{Recirculation Pump}

2.3.1 Design and Performance Considerations. Both the broken and intact loop BWR recirculation pumps are simulated in the TLTA. The broken loop pump is valved off and isolated from the system in the initial part of the transient to protect it from potential damage. Therefore, only the intact loop pump is of significance for model evaluation.

The intact loop drive pump is a horizontally mounted, high pressure, single stage, centrifugal pump with a 3-inch-diameter inlet and 1-1/2-inch-diameter discharge. The impeller is 13 inches and consists of three vanes.

The TLTA pump performance is compared to performance of a typical BWR pump in Table IX.

TABLE IX

TLTA AND TYPICAL BWR RATED PUMP PERFORMANCE

\begin{tabular}{|c|c|c|}
\hline Parameter. & TLTA & BWR \\
\hline Head ( $f t)$ & 680 & 600 \\
\hline Flow (gpm) & 140 & 47,000 \\
\hline Speed (rpm) & 3,550 & 1,700 \\
\hline Epccific speed & 320 & 3,000 \\
\hline
\end{tabular}

The TLTA pump has a shorter coastdown time than its BWR counterparts. To better simulate the BWR pump, a flywheel is attached to the TLTA pump shaft. As a result, the TLTA pump coastdown time constant is about seven seconds, which is believed consistent with the BWR pumps. Pump power is tripped at the onset of the LOCE which results in an exponential decay of the pump output.

2.3.2 Model Considerations. Single-phase pump performance curves were obtained from United Centrigal Pumps and converted to the standard, four-quadrant, homologous curves for use in RELAP4. Two-phase effects are accounted for through use of Semiscale-derived degradation curves. 
2.3.3 Data Comparison. Measured intact loop pump flow is compared to that predicted by RELAP4 for Test 6 in Figure 34. Pump speed and head for Test 3 are. compared in Figures 35 and 36, respectively. The RELAP4 prediction of all three variables agrees quite well with the test data until shortly after lower plenum flashing. At this time, the RELAP4 calculation is affected by a check valve which was used to stop flow through the jet pump drive line. This. valve has been included in recent models as an interim correction to a jet pump modeling problem. This point is discussed further in the next section. The closing of this valve adversely affects the predicted recirculation pump performance, and comparison with data beyond this time is precluded. However, it appears the recirculation pump model would provide a reasonably accurate prediction if not affected by the jet pump model.

2.3.4 Discussion. It is concluded from this evaluation that the RELAP4 pump model provides a reasonable prediction. It is recommended, however, that this comparison be repeated when an improved jet pump model is provided in RELAP4.

\subsection{Jet Pumps}

2.4.1 Design and Performance Considerations. Each of the two TLTA jet pumps is scaled to simulate 10 BWR jet pumps, representing the broken and unbroken loops, respectively. The TLTA jet pump is about 3-1/2 feet long with a tail pipe diameter of 2-1/2 inches. In comparison, the BWR jet pump height is 19 feet with a tailpipe diameter of about 20 inches.

Flow in both jet pumps is initially in the nominal direction, with the drive flow inducing additional liquid from the downcomer, with the mixture discharging into the lower plenum. During the LOCE, this flow pattern is maintained for several seconds in the intact loop jet pump. Eventually, as the drive pump output drops to zero, flows are expected to reverse in the intact loop. Flows are expected to quickly reverse in the broken loop jet pump as liquid is drawn up through the jet pump to the drive line side of the simulated break. Choking is expected at the drive nozzle, which is the minimum area point of this flow path to the pressure suppression system.

2.4.2 Model Considerations. The jet pump is modeled with the RELAP4 two-stream mixing model. This model utilizes a mixing region to allow mixing of two parallel flow streams, such as at the jet pump suction. Several forms of the model are provided to allow solutions for conditions of normal flow in the jet pump, as well as for situations where flow is reversed at any or all of the jet pump flow junctions.

\subsubsection{Data Comparison.}

(1) Intact Loop Jet Pump. The predicted intact loop jet pump flow is compared to Test 1 flow data in Figure 37. The predicted jet pump flow is similạr to but slightly less than the test data through lower plenum flashing. RELAP4 correctly predicts the sharp flow decayas the jet pump suction uncovers. At lower plenum flashing, fluid is forced up into the jet pump resulting in a momentary jet pump flow reversal. This effect is also observed in the RELAP4 calculation. 


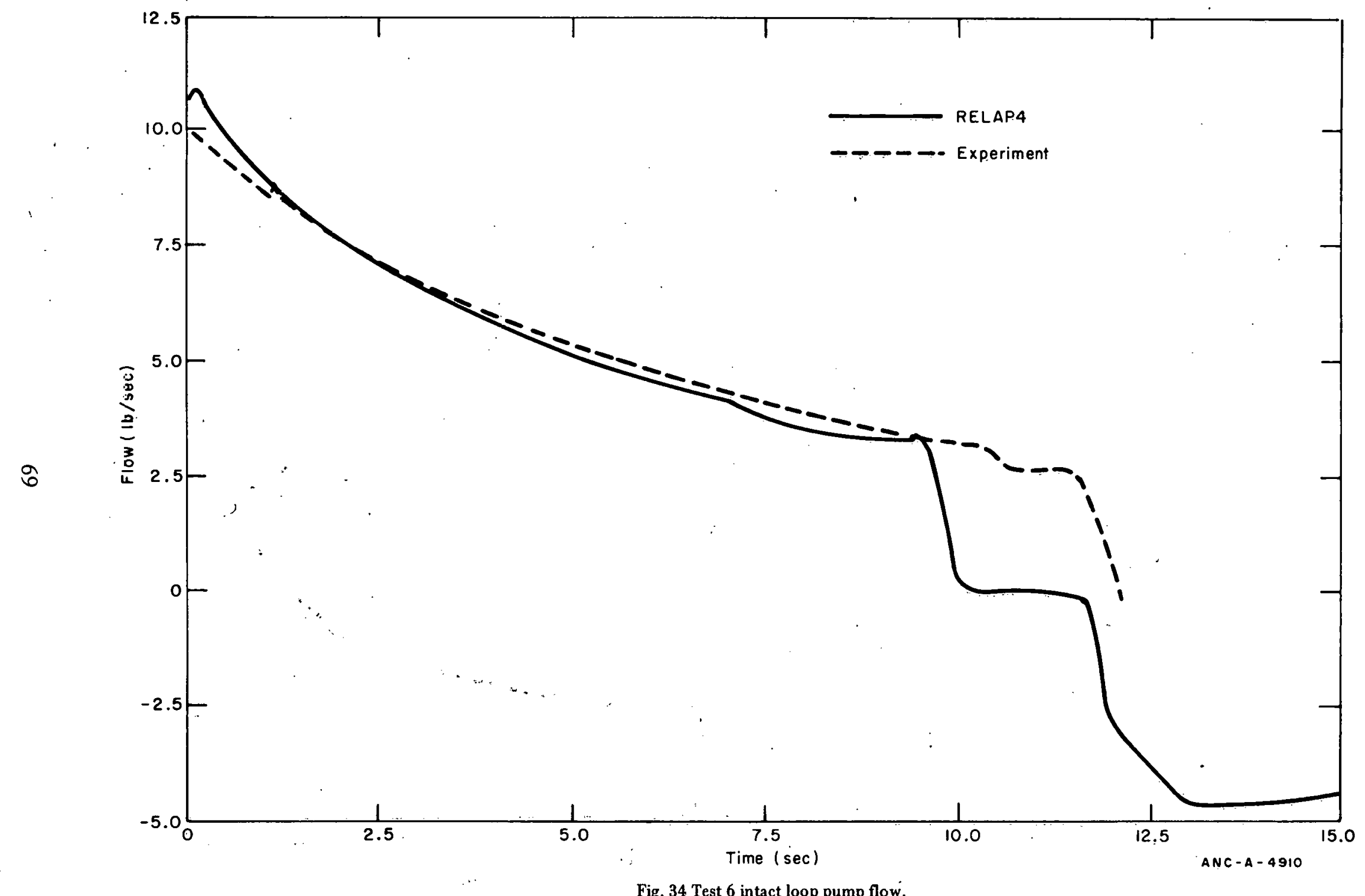

Fig. 34 Test 6 intact loop pump flow. 


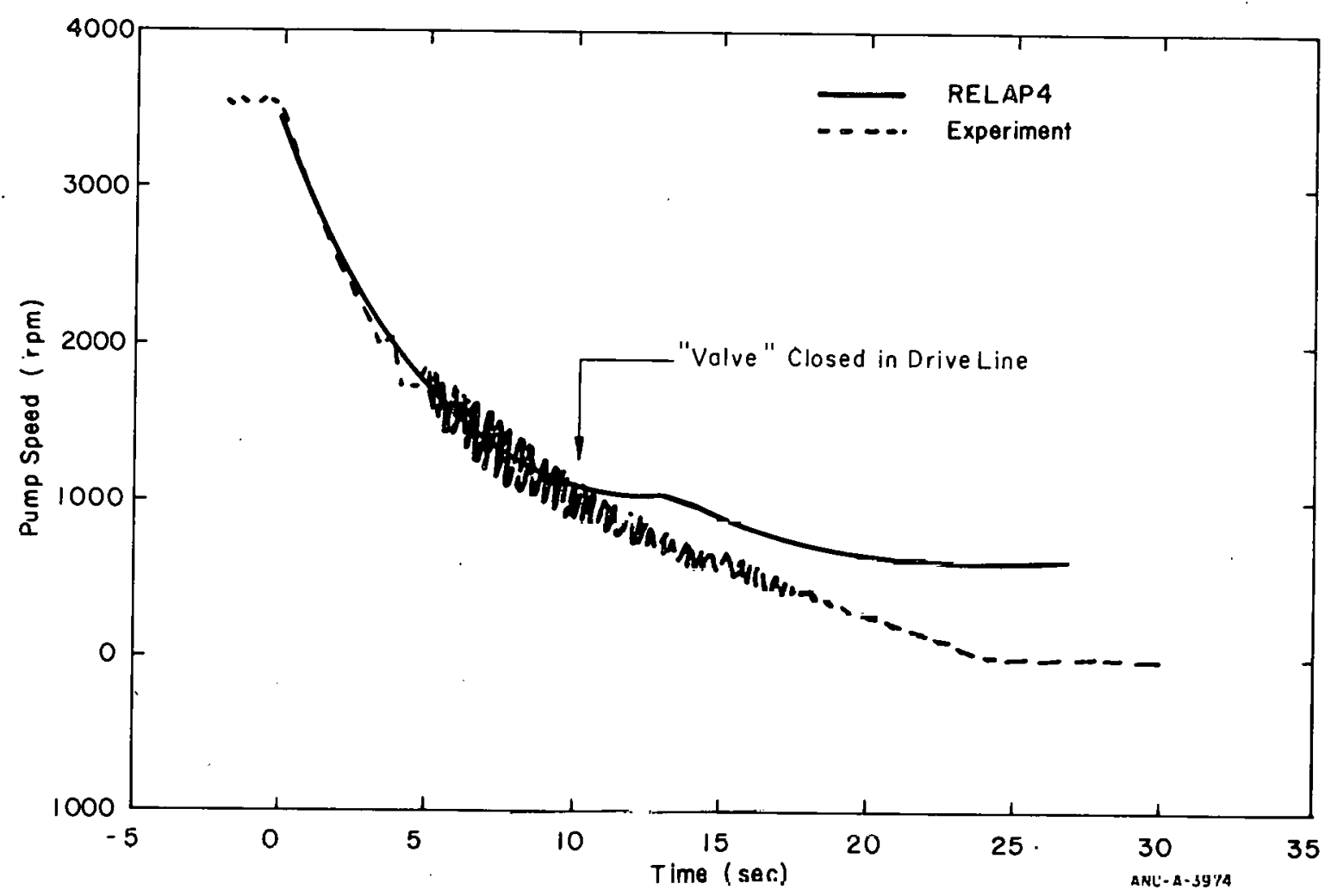

Fig. 35 Test 3 intact loop pump speed.

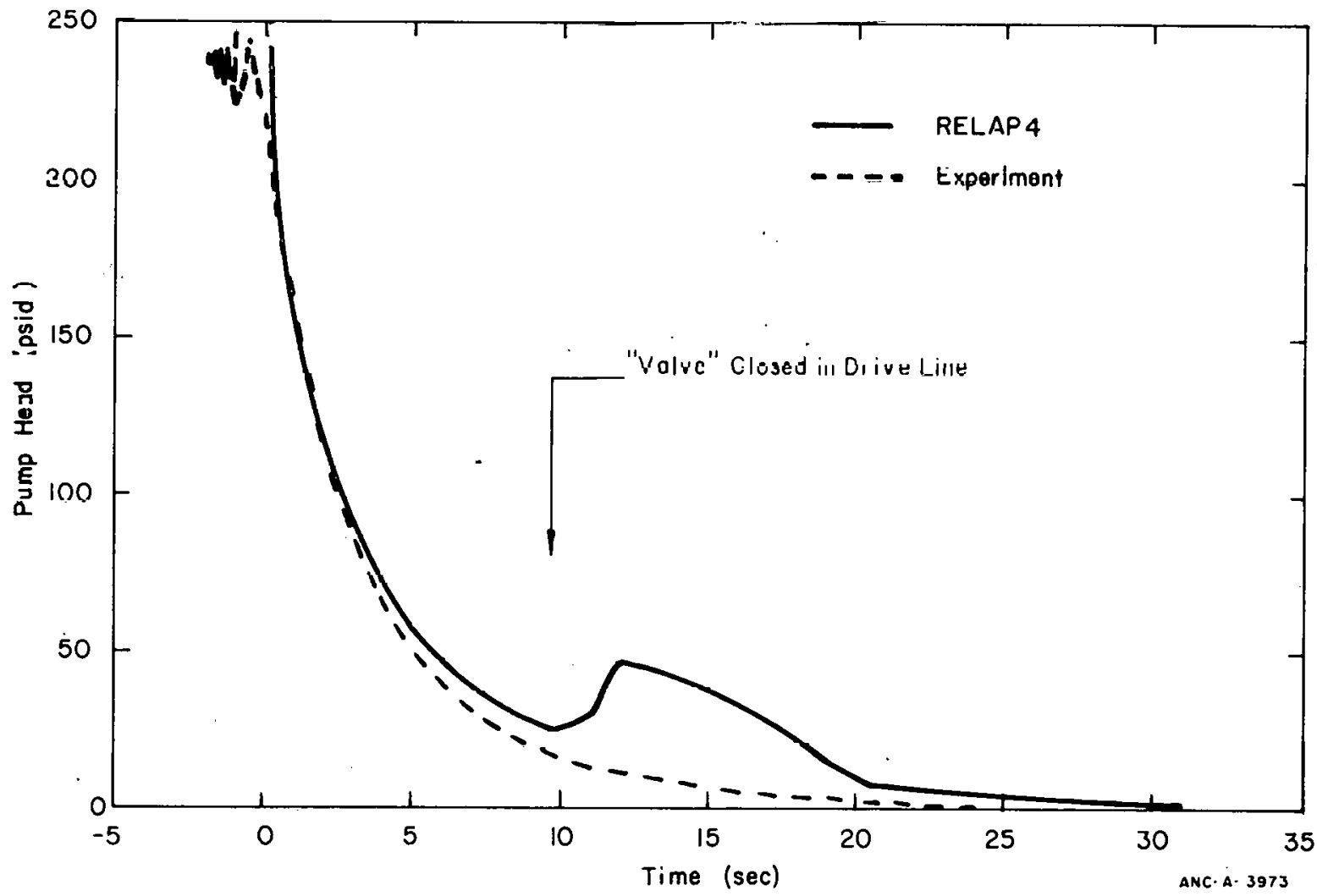

Fig. 36 Test 3 intact loop pump head. 


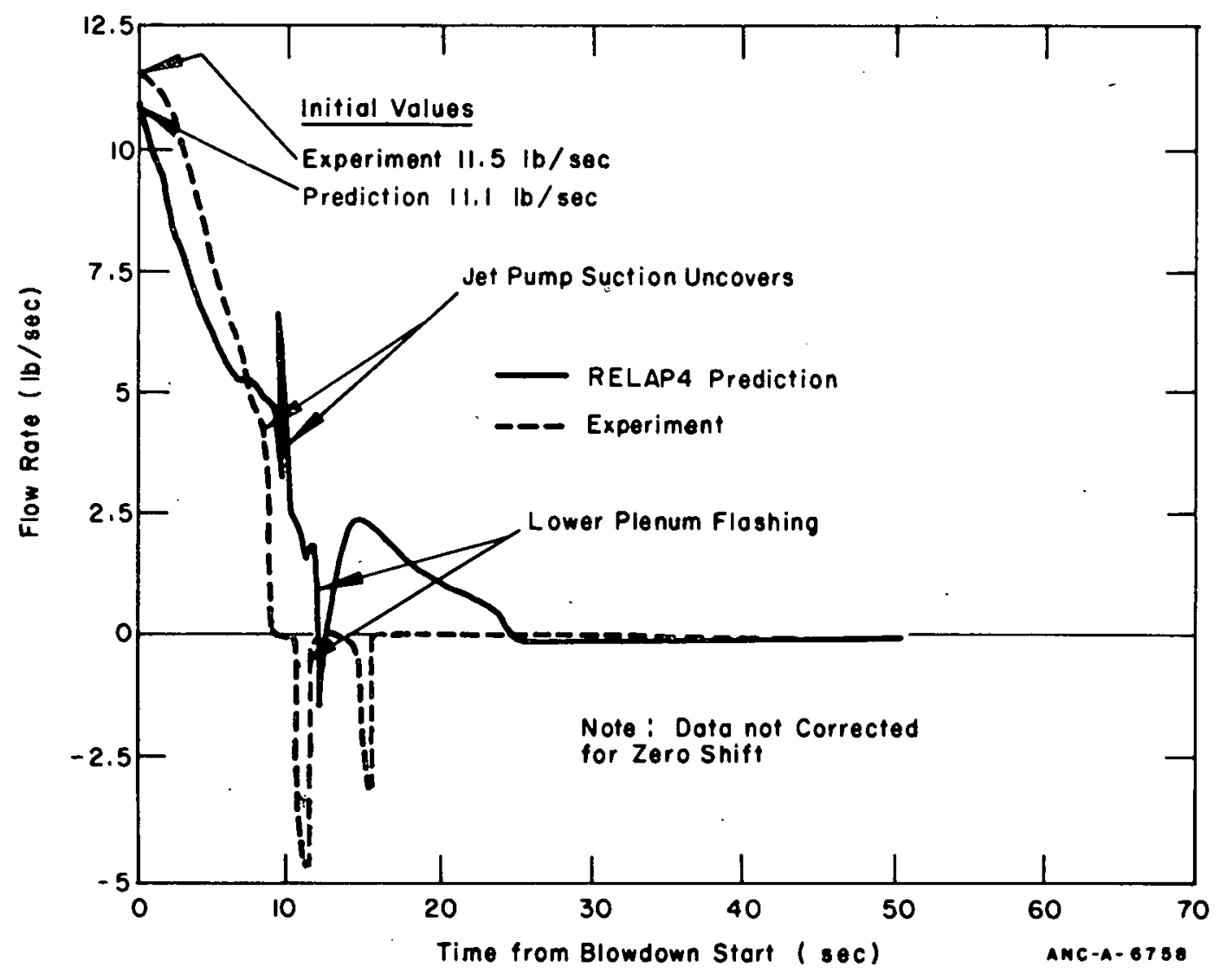

Fig. 37 Test 1 intact loop jet pump flow rate.

Following lower plenum flashing, the measured flow appears to recover from the flow reversal and stabilizes near zero. The predicted flow reverses again to a relatively high positive jet pump flow rate at this time. The difference between the predicted intact flow and the test data after lower plenum flashing suggests that a problem exists in the RELAP4 two-stream mixing model. This problem appears to be tied to flow reversals and off-design conditions in the jet pump. At the onset of the problem, RELAP4 has predicted the occurrence of a flow reversal and selected an alternate form of the two-stream mixing model.

In subsequent analyses, it was discovered that this jet pump problem is propagated through the system calculation, resulting in an overprediction of core flow in the postflashing period. The successful diagnosis of potential modeling problems in the core was thus precluded. To overcome this problem on an interim basis, a user-specified "fix" to the jet pump was developed. This "fix" required the use of a RELAP4 check valve at the jet pump drive nozzle, set to isolate the jet pump from the drive loop when flow reversed in the jet pump.

This approach was used in the Test 3 and 6 calculations. The results of this calculation for Test 6 are compared to Test 6 data in Figure 38. Up to lower plenum flashing, the 


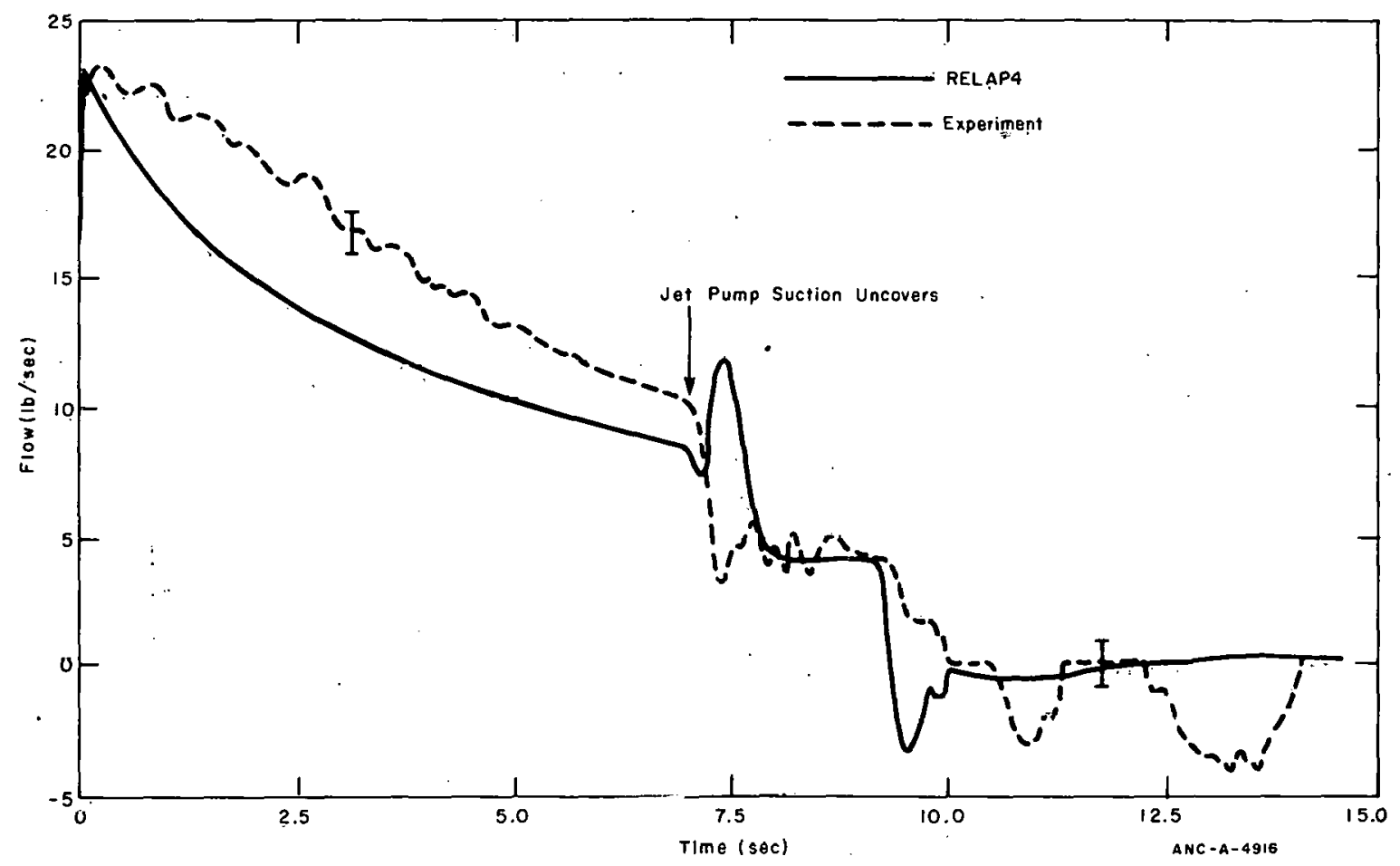

Fig. 38 Test 6 intact loop jet pump flow rate.

results are very similar to the Test 1 comparison. Following flashing, the use of the check valve in Test 6 is observed to correct the flow rise observed in the Test 1 calculation.

(2) Broken Loop Jet Pump. Figure 39 presents a comparison of the RELAP4 prediction and data from Test 3 for flow through the hroken loop jet pump. RELAP4 is observed to correctly predict the early flow reversal as liquid is drawn from the lower plenum to the broken loop jet pump drive nozzle. The magnitude of the reverse flow is overpredicted up to the time the suction line uncovers. Following suction line uncovery, the reverse flow is underpredicted. The reasons for these apparent problems are not presently clear. The possibility exists that, as shown for the intact loop, some problems may be present in the basic jet pump model under off-design flow conditions. It is also possible that the prediction of jet pump flow is being adversely influenced by calculated conditions in the lower plenum. Additional comparisons, with improvements made to other portions of RELAP4, are indicated to complete the diagnosis of this component.

2.4.4 Discussion. Some problem areas are indicated in the calculations of flow in the TLTA jet pumps. While flows appear to be well predicted during normal flow conditions, the trends and accuracy of off-design calculations are not considered satisfactory. Additional work is recommended to thoroughly review the two-stream mixing model under off-design conditions. Separate calculations with the jet pump model isolated from the system model and driven by experimental boundary conditions are also recommended to further diagnose problems in the two-stream mixing model approach. 


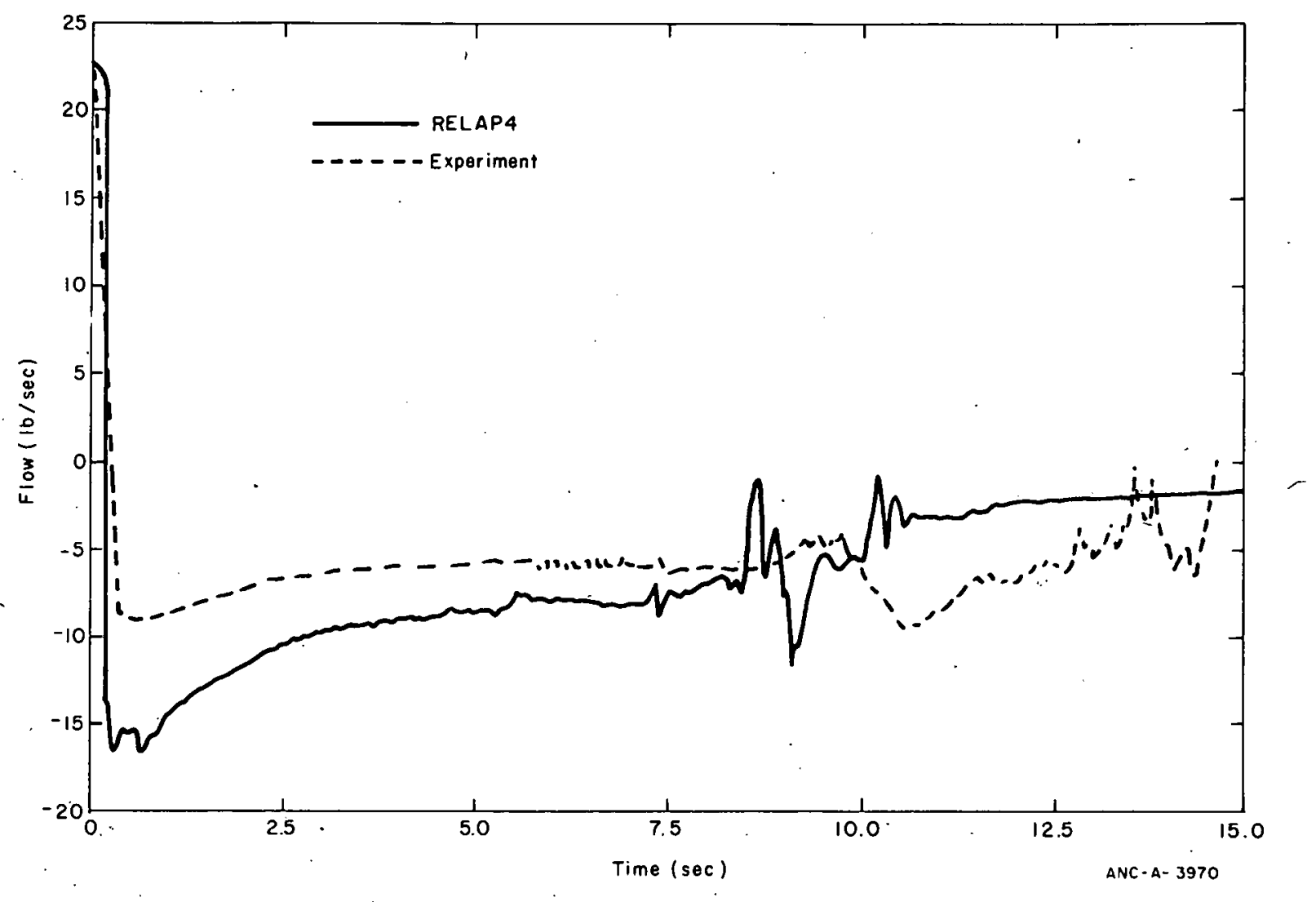

Fig. 39 Test 3 broken loop jet pump flow rate.

\subsection{Lower Plenum}

2.5.1 Design and Performance Considerations. The TLTA lower plenum is constructed of a 16-inch-diameter pipe, about 3-1/2 feet deep. Four guide tube simulators are enclosed in this region, occupying about $50 \%$ of the lower plenum volume. The two jet pumps discharge into the lower plenum at the top. The core and guide tube inlet orifices are about one foot below the top of the lower plenum.

Initially the lower plenum is filled with subcooled water. As the system depressurizes, the conditions approach the saturation point. Flashing generally occurs in the lower plenum when the system depressurization rate accelerates after the suction line uncovers and quality develops rapidly in this region. Following the short-lived flow surge due to flashing, the lower plenum fluid remains in a two-phase state and continues to boil, venting through the core and jet pumps.

The TLTA lower plenum geometry is substantially different from that of the BWR. Those differences that are most significant include the lower plenum depth and relative elevations of the jet pump exhaust, core inlet, and guide tube inlet. These differences may have some influence on TLTA lower plenum performance with respect to the BWR. 
2.5.2 Model Considerations. As in the downcomer region, the RELAP4 bubble rise model is used to determine local conditions in the lower plenum. A single fluid volume is used to represent this region. Nominal bubble rise parameters have been specified in the lower plenum calculations to date.

2.5.3 Data Comparisons. In Figure 40 the predicted density at the core inlet is compared with the measured density from Test 3 . The predicted density is observed to drop at about 8.5 seconds when lower plenum flashing occurs. The measured density is not presented during the flashing period as it is adversely biased by fluid acceleration effects. Immediately after lower plenum flashing, the predicted density is about $5 \mathrm{lb} / \mathrm{ft}^{3}$ lower than the test data. The uncertainty of the measurement is about $\pm 3.5 \mathrm{lb} / \mathrm{ft}^{3}$ in this time period. After about 20 seconds, the predicted density converges within the density measurement uncertainty.

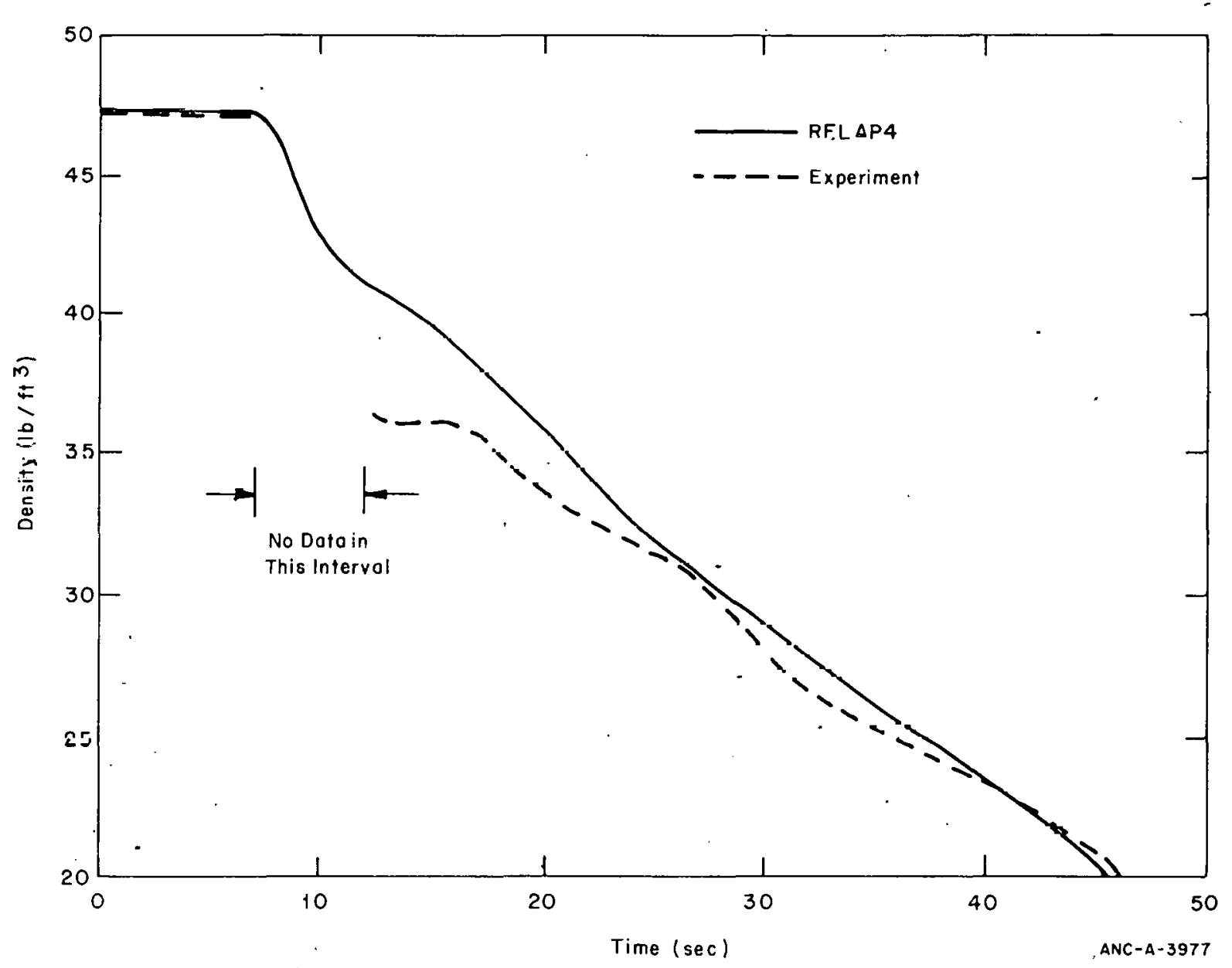

Fig. 40 Test 3 bundle inlet density. 
The predicted lower plenum volume average density is compared to an equivalent experimental density in Figure 41. In addition, measured local densities of Nodes 1, 2, and 3 in the lower plenum are included in the figure. The predicted average density is higher than the experimental density after lower plenum flashing. During this time, there is a significant density gradient in the lower plenum as indicated by the local experimental densities. The difference between the predicted and experimental densities suggest that the single volume lower plenum representation combined with the bubble rise model used in the prediction may not provide sufficient analy tical detail for this region.

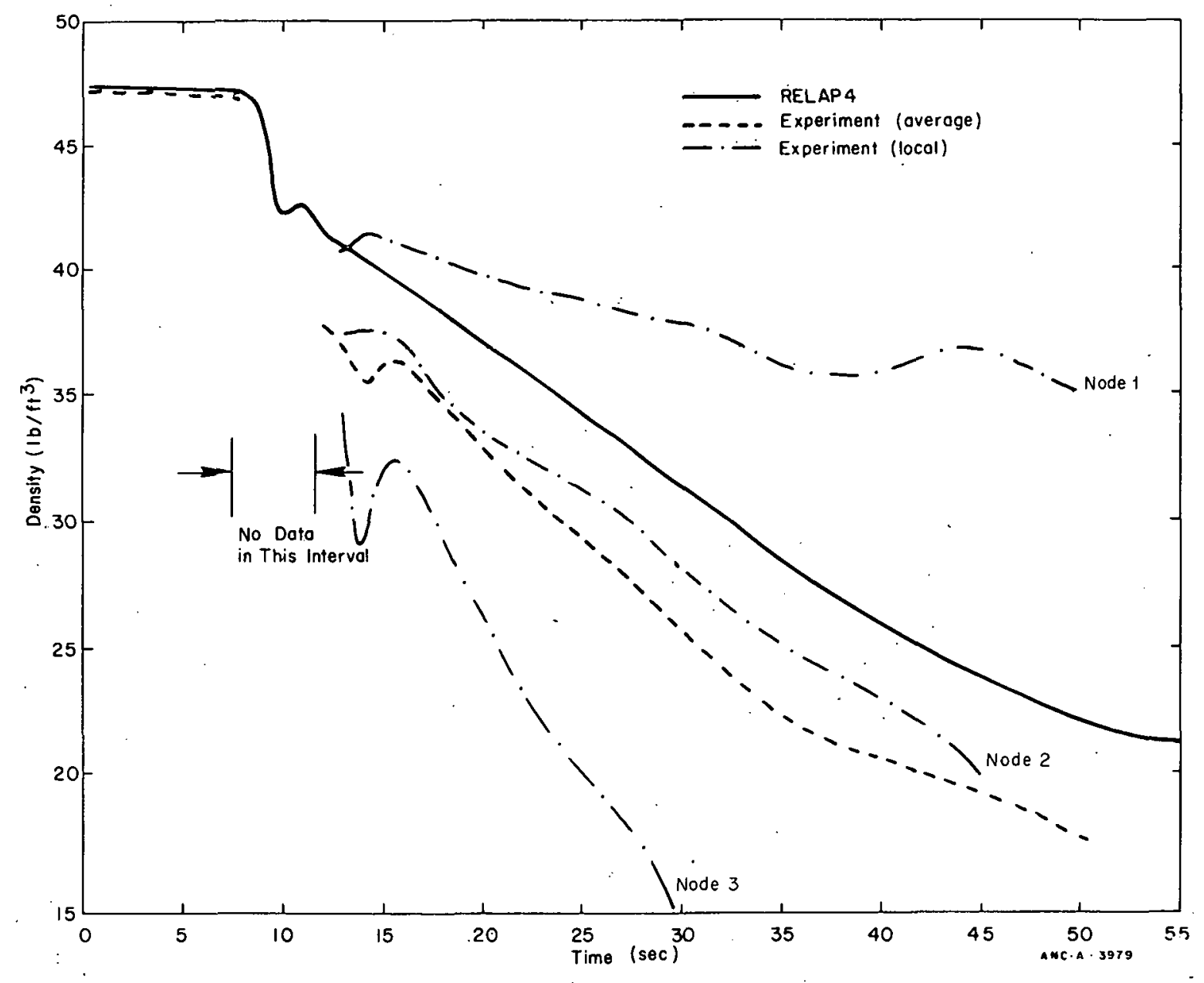

Fig. 41 Test 3 lower plenum density.

2.5.4 Discussion. These comparisons show that RELAP4 is moderately successful in predicting the trends in lower plenum thermodynamic conditions. Some discrepancies are observed in the absolute density values, however. These differences may impact calculation of flow rates out of the lower plenum which are all dependent on local conditions. Additional work is thus recommended to evaluate potential model improvements such as inclusion of more nodal detail in the lower plenum and investigation of more suitable bubble rise constants. The inclusion of slip in this region may also offer a potential model imp rovement. 


\subsection{Core}

2.6.1 Design and Performance Considerations. The TLTA heater rod bundle simulates a single, $7 \times 7$ rod BWR fuel bundle. Geometrically, the simulation is quite close, with exact TLTA reproduction of BWR rod diameter, pitch, and length. BWR decay heat and stored heat conditions are simulated in the TLTA directly heated rods by programming an appropriate electrical power decay rate. Typical BWR radial and axial peaking factors are both included in the TLTA bundle design.

Flow normally enters the bundle at the bottom in a subcooled condition and exits the bundle at the top with moderate quality (10 to $25 \%$ ) which depends on the total bundle power level. During a typical LOCE, bundle flow immediately drops to 25 to $50 \%$ of rated flow as broken loop pumping action is lost. Thereafter, flow decays gradually as maintained by the intact loop pump until lower plenum flashing occurs. Flashing results in a momentary restoration of core flow, which lasts for several seconds. Following this event, all pumping action has ceased, and only a low residual flow is maintained by fluid boil-off . from the lower plenum.

Heat transfer within the bundle can vary from well-cooled, nucleate boiling conditions to nearly zero heat flux. The occurrence of thermal transitions between these modes depends on time, flow conditions, and bundle position. Resultant rod temperatures are quite varied and require detailed interpretation.

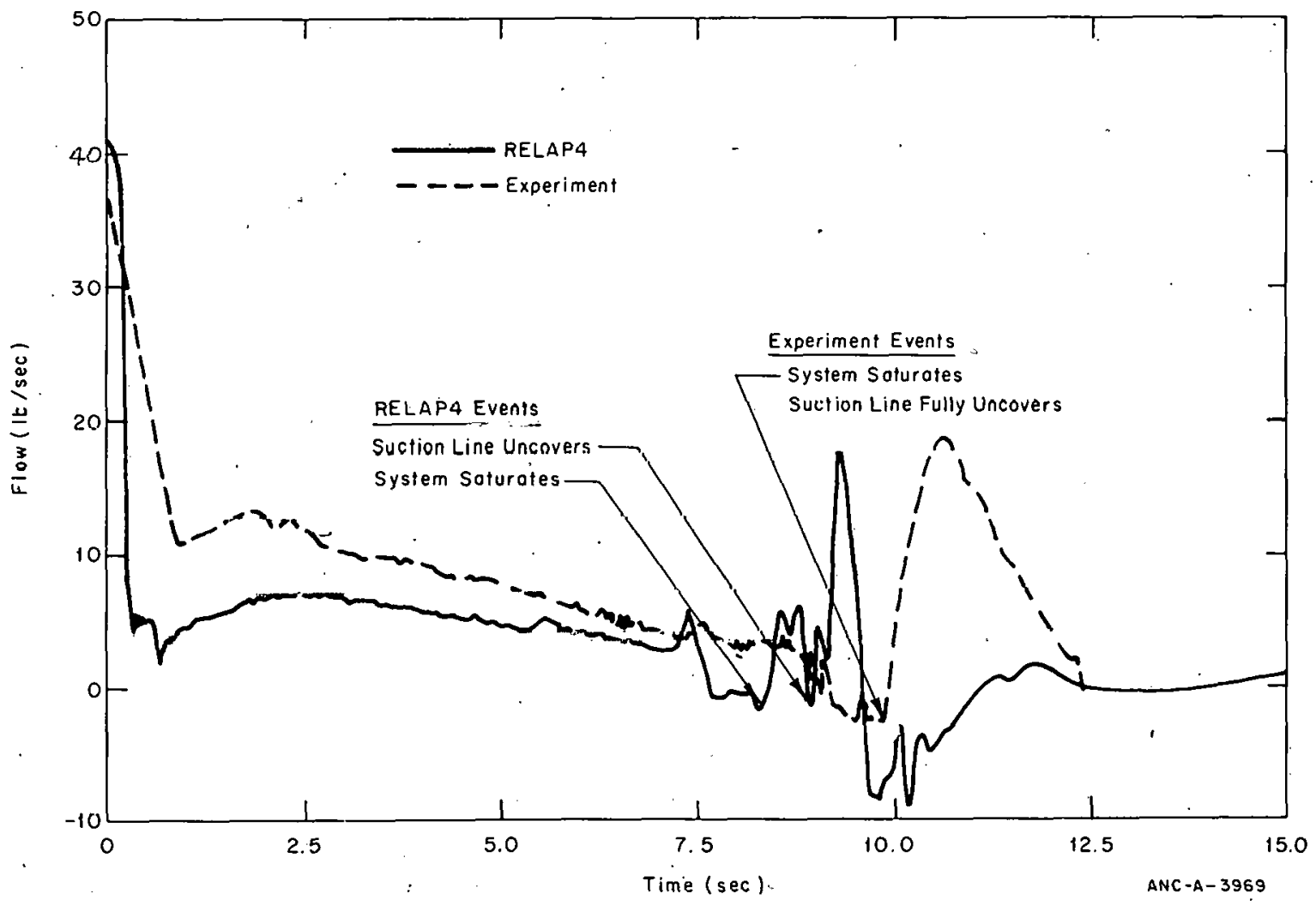

Fig. 42 Test 6 bundle flow rate. 
2.6.2 Model Consideration. As described in Section 1.2 a separate model was developed for the TLTA bundle. The model employs the basic RELAP4 conservation equations in one dimension. Two-phase friction effects are treated through qualitydependent multiplicrs. Heat excharige between the bundle and fluid is accounted for by the RELAP4 heat transfer model. This model includes logic to select one of nine separate heat transfer regimes which depend on the instantaneous flow and fluid conditions adjacent to the heater rods. Internal rod heat transfer is accounted for through one-dimensional, finite-element radial conduction models.

2.6.3 Data Comparisons. The core flow rate is compared to the Test 6 data in Figure 42. The rapid initial drop in core flow is successfully predicted by RELAP4. Following this drop, the experimental flow rate is significantly higher than that predicted during most of the initial nine seconds of the transient. RELAP4 predicts that lower plenum flashing begins at about nine seconds, and its effect is seen in the core by the flow rate spike which lasts less than one second. The measured flashing effect on core flow starts shortly after nine seconds, but rises at a slower rate and is sustained over a longer period than is predicted by RELAP4. Following the flashing period, the measured flow subsides to a near zero value, below its resolution threshold, which precludes further meaningful comparisons with the prediction. Generally, the prediction hovers between 0 and $2 \mathrm{lb} / \mathrm{sec}$ in the postflashing period, which is within the measurement accuracy limits. In attempting to determine the causes of the differences in core flow calculations, it must be recognized that the core is subject to influences propagated throughout the system from other components. Comparisons of jet pump flows, suction line uncovery time, and lower plenum parameters have shown potential inconsistencies in the modeling of these regions. It is presently believed that the fundamental flow model of the core is essentially correct and that the core flow anomalies are produced by the problems in other portions of the model. In turn, these core flow problems potentially contribute to inaccuracies in calculation of heater rod temperatures.

Figure 43 presents the comparison of a typical thermocouple from $\Gamma$ est 1 with a corresponding RELAP4 prediction. This prediction was made with the overall system model, rather than the detailed core model developed for Tests 3 and 6 . The obvious difference between the data and prediction is due to an early prediction of a CHF condition by RELAP4. CHF is not observed in the data until much later in the transient when the core dries out. This unrealistic result is partly due to the underprediction of core flow by the code. The primary cause, however, is believed to lie in the CHF correlation. RELAP4 uses a correlation developed by Barnett $[27]$ which is believed to be conservative under the flow, pressure, and enthalpy conditions encountered at the time of the predicted CHF.

To provide a more reasonable calculation on an interim basis, the Barnett correlation was bypassed in RELAP4, and the core was allowed to dry out and go into a film boiling condition when. local quality exceeded $95 \%$. The results of this approach are shown in Figures 44,45 , and 46 for three typical locations on high-power rods in Test 3. 


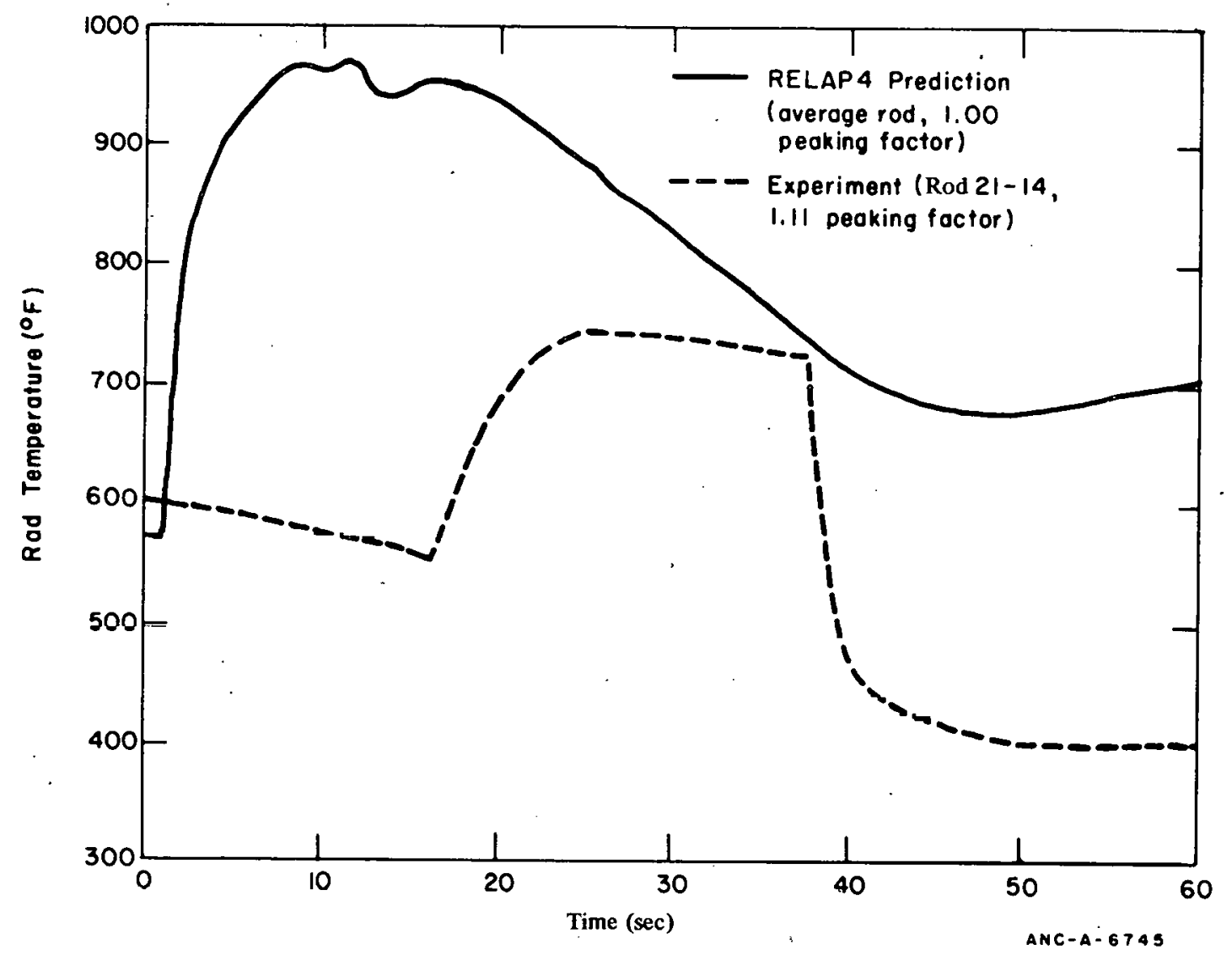

Fig. 43 Test 1 heater rod temperature.

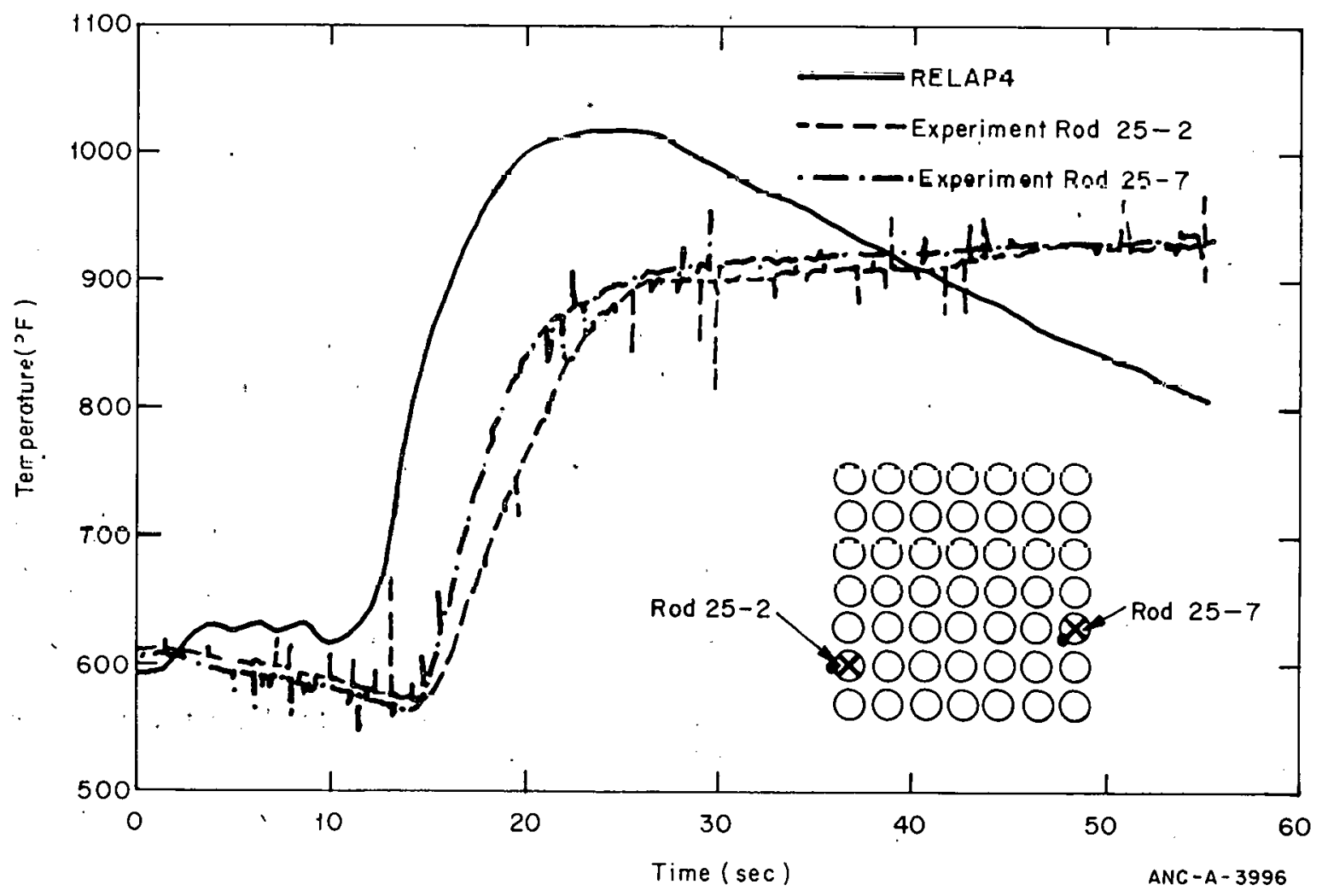

Fig. 44 Test 3 heater rod temperature -71 -inch elevation. 


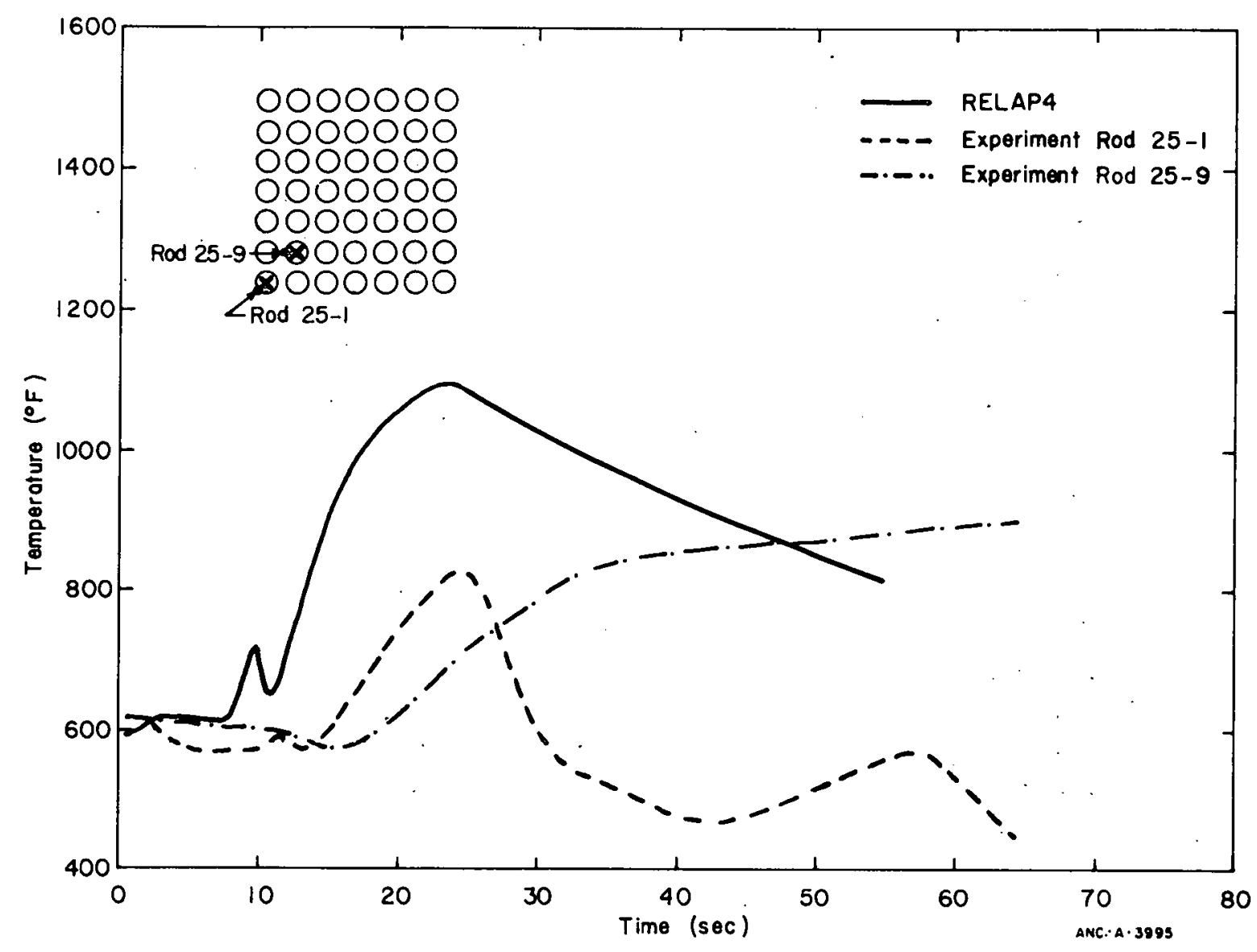

Fig. 45 Test 3 heater rod temperature -98 -inch elevation.

The results show a more realistic temperature response prediction; however, significant differences are still observed in the comparisons.

Several notable effects are observed in the comparisons of predicted and actual rod temperatures:

(1) Shortly after initiation of the transient, a minor rise is observed in predicted rod temperature. This rise is not seen in the thermocouple data. It occurs as RELAP4 changes from a nucleate boiling condition to the "forced convection vaporization" mode (which is based on a correlation developed by Shrock and 'Grossman [28]) where heat transfer is slightly reduced from the nucleate boiling case. This trend is believed to be tied to the underprediction of core flow in this time period. 
(2) The rapid rise in rod temperature associated with core dryout always occurs earlier in the prediction than in the TLTA. In cases where this dryout is predicted before flashing (Figure 46) the low predicted core flow is believed responsible for the discrepancy. When dryout is correctly predicted to occur after lower plenum flashing (Figures 44 and 45), it is still earlier than in the test. This follows from the earlier predicted decay of flow as lower plenum flashing subsides.

(3) The peak temperatures predicted after dryout are always higher than in the experiment. This trend is due to the earlier predicted dryout, which results in a higher power level and stored energy content of the rod at the time of dryout.

(4) Following the temperature peak, the predicted temperatures show a gradual cooling trend not observed in the data. During this period, the RELAP4 heat transfer logic has selected the pool film boiling mode, which is based on a correlation developed by Berensen [29]. Additional work is required to complete the diagnosis of this problem area. Possible causes include an improper core flow prediction or nonapplicability of Berensen's correlation.

Local effects are most obvious in these high-power rod data. The temperature at the axial midpoint of Rod 25-7 (shown in Figure 44) rises rapidly at 15 seconds, levels off at about 26 seconds, and rises slowly through the remainder of the transient. As shown in Figure 46 , at 47 inches above this point, this same rod shows a small temperature increase and then appears to rewet at least twice. This behavior, which occurs in many areas in the core, is attributed to fallback of liquid from the upper plenum, rewetting rods at random locations. Even with improved, multidimensional codes, it will be difficult to model this phenomenon.

Also shown in Figure 46 are the temperatures of two thermocouples on a single rod (Rod 25-9) at the same elevation. They are separated circumferentially by 90 degrees. 'The difference between the time at which the temperatures rise sharply is about two seconds. It is also noteworthy that these two thermocouples have significantly different temperatures until about 42 seconds after the beginning of the transient. This indicates slgnificant radial effects, either in the rod or in the local thermal boundary conditions.

The effect of radial rod location is also evident in the experimental data. In both Figures 44 and 45 , rods with identical powers but located in different bundle positions exhibit significant differences in temperature history.

2.6.4 Discussion. Although the RELAP4 core model predictions are encouraging, additional effort is required to improve the calculations. It is believed that many of the 


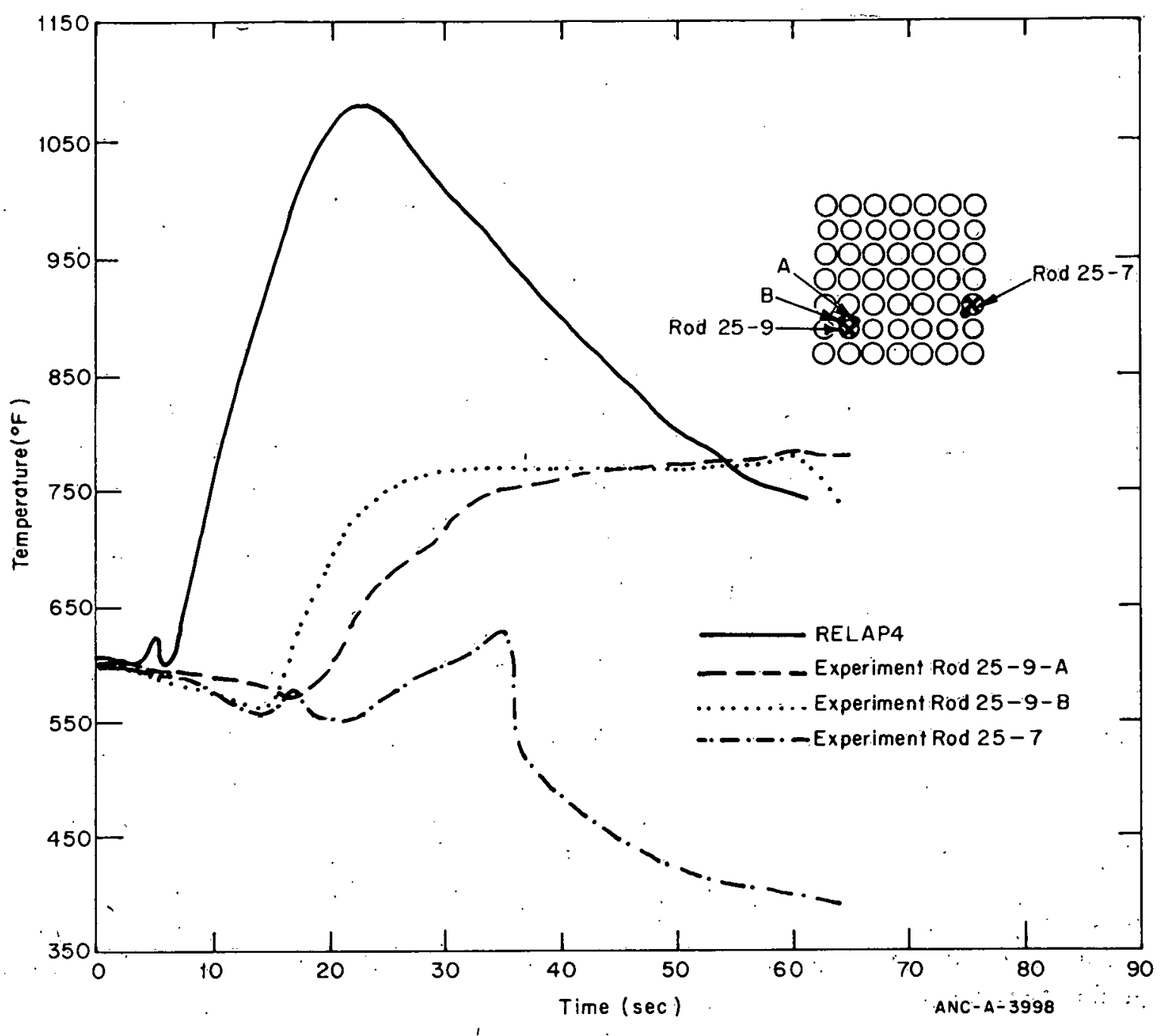

Fig. 46 Test 3 heater rod temperature - 118-inch elevatịon.

problem areas were propagated into the core model from other regions of the TLTA system. The core model should be separated from the system calculation and driven with experimental boundary conditions to remove these influences.

It is further noted that several changes to the RELAP4 heat transfer model have been proposed in forthcoming best estimate versions ${ }^{[26]}$ of the code. These changes may include the substitution of more appropriate heat transfer relationships in place of the Shrock and Grossman, Barnett and Berensen correlations discussed in Subsection 2.6.3.

The experimental evidence of fallback into the bundle and the three dimensionality of bundle phenomena indicate the need for improved model detail. This potential is offered by the slip option which has been implemented in RELAP4 and three-dimensional core codes currently being developed under NRC sponsorship. 


\section{CONCLUSIONS AND RECOMMENDATIONS}

The results of this data comparison have provided an initial assessment of the capability of the code. From these comparisons, guidance is obtained for planning future RELAP4 development and verification activities. Successful completion of the next phase will require a systematic evaluation and correction of various problems indicated by this comparison in the RELAP4 code and user methodology.

The overall accuracy of the RELAP4 calculation can be expressed in terms of heater rod temperature. The model is shown to overpredict Test 3 peak rod temperature by 200 to $400^{\circ} \mathrm{F}$. The peak occurs shortly after bundle dryout in the prediction but is usually observed at the end of blowdown in the experiment. The model is shown to underpredict the temperature of some rods at the end of blowdown. The temperature level at this time is especially important because it influences subsequent bundle behavior during the core spray, reflood, and refill periods of the LOCA.

These discrepancies. would have been even greater if the RELAP4 CHF logic had not been bypassed, the jet pump drive flow had not been altered after flashing, and the break flow calculations had not been adjusted to fit 'Test 3 experimental break flow.

No primary cause of the data-prediction mismatch on bundle temperature is apparent. Rather, the mismatch is believed to result from an accumulation of relatively small anomalies, each having an important impact on system and bundle performance. Many of these problem areas are readily identified; however, some are masked by complex thermal-hydraulic interactions between components in the TLTA and will require additional studies to isolate causes and determine corrective actions.

Table $X$ presents the findings of this comparison for major components within the TLTA. Included in the table are a synopsis of the analytical model used for each component, a summary of the data comparison, and conclusions reached from the study. On the basis of these results; a number of recommendations for future work are made. Specifically, studies are suggested in the following areas:

(1) Bundle flow and heat transfer

(2) Separation effects in vertically oriented volumes

(3) Jet pump performance

(4) Horizontal slip and drawdown

(5) Critical flow

(6) Wall heat transfer. 
These recommendations should be used as a guide for the NRC as well as ANC in setting priorities and defining BWR safety analysis activities in the future. The recommendations cover code development needs, model verification tasks, and improvements required in the experimental measurements. 
OVERVIEW OF RELAP4 COMPARISONS WITH TLTA DATA

\begin{tabular}{|c|c|c|}
\hline Component & RELf 34 Model Iescripticn & Summary of Comparison \\
\hline Core & $\begin{array}{l}\text { Single channel and average poiser rods usec } \\
\text { to simulate bundle in system calculation. } \\
\text { ingle, closed channel and singie. rod used } \\
\text { in separate caiculation of indlvilual rod } \\
\text { performance. CHF logic bypa:ssed to avald } \\
\text { early, unrealfistic CHF. }\end{array}$ & $\begin{array}{l}\text { Pradicted bundle flow rates are } \\
\text { less than actual through lower } \\
\text { plenum flashing. Postflashing } \\
\text { flow rates cannot be compared } \\
\text { due to data limitation. Early } \\
\text { prediction of dryout in bundle } \\
\text { results in eariy rod temperatur } \\
\text { exzursion. Peak temperature } \\
\text { pradicted was generally higner } \\
\text { than observes. Postdryout tem- } \\
\text { perature predictions show cool- } \\
\text { ing trend not observed in data. } \\
\text { Predicted temperature at end of } \\
\text { blovdown was generally lower } \\
\text { than observed. }\end{array}$ \\
\hline
\end{tabular}

\begin{tabular}{|c|}
\hline ct cause of cata-prediction \\
\hline 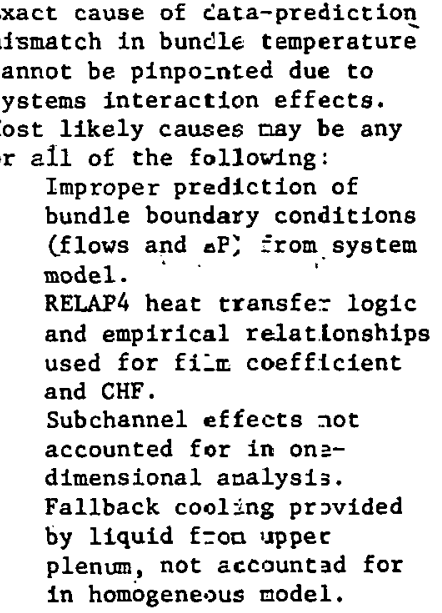 \\
\hline
\end{tabular}
The comparisons should be repeated when the bestestimate version of the code becomes avallable, driving the bundle model with experimental (rather than predicted) boundary conditions. Calculations should also be made to investigate potential benefits of using a separation model with slip in the core.

GE should consider alternate methods for provision of postdryout bundle flow of postdryout bundle flow nosis.
Lower Both regions are nodelect with: a single Plenum volume representing average fiuld con- and ditions. Separat on ef:ects conelder Lower ed through RELAP4 bubble rise model Down- which assumes one-dimensitonal flcw. User-specified Inputs contral butble rise velocity and vertical density distribution.

In both regions, average densitg The single volune model cannot Consideration should be given is overpredicted and qual1ty is fully account for the strat1fi- to 1mproving the predictions underpredicted. Local densities cation and as a rasult, average in these regions through more at flow functions are also not and local propertles are in- detafled models and incorpoIn complete agreement with data. correctly calcula:ec at times. ration of the RELAP4 s11p This may influence calculated The errors in local density may option. The various constants flows out of these regions. blas flow rate salculations used with the bubble rise and The test data at times show a for the downcomer and lower slip models should be reviewed sigaificant stracification. plenum. witinin these regions. with some portions subcooled ard others saturated. The prediction does not allow stratification to occur.within a single velume.

-


TABLE X (contd.)

\section{OVERVIEW OF RELAP4 COMPARISONS WITH TLTA DATA}

\begin{tabular}{|c|c|c|}
\hline Component & RELAP4 Mode1 Description & Summary of Comparison \\
\hline Jet Pump & $\begin{array}{l}\text { RELAP4 contains a two-stream flow mixing } \\
\text { model which is used for jet pump analy- } \\
\text { sis. The model allows complete mixing } \\
\text { of the two streams (drive and induced } \\
\text { flow) in a separate mixing secilon, } \\
\text { where energy, continuity, and momentum } \\
\text { relationships are satisfied. Several } \\
\text { mixing opt lons are avallable for use } \\
\text { which are automatically selected } \\
\text { depending on the instantaneous direc- } \\
\text { tion of flow at the mixing functions. }\end{array}$ & $\begin{array}{l}\text { Predictions compare favorably } \\
\text { with test data where drive } \\
\text { flow, induced flow, and total } \\
\text { flow are in normal operating. } \\
\text { directions. These conditions } \\
\text { are matntained in the intact } \\
\text { loop jet pump until lower } \\
\text { plenum flashing occurs, but } \\
\text { flow reverses within one } \\
\text { second in the broken loop } \\
\text { pump. During off-design } \\
\text { flow conditions where flow } \\
\text { has reversed at one or more } \\
\text { junctionsing the jet pump, } \\
\text { the predictions and data gen- } \\
\text { erally do not agree. These } \\
\text { anomalies in predicted fet } \\
\text { pump behavior in both loops } \\
\text { are believed to affect flow } \\
\text { rates in other reglons of } \\
\text { the TLTA. }\end{array}$ \\
\hline
\end{tabular}

Recircula- The centrifugal pump interaction with tion Pump system fluid is accounted for tinrough the four quadrant curves. These curves which define head and torque as functions of flow and speed for singlephase liquil are derived from measured TLTA ?ump $p$ erformance and input to RELAP't by tie user.

Degradation of pump. head and torque from two-phase ezfects is accounted for through characteristic curves, Elso supplied by the. user. Pump speed calculations require user-specifiec pump inertic and friction torque.

\section{Conclusions \\ Present RELAP4 jet pump model needs to be improved}

Pump performance predictions during coastdown closely match TLTA test data. As predicted flows in the Intact loop jet pump begin to deviate from the data, rectrculation pump performance predictions also show disagreement.

This trend 1s. belfeved due to the Jet pump problem being propagated into the rectrculation loop and pump. ditions.

Recommendations

RELAP4 two-stream mixing model should be thoroughly revlewed with emphasis on lisolating cause of anomalies during off-design

Ilow conditions.

A separate TLTA jet pump model should be developed and run with boundary conditions determined from TLTA tests and other available jet pump data. Predicted jet pump performance should be compared with experimental performance.

Consideration should be given to development of a black box" jet pump model similar in concept to the recirculation pump model presently used in RELAP4. The need for this approach would be identified through steps mentioned above.

The pump model is belleved edequate when appropriate Fump model Inputs are availtwo-phase degradation, pump

Review predicted recirculation pump performance again when Improvements are made in RELAP4 jet pump mode1. 
TABLE X (Contd.)

OVERVIEW OF RELAP4 COMPARISONS WITH TLTA DATA

\begin{tabular}{|c|c|c|}
\hline Component & REL.AP4 Moded Description & Summary of Comparison \\
\hline Wa11 Heat Transfer & $\begin{array}{l}\text { Heat trar.sfer from the vessel walls to } \\
\text { the conteinec fluic is zased on the same } \\
\text { logic anc correlatjons as used in the rod } \\
\text { bundle. }\end{array}$ & $\begin{array}{l}\text { No direct comparisons were made } \\
\text { on wall heat transfer rates. } \\
\text { Based on system pressure compar- } \\
\text { isons, it is suspected that en } \\
\text { cverprediction of wall heat } \\
\text { transfer is retarding the pre- } \\
\text { dicted postitashing pressuse } \\
\text { decay rate. }\end{array}$ \\
\hline
\end{tabular}

Recirculation Line Flow into this 2-1'2-irch-diameter volFlow Tube ume from the downcomer is controlled by a "vertical junction". This junction option allows flow to accur in two phases as the dowilomer mixture level falls accoss the vartically-oriented entrance to the flow tube. Assuming no slip, lifuid and vapor jolumetric flows are compated based on reletive junction area abose and below the mizture level.

Break Eritical flew is calculated by user-specified medels Gienry, Moody, Sonic choking) with user 1np:t ilow multipliers. Logic is avallable to change pliem Her:y nodel in suixcooled flow to Moody madel under saturaced conditions.
Observation of the experimental nixture level as it passes through the flow tube significant drawdown and slip occurs here during the-uncovering period. RELAP4, which does not account for these effects, preAicts a much higher flow rate luring this interval. Full un-overy of the flow tube entrance is predicted in about 0.1 second -ompared to over 1 second in the experiment.

Break flow model was forced to ratch the TLTA Test 3 Jata. natch the gLTA Test 3 data. estimate flow multipliers unde predicted break flow considerably, resulting in improper. timing of major events such. suction line uncovery and flash ing. entrance region suggests tha:

\section{$\frac{\text { Corc-ustons }}{\text { Wa11 heat :ransfer rates }}$ \\ may be ove-predicted with may be ove:pzedicted with
curnent RE:AP4 metiodology.}




\section{REFERENCES}

1. G. W. Burnette, D. W. Danielson, K. A. Nilsson, Blowdown Heat Transfer Program, Task C-1 Informal Report, Preliminary System Design Description of Two-Loop Test Apparatus, GEAP-13276-1 (November 1973).

2. R. W. Griebe and J. W. McConnell, Boiling Water Reactor Full-Length Emergency Core Cooling Heat Transfer (BWR-FLECHT) Test Project Final Report on Atmospheric Pressure Stainless Steel Experiments, ANCR-1115 (November 1973).

3. J. D. Duncan and J. E. Leonard, Emergency Cooling in Boiling Water Reactors Under Simulated Loss of Coolant Conditions, GEAP-13197 (June 1971).

4. K. V. Moore and W. H. Rettig, RELAP4 - A computer Program for Transient Thermal-Hydraulic Analysis, ANCR-1 127 (December 1973).

5. W. J. Wnek et al, Transient Three Dimensional Thermal-Hydraulic Analysis of Nuclear Reactor Fuel Rod Arrays: General Equations and Numerical Scheme, ANCR-1207 (November 1975).

6. LOFT Integral Test System, LOFT Program Description, LPD-1, Aerojet Nuclear Company (January 1975).

7. Semiscale Program Description, Aerojet Nuclear Company, (February 1975).

8. R. A. Livingston, Semiscale Pressure Suppression System Performance During The Isothermal Blowdown Test Series, ANCR-1 164 (November 1974).

9. W. F. Cleary et al, FLECHT-SET Phase B. System Design Description, WCAP-8410 (December 1974).

10. R. E. Rice and J. B. Colson, Evaluation of Two Loop Test Apparatus (TLTA) Measurement Accuracies, Aerojet Nuclear Company (September 16, 1974) (available from the NRC Public Document Room).

11. S. J. Kline and F. A. McClintock, "Describing Uncertainties in Single Sample Experiments," Mechanical Engineering (January 1953).

12. . Thirty-Seventh Monthly Report BWR Blowdown Heat Transfer Program, General Electric Company, San Jose, California (August 1974).

13. G. E. Gruen, Design Basic Accident Analysis of the Newbold Island Reactor, Interim Report 1-180-73-2.1, Aerojet Nuclear Company (December 1973) (available from the NRC Public Document Room).

14. Thirty-Eighth Monthly Report BWR Blowdown Heat Transfer Program, General Electric Company, San Jose, California (Seplember 1974). 
15. Thirty-Ninth Monthly Report BWR Blowdown Heat Transfer Program, General Electric Company, San Jose, California (October 1974).

16. Fortieth Monthly Report BWR Blowdown Heat Transfer Program, General Electric Company, San Jose, California (November 1974).

17. Forty-First Monthly Report BWR Blowdown Heat Transfer Program, General Electric Company, San Jose, California (December 1974).

18. Forty-Second Monthly Report BWR Blowdown Heat Transfer Program, General Electric Company, San Jose, California (January 1975).

19. Forty-Third Monthly Report BWR Blowdown Heat Transfer Program, General Electric Company San Jose, California (February 1975).

20. Forty-Fourth Monthly Repurl BWR Blowdown Heat Transfer Program, General Electric Company, San Jose, California (March 19'/s').

21. K. D. Wing, Blowdown Heat Transfer Program Task B-1 BWR Fuel Rod Simúlation Using Skin Heaters, GEAP-13259 (January 1972).

22. Proposed American Nuclear Society Standards, Decay Energy Release Rates Following Shutdown of Uranium-Fueled Thermal Reactors. Approved by Subcommittee ANS-5, ANS Standards Committee (October 1971).

23. G. R. Sawtelle, Analytic. Prediction of the General Electric Blowdown Heat Transfer Two-Loop Test Apparatus System Response, Test 3 Bundle 1, 4.55 MW Case, Aerojet Nuclear Company (July 26, 1974) (available from the NRC Public Document Room).

24. G. R. Sawtelle and T. R. Charlton, Best Estimate Prediction of the General Electric Blowdown Heat Transfer System Response, Test 6, Slandard Problem 4, Aerojet Nuclear Company (October 7, 1974) (available from the NRC Public Document Rnoml.

25. T. R. Charlton and G. R. Sawtelle, A Comparison of RELAP4 Analysis with Dulu from GE TLTA Test 3, Aerojet Nuclear Cómpany (Deceniluer 1971) (nvailable from the. NRC Public Document Room).

26. K. R. Katsma et al, "Small Break Analysts Models in the REL $\Lambda$ P 4 Cumputer ronds," American Nuclear Society Winter Meeting, San Francisco, California, November $17-21,1975$.

27. P. G. Barnett, A Correlatton of Burnout Data for Uniformly Heated Annuli and its Use for Predicting Burnout in Uniformly Heated Rod Bundles, AEEW-R 463 (1966). 
28. V. E. Shrock and L. M. Grossman, Forced Convection Boiling Studies, Final Report on Forced Convection Vaporization Project, TID-14632 (1959).

29. P. J. Berensen, "Film Boiling Heat Transfer from a Horizontal Surface," Journal of Heat Transfer (August. 1961) pp 351-358. 
DISTRIBUTION RECORD FOR ANCR-NUREG-1277

\section{Internal}

$$
\begin{aligned}
& .1 \text { - Chicago Patent Group-ERDA } \\
& 9800 \text { South Cass Avenue } \\
& \text { Argonne, Illinois } 60439
\end{aligned}
$$

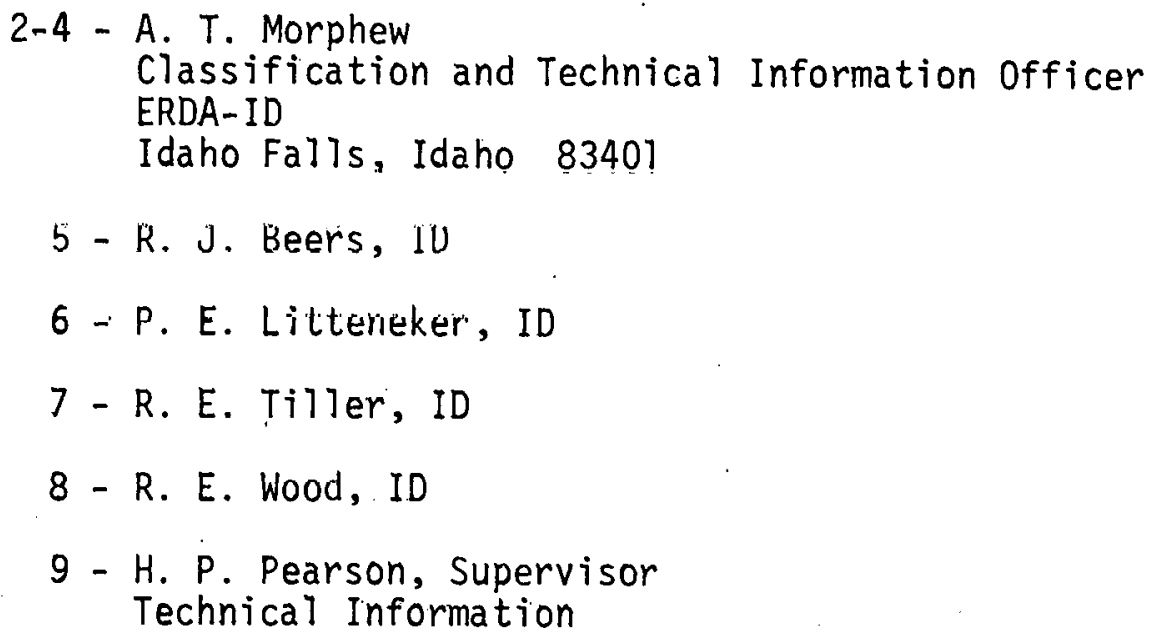

10-19 - INEL Technical Library

20-49 - Authors

\section{External}

50-51 - Saul Levine, Director, Office of Nuclear Regulatory Research, NRC Washington, D. C. 20555

52-356 - Distribution under NRC-2 